\title{
Teste e verificação formal do comportamento excepcional de programas Java
}

Alexandre Locci Martins

\author{
DissertaÇÃo Apresentada \\ $\mathrm{AO}$ \\ Instituto de Matemática e Estatística \\ DA \\ Universidade de SÃo Paulo
}

\author{
Programa: Ciência da Computação \\ Orientadora: Profa. Dra. Ana Cristina Vieira de Melo
}

Durante o desenvolvimento deste trabalho o autor recebeu auxílio financeiro da CAPES

São Paulo, Junho de 2014 


\section{Agradecimentos}

Gostaria de agradecer a Professora Ana Cristina Vieira de Melo por ter me acolhido como orientado e, acima de tudo, por ter dado a chance de realizar este trabalho. Sou eternamente grato.

A minha colega e amiga Simone Hanazumi por todo apoio, ajuda e por ter sempre dado a opinião certa no momento certo.

A minha esposa Eliane Sebeika Rapchan por todo carinho, amor e apoio incondicional dado a mim e a este trabalho.

Agradeço a minha mãe Marly Santina Locci Martins pelo apoio e ao meu Pai Ernesto Martins por estar aqui para receber este agradecimento. Não foram poucas as vezes que eu e ele achamos que isso não aconteceria.

A minha Sogra Ienina Sebeika Rapchan pelo apoio e carinho e ao meu Sogro José Otto Rapchan que viu o início deste trabalho mas não seu termino.

A minha avó Zayra Belluomini Locci que com seus cem anos torceu muito para que este trabalho desse certo. A meu avô Ameleto Locci uma ausência sempre sentida.

A todos os amigos que fiz no IME, particularmente aos camaradas da sala de 17 .

Por fim, não um agradecimento mas um pedido de perdão. A minha filha Sofia Rapchan Martins, que não está perto do pai dela a quase dois anos. Espero que, quando você puder ler estas linhas, possa entender que eu tinha de fazer isso, mas que nunca, nem por um segundo, você, minha filha, saiu de meus pensamentos. 


\section{Resumo}

LOCCI, A. M. Teste e verificação formal do comportamento excepcional de programas Java. 2014. Dissertação (Mestrado) - Instituto de Matemática e Estatística, Universidade de São Paulo, São Paulo, 2014.

Estruturas de tratamento de exceção são extremamente comuns em softwares desenvolvidos em linguagens modernas, como Java, e afetam de forma contundente o comportamento de um software quando exercitadas. Apesar destas duas características, as principais técnicas de verificação, teste de software e verificação formal, e as ferramentas a elas vinculadas, tendem a negligenciar o comportamento excepcional. Alguns dos fatores que levam a esta negligência são a não especificação do comportamento excepcional em termos de projeto e a consequente implementação das estruturas de tratamento com base no julgamento individual de cada programador. Isto resulta na não consideração de partes expressivas do código em termos de verificação e, consequentemente, a possibilidade de não serem detectados erros relativos tanto às próprias estruturas de tratamento quanto às estruturas de código vinculadas a estas. A fim de abordar este problema, propomos uma técnica, baseada em model checking, que automatiza o processo de exercício de caminhos excepcionais. Isto permite que seja observado o comportamento de um software quando da ocorrência de uma exceção. Pretendemos, com esta técnica, dar suporte para que seja aplicado aos caminhos que representam o comportamento excepcional de um software as mesmas técnicas de detecção de erros que são aplicadas aos caminhos que representam o comportamento normal e, com isso, agregar um aumento na qualidade do desenvolvimento de software.

Palavras-chave: exceção, comportamento excepcional, Java, model checking, model checker. 


\section{Abstract}

\section{LOCCI, A. M. Testing and formal verification of the exceptional behavior of Java pro-}

grams. 2014. Qualifying Exam Proposal (Master's Degree) - Institute of Mathematics and Statistics, University of São Paulo, São Paulo, 2014.

Software developed in modern languages, such as Java, commonly present structures of exception handling. These structures, when exercised, may affect the software behavior. Despite these two characteristics, the main verification techniques, software testing and formal verification and the tools related to them, tend to neglect the exceptional behavior. The nonexistent specification of software exceptional behaviors at the design level, and, the subsequent implementation of exception handling based on the judgment of each programmer, are some factors that lead to this neglect. These factors result in the non-consideration of the expressive parts of the code in verification terms and, consequently, the impossibility of errors detection concerning either the exception treatment structures or the code structures linked to them. Taking this fact into consideration, we propose a technique based on the model checking process, which automates the process of exercising exceptional paths to address this problem. This allows the observation of the software behavior when an exception occurs. With this technique, we intend to support the application of the same error detection techniques for program normal behavior paths to the paths that represent the software exceptional behavior. Therefore, using the proposed technique, we aim to increase the software development quality.

Keywords: exception, exceptional behavior, Java, model checking, model checker. 


\section{Sumário}

Lista de Abreviaturas $\quad$ xiii

Lista de Símbolos $\quad$ xv

Lista de Figuras $\quad$ xvii

Lista de Listagens $\quad$ xix

1 Introdução $\quad 1$

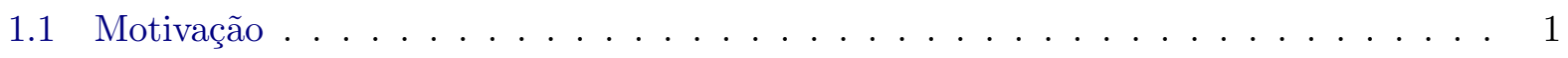

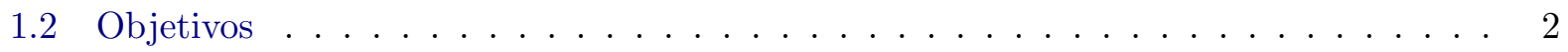

1.3 Cenário de Uso da Técnica . . . . . . . . . . . . . . . . 3

1.4 Trabalhos Relacionados . . . . . . . . . . . . . . . . . . . 4

1.5 Organização do Trabalho . . . . . . . . . . . . . . . . . 5

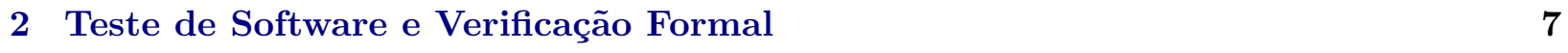

2.1 Validação e Verificação de Exceções . . . . . . . . . . . . . . . . . . . . . . . . . 7

2.2 Teste de Software . . . . . . . . . . . . . . . . . . . . . . . . 8

2.2.1 Limites do Teste de Software . . . . . . . . . . . . . . . . . . . 9

2.2.2 Teste de Software e Exercício do Comportamento Excepcional . . . . . . . . 10

2.3 Verificação Formal . . . . . . . . . . . . . . . . . . . . . . . . . 10

2.3.1 Definição de Model Checking . . . . . . . . . . . . . . . . 10

2.3 .2 Semântica . . . . . . . . . . . . . . . . . . . . . . . . . 13

2.3.3 Computation Tree Logic . . . . . . . . . . . . . . . . . . . . . . . . 14

2.3.4 Limites da Verificação Formal . . . . . . . . . . . . . . . . . . . . . . . 15

2.3.5 Verificação Formal e Comportamento Excepcional . . . . . . . . . . . . 16

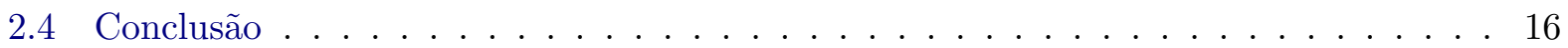

3 Tratamento de Exceções $\quad 17$

3.1 Comportamento Excepcional _. . . . . . . . . . . . . . . . . 17

3.2 Conceitos Vinculados à Manipulação de Exceções . . . . . . . . . . . . . . . . . . . 18

3.3 Linguagens de Programação e Manipulação de Exceções . . . . . . . . . . . . . . . 19

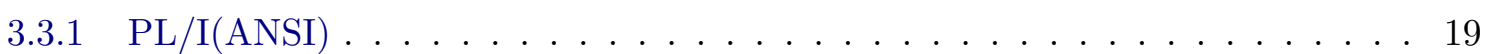

$3.3 .2 \quad$ Ada . . . . . . . . . . . . . . . . . . . . . . . 19

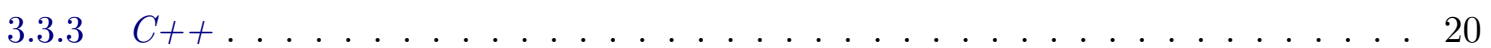

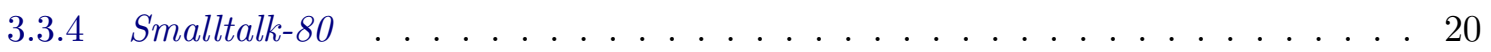




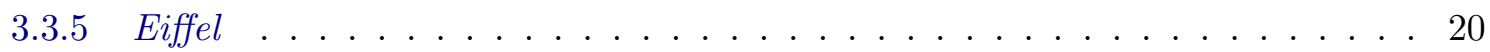

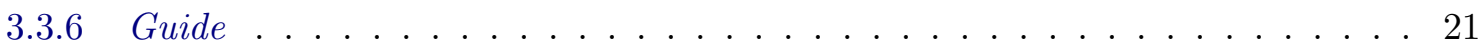

3.3 .7 Java . . . . . . . . . . . . . . . . . . . . . . 21

3.3.8 Tratamento de uma Exceção Lançada em Java . . . . . . . . . . . . . . . . . 23

3.4 Conclusão . . . . . . . . . . . . . . . . . . . . . . . . . . 24

4 Modelo de Comportamento Excepcional $\quad 25$

4.1 Conceitos Preliminares . . . . . . . . . . . . . . . . . 25

4.1 .1 Conceitos de teste fluxo de dados . . . . . . . . . . . . . . . 25

4.2 Estudo do Modelo do Comportamento Excepcional em Programas Java . . . . . . 29

4.2.1 Considerações sobre o Modelo de Sinha e Harrold . . . . . . . . . . . . . . . . 33

4.3 Novo Modelo de Comportamento Excepcional . . . . . . . . . . . . . . . . . . . . . 34

4.3 .1 Identificação de ativação e desativação . . . . . . . . . . . . . . . . . . . . 37

4.3 .2 Grafo de Ativação/Desativação . . . . . . . . . . . . . . . . . . . . . 40

4.3 .3 Representação Gráfica . . . . . . . . . . . . . . . . . . . . . . . . . . . . 41

4.4 Exemplos de Construção do XADCFG . . . . . . . . . . . . . . . . . . . . . 41

4.4.1 Exemplo 1 - Exceção ocorre dentro de um Bloco try . . . . . . . . . . . . . . 41

4.4.2 Exemplo 2 - Exceção ocorre dentro de um método que declara throws . . . . 43

4.4.3 Exemplo 3 - Exceção Programada . . . . . . . . . . . . . . . . . . . . . . . 44

4.5 Algoritmos para de Construção do XADCFG e Identificação de Pares de Ativação e Desativação de Exceções . . . . . . . . . . . . . . . . . . . . . . . . . . . 45

4.5 .1 Construção do Grafo . . . . . . . . . . . . . . . . . . . . 46

4.5.2 Definição dos Pares . . . . . . . . . . . . . . . . . . . . . . . . 46

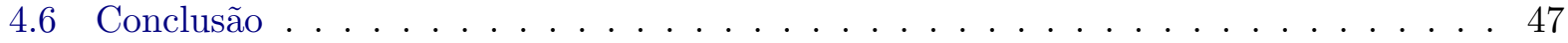

5 Instrumentação para o Exercício do Comportamento Excepcional $\quad 49$

5.1 Objetivo das Regras de Instrumentação para Verificação de Comportamento Excep-

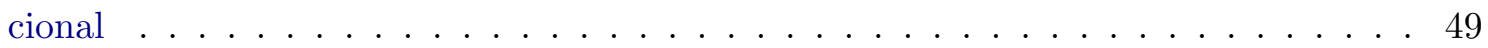

5.1 .1 Exemplo de Aplicação ds Regras de Instrumentação .......... 51

5.2 Classe VerifyEx . . . . . . . . . . . . . . . . . . . . 53

5.3 Ferramenta de Automação . . . . . . . . . . . . . . . . . . . . . . . . 55

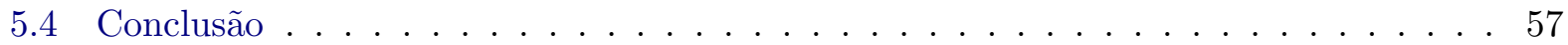

6 Estudo de Caso - Vending Machine $\quad 59$

6.1 Vending Machine . . . . . . . . . . . . . . . . . . . . . . 59

6.2 Resultados Obtidos . . . . . . . . . . . . . . . . . . . 70

6.2.1 Execução da Listagem 6.2 e Determinação dos Valores de Cobertura para JVM 71

6.2.2 Execução da Listagem 6.2 e Determinação dos Valores de Cobertura para

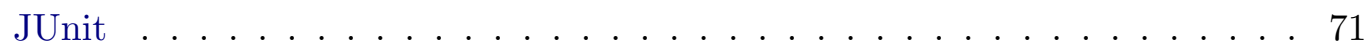

6.2.3 Execução da Listagem 6.2 na Ferramenta de Verificação JPF ...... . 75

6.3 Análise dos Resultados . . . . . . . . . . . . . . . . . 76

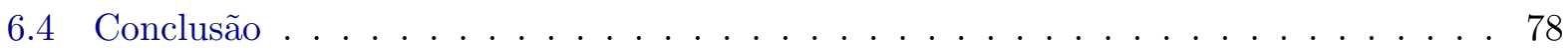


$\begin{array}{lll}7 & \text { Resultados e Conclusão } & \mathbf{7 9}\end{array}$

7.1 Resultados . . . . . . . . . . . . . . . . . . . . . 79

7.1 .1 Resultados Execução JVM e JUnit . . . . . . . . . . . . . . . . . . . . 79

7.1 .2 Análise dos Resultados Execução JVM e JUnit . . . . . . . . . . . . . . . . 80

7.1 .3 Resultados Execução JPF . . . . . . . . . . . . . . . . . . . . . . . . 81

7.1 .4 Análise dos Resultados Execução JPF . . . . . . . . . . . . . . . . 85

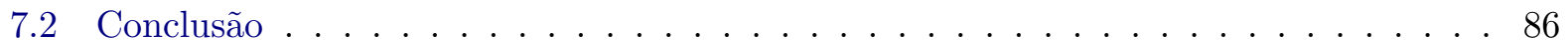

7.2 .1 Resultados Obtidos . . . . . . . . . . . . . . . . 86

7.2 .2 Trabalhos Futuros . . . . . . . . . . . . . . . . . 87

$\begin{array}{ll}\text { Referências Bibliográficas } & 89\end{array}$ 


\section{Lista de Abreviaturas}

$\begin{array}{ll}\text { BSL } & \text { Bandera Specification Language } \\ \text { BDD } & \text { Binary Decision Diagrams } \\ \text { CCS } & \text { Calculus of Communicating Systems } \\ \text { CSP } & \text { Communicating Sequential Processes } \\ \text { CTL } & \text { Computation Tree Logic } \\ \text { GFC } & \text { Grafo de Fluxo de Controle } \\ \text { GFCI } & \text { Grafo de Fluxo de Controle Interprocedural } \\ \text { IDE } & \text { Integrated Development Environment } \\ \text { JVM } & \text { Java Virtual Machine } \\ \text { JPF } & \text { Java Pathfinder } \\ \text { LT } & \text { Lógica Temporal } \\ \text { LTL } & \text { Lógica Temporal Linear } \\ \text { LM } & \text { Lógica Modal } \\ \text { MC } & \text { Model Checking } \\ \text { MC/DC } & \text { Modified Condition/Decision Coverage } \\ \text { NASA } & \text { National Aeronautics and Space Administration } \\ \text { PROMELA } & \text { PROcess MEta LAnguage } \\ \text { RA } & \text { Relação de Acessibilidade } \\ \text { SAnToS } & \text { Specification, Analysis, and Transformation of Software } \\ \text { SPIN } & \text { Simple Promela INterpreter } \\ \text { SUT } & \text { System Under Test } \\ \text { VDM } & \text { Vienna Development Method } \\ & \end{array}$




\title{
Lista de Símbolos
}

\author{
c Caminho \\ $A, E \quad$ Operadores de caminho \\ $k, i, j$ Índices \\ E Conjunto de arestas de um grafo \\ $G \quad$ Grafo \\ $K \quad$ Estrutura de Kripke \\ $N \quad$ Conjunto de nós de um grafo \\ num Variável inteira \\ $P \quad$ Conjunto de casos de teste \\ $p \quad$ Propriedade \\ $s \quad$ Nó de entrada de um grafo \\ $S \quad$ Software \\ $S_{m} \quad$ Conjunto de estados do modelo \\ $S_{0} \quad$ Conjunto dos estados iniciais \\ $o \quad$ Nó de saída de um grafo \\ $t \quad$ Estado \\ $T$ Conjunto de relações de transição \\ L Função \\ AP Conjunto contável de proposições atômicas \\ $\sigma \quad$ Propriedade \\ $\bigcirc \quad$ Operador temporal \\ $\square \quad$ Operador temporal \\ $\diamond \quad$ Operador temporal \\ $U \quad$ Operador temporal \\ $W \quad$ Operador temporal
}




\section{Lista de Figuras}

1.1 Elementos do Sistema Alvos da Técnica . . . . . . . . . . . . . . . . . . . . 3

2.1 Autômato Temporal . . . . . . . . . . . . . . . . . . . . . . . . . 11

2.2 Representação de uma CTL . . . . . . . . . . . . . . . . . . . . . . . . 14

4.1 Fluxo de Controle da Listagem $4.1 \ldots \ldots$. . . . . . . . . . . . . . 30

4.2 Fluxo de Controle da Listagem 4.1 Alterado . . . . . . . . . . . . . . . . 31

4.3 Fluxo de Controle Interprocedural da Listagem $4.1 \ldots \ldots$. . . . . . . . . . . . 32

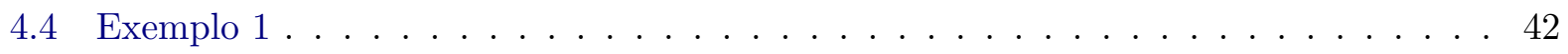

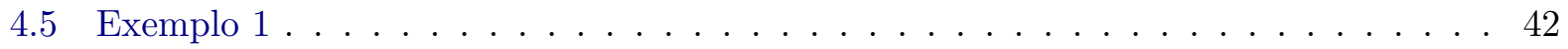

4.6 Exemplo 2 - Fluxo de Controle Normal . . . . . . . . . . . . . . . . . . . . . 43

4.7 Exemplo 2 - Pares de Ativação/Desativação Estabelecidos . . . . . . . . . . . . . . . 44

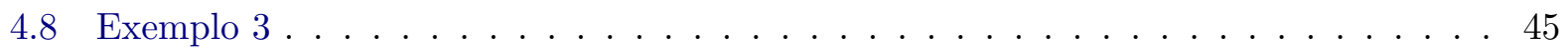

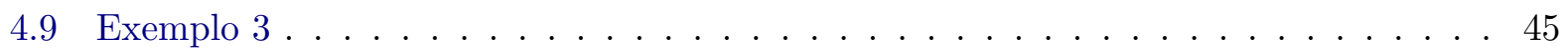

5.1 Interface de Instrumentação $\ldots \ldots \ldots \ldots \ldots$

6.1 Relação de Ativação e Desativação de Exceções . . . . . . . . . . . . . . . . . . . 77 


\section{Lista de Listagens}

3.1 Programa CheckValue . . . . . . . . . . . . . . . . . . . . . . 22

4.1 Exemplo de Modelagem de Exceções . . . . . . . . . . . . . . . . . . . . 29

4.2 Algoritmo para construção de GFCI desenvolvido por Sinha e Harrold[SJ00] . . . . . 33

4.3 Apenas Código Fonte Disponível . . . . . . . . . . . . . . . . 34

4.4 Exceção Programada . . . . . . . . . . . . . . . . . . . . . . 34

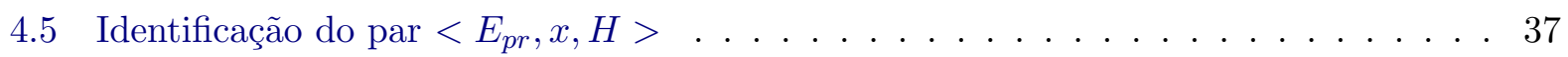

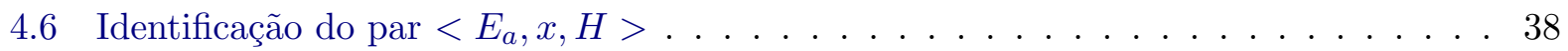

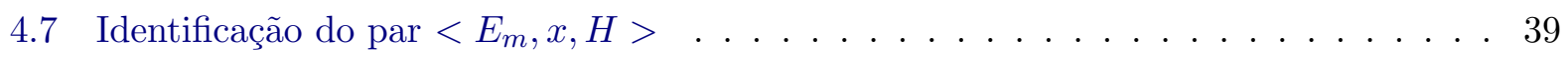

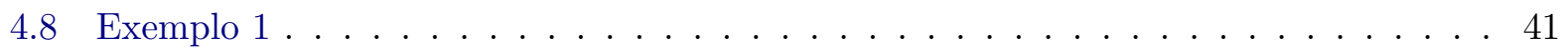

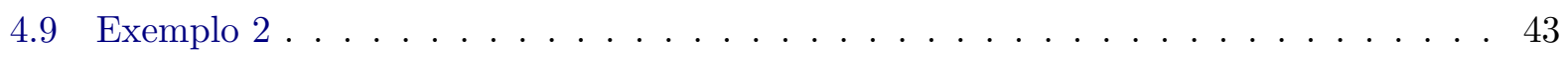

4.10 Exemplo 2 reescrito $\ldots \ldots \ldots \ldots \ldots \ldots \ldots$

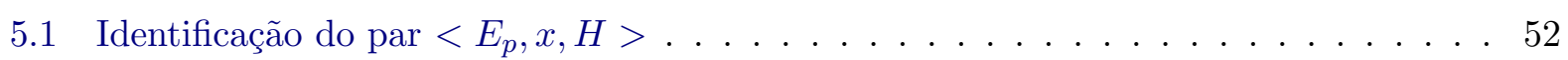

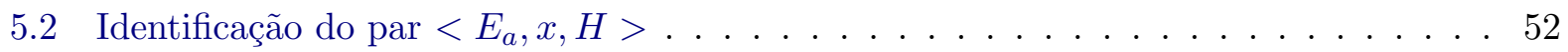

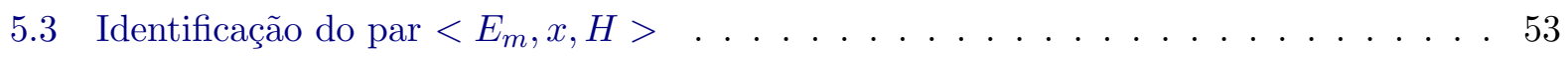

5.4 Implementação da classe VerifyEx . . . . . . . . . . . . . . . . . 54

5.5 Implementação da classe Monitor . . . . . . . . . . . . . . . . . . 54

5.6 Instrumentação Automática . . . . . . . . . . . . . . . . . . 55

5.7 Instrumentação Automática . . . . . . . . . . . . . . . . 56

6.1 Vending Machine . . . . . . . . . . . . . . . . . . . . . . 59

6.2 Vending Machine - Pontos de Instrumentação . . . . . . . . . . . . . . . . . 65

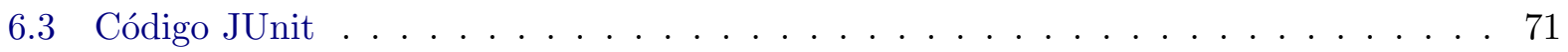

6.4 Saída JUnit . . . . . . . . . . . . . . . . . . . . . . . . . . 73

6.5 Saída JPF . . . . . . . . . . . . . . . . . . . . . . . . 75

6.6 Saída JPF . . . . . . . . . . . . . . . . . . . . . . . . . 75

7.1 Programa Biff Instrumentado Executado no JPF . . . . . . . . . . . . . . 81

7.2 Progrma Jipa Instrumentado Executado no JPF . . . . . . . . . . . . . . . . . . . . . . . . . . . . . 83

7.3 Programa Biff Não Instrumentado Executado no JPF $\ldots \ldots$. . . . . . . . . . . . . 83

7.4 Progrma Jipa Não Instrumentado Executado no JPF . . . . . . . . . . . . . . . . . . . . . . . . . . . . . 84

7.5 Uso de Exceções Programa Jipa . . . . . . . . . . . . . . . . . . . . . . . 85 


\section{Capítulo 1}

\section{Introdução}

Este capítulo é constituído por uma apresentação da motivação para pesquisa e dos objetivos que este trabalho pretende alcançar. A motivação tem por base o interesse pelas questões teóricas e técnicas suscitadas pelo estudo do comportamento excepcional em programas escritos em linguagens que fornecem tratamento de exceções. Este tratamento visa garantir maior robustez das aplicações e proporcionar maior qualidade no desenvolvimento de software. Por sua vez, os objetivos a serem alcançados por este trabalho visam a produção de uma técnica que permita automatizar o processo de exercício do comportamento excepcional. Isso é de grande valia para áreas de teste de software e verificação formal que buscam agregar alta qualidade à produção de software.

\subsection{Motivação}

Assegurar a qualidade de um software é uma das atividades mais onerosas do processo de desenvolvimento, pois agrega grande quantidade de recursos humanos e/ou materiais [A.07]. Apesar do seu alto custo, a busca pela qualidade é uma atividade indispensável devido à quase onipresença dos sistemas de software no dia-a-dia. O que é notado nas mais corriqueiras atividades, como pagamentos de contas ou compras eletrônicas, até nas mais complexas e delicadas, como sistemas de aeronáutica e sistemas de suporte de vida. Qualquer falha em um desses sistemas pode gerar desde pequenos incômodos até grandes acidentes que resultam em perdas de bens e/ou vidas [dS08]. Logo, pesquisas que levem à redução de custos e à maior eficiência e eficácia no processo de agregar qualidade a um software possuem uma relevância técnico-acadêmica a ser considerada.

Qualidade de software pode ser entendida como o grau de adequação entre o produto final e as especificações determinadas no projeto [P.12]. O grau de adequação do software pode ser medido comparando-se o comportamento observado com o comportamento esperado, que foi definido nas especificações. Se o comportamento observado difere do esperado, isto é um indício de que um erro foi identificado. A fim de aferir este grau de adequação são utilizadas na indústria técnicas de verificação de software, algumas destas técnicas são:

- Análise Estática de Programa engloba uma família de técnicas (inspeção de software, Walkthroughs) que visam fornecer informações sobre o comportamento de um dado software sem a necessidade de uma execução. O processo de análise é realizado por um desenvolvedor (inspetor) que executa, mentalmente o código, instrução por instrução, visando encontrar erros previamente definidos [DKW08].

- Teste de software consiste em analisar o comportamento estimulado num software mediante atribuição de valores que pertencem a um subconjunto do conjunto de entradas válidas, denominados casos de teste, a fim de determinar se o comportamento estimulado equivale ao esperado para cada caso de teste [PJ08].

- Verificação formal corresponde a um processo de prova matemática no qual o software a ser verificado é descrito por expressões lógicas ou por um modelo [B.99, CP08, M.11]. As 
descrições são construídas sobre as especificações do software. A satisfação de um conjunto de expressões ou a verificação da violação das propriedades do modelo fornece resultados para definir a corretude do software, ou seja, definir se o software opera nas especificações ou fornece um contra-exemplo, nas técnicas de model checking, para justificar a existência de incompatibilidades entre o software e suas especificações.

Das técnicas acima listadas, as duas últimas são de interesse deste trabalho.

Apesar de serem distintos, a maioria dos trabalhos acadêmicos para teste e verificação possui um elemento em comum. Em ambos os casos o foco concentra-se no comportamento normal de um software enquanto o comportamento excepcional é negligenciado [SJ00, LHP06, CCS07, PN12]. Esta situação não expressa a importância que as estruturas de tratamento de exceção possuem no código e nem expressa o potencial destas estruturas em afetar o comportamento de um software [SJ00, W.06, BP07, DOFJ12].

Uma exceção é qualquer comportamento inesperado e indesejável, detectado por software ou hardware, que requer algum tratamento especial [W.06]. Este procedimento implica numa mudança no fluxo de execução normal de um programa [Orab]. Este desvio é definido como caminho excepcional. A despeito da pouca atenção dada à especificação do tratamento de exceções, várias pesquisas demonstram que estas estruturas são extremamente comuns e estão presentes em um grande número de softwares que compõem grandes sistemas [SJ00, BP07, DOFJ12]. Como consequência, há um grande número de possíveis comportamentos excepcionais, vinculados a estes caminhos, que comumente não são exercitados e, portanto, não são avaliados ou não são levados em consideração no momento da modelagem do software.

Logo, as motivações para este trabalho são:

- o reconhecimento da importância que as estruturas de tratamento de exceções possuem na determinação do comportamento de um dado software; e,

- o fato destas estruturas serem negligenciadas pelas principais técnicas que buscam agregar qualidade a um software, no caso, teste e verificação.

Pautados nestas constatações, propomos uma técnica de exercício de caminhos excepcionais utilizando ferramentas de teste e verificação e um modelo de definição de comportamento excepcional. Esta técnica é proposta tanto para o exercício de caminhos excepcionais visando o teste de software quanto para a verificação formal. Esta técnica será aplicada em programas escritos em linguagem Java dado que:

- é uma linguagem de uso geral;

- é amplamente utilizada no desenvolvimento de software;

- oferece tratamento de exceções; e,

- há atualmenteum conjunto de ferramentas para teste e verificação de código escrito em linguagem Java que serão estudadas e utilizadas nesse trabalho.

Além da linguagem Java, nosso estudo pode ser aplicado, com certos ajustes, as linguagens $C++$ por possuír estruturas de tratamento de exceções nas quais Java foi baseado. Outras linguagens, com estruturas de tratamento de exceções similares à linguagem Java, como a linguagem Python, também podem se valer deste estudo, apenas devem ser observadas as diferenças sintáticas entre as estruturas (instrução throws da linguagem Java e instrução raise da linguagem Python).

\subsection{Objetivos}

Os objetivos deste trabalho são: 
- Colaborar com as pesquisas que têm por foco o efeito do tratamento de exceções no comportamento de softwares ${ }^{1}$.

- Apresentar um estudo de um modelo de comportamento excepcional que permita identificar:

- estruturas de tratamento;

- pontos de lançamento de exceção;

- comportamento do fluxo de controle afetado pelas exceções; e,

- comportamento do fluxo de dados afetado pelas exceções.

- Desenvolver um processo automático ou semi-automático para exercício de caminhos excepcionais que permita:

- suporte à geração de casos de teste para o exercício de exceções; e,

- suporte à verificação de propriedade agregadas ao uso de exceções.

- Implementar um protótipo de ferramenta que viabilize o exercício de exceções baseado em ferramentas de verificação de modelo de uso mais geral.

\subsection{Cenário de Uso da Técnica}

A técnica proposta tem por alvo exercitar exceções cujas estruturas (ativação e desativação) estão diponíveis no código fonte da aplicação que se deseja verificar. Desta forma, não são considerados exceções ativadas por chamadas de bibliotecas. Logo, o foco está nas estruturas excepcionais que estão presentes no código fonte da aplicação que se deseja verificar. Esta escolha foi feita pois:

- as bibliotecas podem não ter seu código fonte disponível a manipulação de bytecode está fora dos objetivos técnico-científicos deste trabalho;

- o código das bibliotecas não faz parte efetivamente do escopo do sistema que se deseja verificar;

- a técnica utiliza instrumentação de código e não é aconselhável instrumentar bibliotecas que podem ser utilizadas por outras aplicações simultaneamente a aplicação que se deseja testar; e,

- o foco da técnica é o exercício das estruturas de tratamento de exceções escritas pelo desenvolvedor do sistema.

A Figura 1.1 representa os elementos de um Sistema que são alvos da técnica proposta.

\section{Sistema}

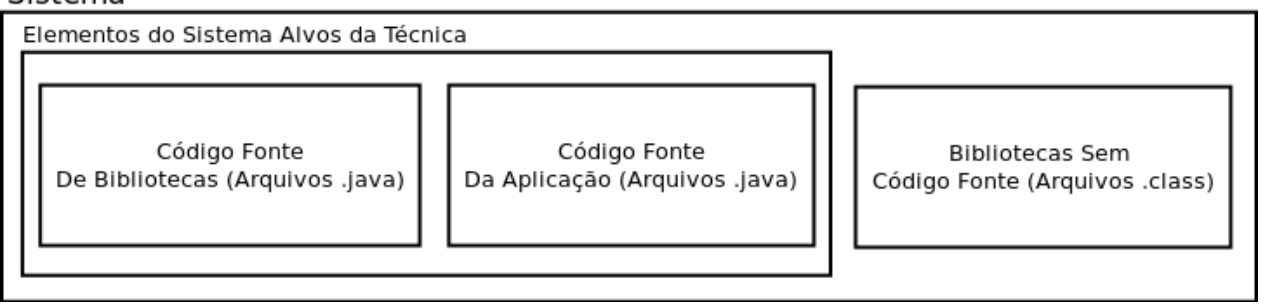

Figura 1.1: Elementos do Sistema Alvos da Técnica

\footnotetext{
${ }^{1}$ Ver trabalhos relacionados na Seção 1.4 .
} 


\subsection{Trabalhos Relacionados}

Os trabalhos de Sinha e Harrold [SJ98, SJ00] podem ser considerados entre os primeiros a sintetizar e delimitar o campo de estudos do comportamento excepcional de um software. Dentre os elementos mais importantes presentes nesses trabalhos é possível destacar,

- análises quantitativas das estrutura de tratamentos de exceções em softwares complexos escritos em Java. Essas análises revelam que as estruturas de tratamento de exceções ocorrem em grande quantidade e estão presentes na maioria desses softwares;

- análise qualitativa do efeito do tratamento de exceções. Estas análises demonstram o impacto que o tratamento de exceções possui no comportamento de dado software;

- desenvolvimento de um modelo de comportamento excepcional que permite identificar tanto os principais elementos presentes no tratamento de exceções quanto os comportamentos esperados num dado software quando da ocorrência de exceções;

- sinalização da negligência da maioria das técnicas de verificação em relação ao comportamento excepcional; e

- apresentação de um conjunto de requisitos de testes para identificar falhas de software vinculadas as estruturas de tratamento de exceções. Estas falhas são originadas por erros derivados do mal uso destas estruturas por parte dos desenvolvedores.

O trabalho, apresentado nessa dissertação, é baseado nos elementos apontados por Sinha e Harrold [SJ98, SJ00] em relação ao estudo do comportamento excepcional como um elemento importante no processo de verificação de um software e na necessidade de desenvolvimento de técnicas que permitam exercitar esse comportamento. Por isso, o modelo de comportamento excepcional desenvolvido por Sinha e Harrold [SJ00] constitui um elemento importante dessa pesquisa, como apresentado na Seção 4.2, no que se refere ao desenvolvimento de um modelo específico utilizado nessa dissertação que, contudo, difere do modelo de Sinha e Harrold pois abarca todas as estruturas de tratamento exceções presentes na linguagem Java o que não ocorre no modelo de Sinha e Harrold, ver Seção 4.2.

O trabalho de Cabral e Marques [BP07] é um amplo e profundo estudo quantitativo da forma como as estruturas de tratamento de exceção são utilizadas pelos desenvolvedores de software. Apontam que, na maioria dos casos, os projetos de software não contemplam especificações sobre o comportamento excepcional. Isso acarreta os seguintes problemas:

- o desconhecimento de comportamentos que podem ser gerados quando da ocorrência de uma exceção;

- a implementação é deixada a cargo do desenvolvedor, que define como o tratamento de exceções será feito. Isso implica numa falta de abordagem comum para todo software no tocante ao tratamento de exceções; e, vinculada ao item anterior, gera

- a ocorrência de um grande número de más práticas de programação que levam a erros e ineficiência no tratamento de exceções.

Logo, o trabalho de Cabral e Marques [BP07] demonstra que estruturas de tratamento de exceções são, via de regra, mal usadas. Sensibilizados por esta constatação, propomos uma técnica de exercício destas estruturas que ofereça subsídios para a identificação deste mau uso e, com isso, diminuia a ocorrência de erros e maximize a eficiência no tratamento de exceções.

O trabalho de Li, Hoover e Rudnicki [LHP06] e o trabalho de Artho e Sommer [CCS07] propõem uma técnica de verificação de estruturas de tratamento de exceção baseada na utilização de ferramentas de model checker. Estes trabalhos foram importantes para definir a ferramenta de model checker adotada nesse trabalho. A ferramenta utilizada por ambos os trabalhos é conhecida como Java Pathfinder (JPF). Suas principais características são: 
- capacidade de explorar o espaço de estados do software sob verificação;

- habilidade de exercitar o comportamento excepcional dos programas sob verificação; e,

- potencial para ser usada na verificação de possíveis violações de propriedade vinculadas ao uso de estruturas de tratamento de exceções.

O trabalho de Artho, Biere e Honiden [CAS06] segue a mesma linha do trabalho de Li, Hoover e Rudnicki para o exercício de exceções diferindo daquele por utilizar como meio para ativação das exceções a ferramenta de teste unitário Junit e porque sua instrumentação é feita no bytecode do programa Java. Neste trabalho o bytecode do programa a ser verificado é instrumentado e posteriormente são efetuados testes escritos manualmente para a ferramenta Junit a fim de produzir chamadas às partes do código que foram instrumentadas.

Estes trabalhos demonstram que é possível utilizar ferramentas de teste e model checking para exercitar o comportamento excepcional. Nosso trabalho segue a mesma abordagem, ou seja, adota o uso de ferramentas de teste e/ou model checking para exercício de comportamento excepcional. Além disso, fazemos uso das mesmas ferramentas, Java Pathfinder. Entretanto, nosso trabalho se diferencia dos trabalhos de Li, Hoover e Rudnicki [LHP06] e Artho e Sommer [CCS07] pois, enquanto estes se valem da ferramenta JPF sem realizar nenhuma alteração, acreditamos que certas modificações podem ser introduzidas para melhorar a eficiência do exercício do comportamento excepcional feito pelo JPF. Com relação a Junit, acreditamos ser possível gerar de maneira automática os testes que permitam o exercício do comportamento excepcional. Vale colocar, que ambos os trabalhos estão limitados ao uso do modelo de Sinha e Harrold para determinar os pontos de exercício de exceções, o que representa uma limitação comum e partilhada pois, como foi colocado anteriormente, o modelo de Sinha e Harrold não abarca todas as estruturas de tratamento de exceções pois apenas analisa as exceções que são explicitamente lançadas pelo usuário (exceções lançadas via instrução throw). Assim, propomos um estudo mais detalhado de técnicas de instrumentação de código que viabilizem esse exercício baseado em modelo abstrato do fluxo de controle/dados do comportamento excepcional.

Por fim, o trabalho de Staats [M.09] apresenta um estudo para capacitar o JPF a realizar medidas de cobertura de código complexas tais como o Modified Condition/Decision Coverage (MC/DC) [J.01]. Para tanto, apresenta uma técnica de instrumentação de código que permite explorar o espaço de estados de um dado programa e capturar os valores de cobertura. Um dos elementos centrais desta técnica é alterar o comportamento do JPF, via inserção de novas classes, a fim de capacitá-lo a operar com um novo tipo de problema. Apesar de não tratar do comportamento excepcional, esse trabalho é importante por demonstrar que a ferramenta JPF é flexível a ponto de permitir alterações de sua arquitetura a fim de torná-la mais adequada ao tratamento de um dado problema. A técnica de instrumentação utilizada por Staats [M.09] será reutilizada nesse trabalho para produzir uma maior eficiência no tratamento do comportamento excepcional.

\subsection{Organização do Trabalho}

Este trabalho é organizado conforme descrito abaixo:

- Capítulo 2: apresentação tanto dos conceitos que envolvem teste de software e verificação formal quanto do modo como estes conceitos se aplicam ao estudo do comportamento excepcional. Definição dos principais termos.

- Capítulo 3: apresentação dos principais conceitos que envolvem o tratamento de exceções e também do modo como estes conceitos são identificados nos projetos de linguagens modernas de programação tais como PL/I, Ada, $C++$, Eiffel, Smalltalk-80, Guide e Java.

- Capítulo 4: apresentação dos principais critérios de teste aplicáveis à verificação de exceções e de como esses critérios permitem definir quais elementos em um SUT (System Under Test) 
são responsáveis pelo lançamento e tratamento de exceções além da indicação de como esses elementos podem ser relacionados de modo a definir um modelo que retem essas informações. Por fim, usaremos esse modelo para orientar o processo de instrumentação de código escrito em Java a fim de exercitar exceções.

- Capítulo 5: definição de Regras de instrumentação, baseadas nos critérios de ativação/desativação, para definir e implementar um processo de exercício do comportamento excepcional de um SUT e apresentação de uma ferramenta para instrumentação do código.

- Capítulo 6: apresentação de um estudo de caso no qual utilizamos o processo de instrumentação para verificar o comportamento excepcional de um programa escrito em Linguagem Java.

- Capítulo 7: apresentação dos resultados obtidos, indicação de trabalhos futuros e conclusões. 


\section{Capítulo 2}

\section{Teste de Software e Verificação Formal}

Apresentaremos a seguir os conceitos que envolvem teste de software e verificação formal bem como o modo como esses conceitos se aplicam ao estudo do comportamento excepcional. Em seguida definiremos os principais termos utilizados nessas áreas de desenvolvimento.

\subsection{Validação e Verificação de Exceções}

Tratamento de exceções é uma facilidade disponibilizada pela maioria das linguagens modernas de programação [W.06]. Quase todas as linguagens contemporâneas fornecem algum tipo de estrutura de tratamento excepcional que permite a recuperação de uma aplicação quando da ocorrência de uma exceção [W.06].

As vantagens que o tratamento de exceções agrega aos softwares que o utilizam tornam as estruturas de tratamento excepcional muito comuns em toda a codificação. Considerando apenas os softwares escritos em Java, ${ }^{1}$ o trabalho de Dúlaigh [DOFJ12] aponta que, em média, $21,5 \%$ dentre todos os métodos que compõem estes softwares possui algum tipo de estrutura para tratamento de exceção.

Além disso, as estruturas de tratamento de exceção afetam o fluxo de execução de um software. Este efeito causa variações na execução convencional e gera novos comportamentos ${ }^{2}$. Como citado, determinar se os comportamentos observáveis de um dado software são adequados às suas especificações equivale a determinar seu grau de qualidade. Infelizmente, como já mencionado, determinar a qualidade de um software, via de regra, é uma tarefa que negligencia o comportamento excepcional [SJ98, SJ00, DOFJ12, BP07]. Nota-se que o teste de software e a verificação formal negligenciam o comportamento excepcional pois não abordam estruturas de tratamento de exceções do mesmo modo como abordam as estruturas que pertencem ao comportamento normal de um software [SJ98, SJ00, DOFJ12, BP07].

Os argumentos acima levantados constituíram uma linha de pesquisa[SJ98, SJ00] que se dedica ao estudo do comportamento excepcional. Um de seus focos é capacitar técnicas de teste de software e de verificação formal agregando a elas elementos que as permitam lidar com o comportamento excepcional. Nas próximas seções serão apresentados os conceitos de teste de software e de verificação formal, bem como a argumentação de como é possível incorporar ganhos a essas duas técnicas a partir da análise do comportamento excepcional.

\footnotetext{
${ }^{1}$ Dúlaigh estudou os seguintes softwares: ANT, ANTLR, ArgoUML, Azureus, Freccol, Hibernate, JGraph, JMeter, Jung, JUnit, Lucene e Weka [DOFJ12].

${ }^{2}$ As características do tratamento de exceções e seu efeito na execução de um dado programa serão apresentadas no Capítulo 3.
} 


\subsection{Teste de Software}

Antes de iniciar um teste de software é preciso definir o que se deseja testar [ECM07] pois é impossível realizar testes exaustivos de software de maneira que todos os valores de entrada e suas respectivas saídas sejam exercitadas. Logo, é necessário escolher critérios de teste que definam:

- quais elementos do software devem ser testados (variáveis, pontos de decisão, instruções, pontos de entrada/saída etc.);

- qual a intensidade do teste;

- quais elementos do conjunto de dados de entrada devem ser usados; e,

- qual deve ser o momento de interrupção e de término dos testes.

O subconjunto de valores de entrada de um programa $P$ que atende ao critério de teste é denominado conjunto de casos de teste e cada elemento desse conjunto é conhecido como caso de teste. Um caso de teste tem a propriedade de satisfazer um ou mais critérios de teste. Se um caso de teste, ao exercitar um dado comportamento, provoca uma ação inesperada e indesejável, admite-se que foi localizado um erro no software. Um erro é qualquer irregularidade introduzida no código durante o processo de escrita. A manifestação de um ou mais erros é definida como falha e um defeito é qualquer comportamento anormal de um software provocado por uma ou mais falhas [P.12].

A definição de critérios de teste e, por conseguinte, de casos de teste, segue duas abordagens distintas porém complementares, conhecidas como teste caixa preta e teste caixa branca.

Teste Caixa Preta (Black Box Testing) [ECM07, MM08] é uma metodologia pautada apenas nas especificações do software que se deseja testar e não leva em conta nenhum detalhe de implementação (linguagem, estrutura do código etc.). Os critérios de teste são derivados das especificações de projeto de modo a identificar quais comportamentos do software se deseja exercitar. Desta forma, os casos de teste são selecionados com base na propriedade de gerarem o comportamento desejado.

Os critérios de caixa preta são definidos como:

- Sistêmico: baseia-se no particionamento do conjunto de valores de entrada em classes de casos de testes vinculados a um dado critério. Cada classe deve conter casos de testes que o satisfaçam, bem como valores que exercitem situações extremas dos critérios, chamados de valores limites.

- Error guessing: uma abordagem ad-hoc pautada em um argumento de autoridade ${ }^{3}$ que define um conjunto de prováveis erros e casos de teste que permitem detectá-los.

Teste Caixa Branca (White Box Testing) [ECM07, MM08] baseia a definição dos critérios de teste em elementos específicos da estrutura do código da implementação. Tipos de teste Caixa Branca são $\left[\mathrm{K}^{+} 11\right]$ :

- Loop Testing: o foco deste teste é a validação dos laços existentes em um dado código visando determinar a ocorrência de erros de inicialização, problemas de desempenho e problemas de repetição do laço.

- Basis Path Testing: este método examina a relação linear entre comando existente em um código. Esta relação linear é definida pelo conjunto de instruções que pode ser executada em um caminho sem que ocorra um ponto de decisão, ou seja, sem que ocorra um desvio no fluxo.

\footnotetext{
${ }^{3} \mathrm{Um}$ expert do software.
} 
- Branch Testing: neste teste cada branch (if, while, else, etc..) é exercitado para que assuma dois valores possíveis, true ou false, o que acarreta a manifestação de caminhos distintos no código.

Além dos testes acima relacionados, destacamos o Data Flow Testing o qual representa os elementos estruturais do código por meio da construção de um Grafo do Fluxo de Controle (GFC) do software definido como $G=N, E, s, o$ sendo:

- $N$ : conjunto de nós do grafo que representa blocos de uma ou mais instruções. Assume-se, na representação, que o bloco é executado na sua integridade, ou seja, da primeira à última linha sem nenhum desvio interno;

- E: conjunto de arestas que representa as passagens entre os blocos;

- $s$ : representa um único nó de entrada; e,

- o: representa um único nó de saída.

Com base no GFC é possível definir caminhos no interior do grafo que representam sequências de execução entre os blocos. Um caminho é definido como uma sequência finita do tipo $c=\left(n_{1}, n_{2}, n_{3}, \ldots, n_{k}\right)$, para $K \geq 2$, de modo que existe uma única aresta entre $n_{i}$ e $n_{i+1}$, para $i=1,2,3, \ldots, k-1$.

O GFC é posteriormente utilizado para identificar os elementos definidos pelos critérios do Teste Caixa Branca. Os mais comuns são:

- Complexidade Ciclomática (critério de McCabe): métrica que fornece um valor quantitativo da complexidade de um software. Baseia-se na identificação de caminhos independentes no GFC de modo a identificar pelo menos um caso de teste que exercite totalmente este caminho.

- Fluxo de Controle: são utilizadas apenas as estruturas de desvio de fluxo (if, while e switch) para definir quais estruturas devem ser avaliadas. As estruturas mais exercitadas são:

- todos os nós;

- todas as arestas; e,

- todos os caminhos

- Fluxo de Dados: utiliza o fluxo de dados em um software para derivar os requisitos de teste. Tem por base a determinação da interação entre declaração e uso de uma variável (def/use) para derivar casos de teste.

\subsubsection{Limites do Teste de Software}

O teste de software não permite afirmar de forma categórica que um determinado software está livre de erros. Em outras palavras, o teste de software não permite comprovar a corretude [ECM07] de um dado software. Um software é dito correto se, para todos os elementos do domínio de entrada, ele apresenta o comportamento observável igual ao comportamento esperado [P.12].

Em termos práticos, é impossível exercitar todas as entradas de um software. Logo, um teste de software de uma dada aplicação utiliza apenas um subconjunto de valores de entrada selecionados com base em alguns dos critérios acima descritos. Contudo, deve-se sempre considerar a possibilidade de que algum erro não será encontrado na situação em que o caso de teste que o revelaria não for selecionado. 


\subsubsection{Teste de Software e Exercício do Comportamento Excepcional}

Uma derivação positiva direta do teste de software, que leva em conta o comportamento excepcional, é a possibilidade de que esse comportamento seja adequadamente testado. Cabral e Marques [BP07] apontam para a necessidade do teste das estruturas de tratamento de exceção dado que:

- elas não são normalmente testadas;

- geralmente, as especificações de projeto não contemplam o tratamento de exceções; e,

- o fato de estudos empíricos apontarem para um extremo mau uso destas estruturas por parte dos desenvolvedores.

Some-se a isso a possibilidade de determinar como as partes do software vinculadas ao tratamento de exceção, e não somente as estruturas de tratamento excepcional, comportam-se quando testadas. Isso implica em saber se é possível satisfazer aos critérios de teste, considerando o comportamento excepcional de um software.

\subsection{Verificação Formal}

A verificação formal [B.99, CP08, M.11] de um software corresponde a fornecer uma prova matemática de que ele está de acordo com todas as especificações do projeto, ou seja, assegurar que o software está livre de erros. Em termos mais formais, dado um software $S$ e uma especificação descrita na forma de uma propriedade $\sigma$ deseja-se determinar se $S$ satisfaz $\sigma$, ou seja,

$$
S \models \sigma
$$

Para tanto, a verificação formal utiliza uma técnica conhecida como métodos formais que descreve um dado software em termos matemáticos. O processo de verificação do software, por sua vez, é feito por meio de dois tipos de formalismos distintos que são:

- Sistema de Prova de Programa: nessa técnica as especificações do sistema que se deseja verificar são representadas em termos de uma linguagem formal

${ }^{4}$ Posteriormente, esta representação é analisada com base em um sistema de prova adequado à linguagem utilizada na representação.

- Verificação por modelo ${ }^{5}$ : também conhecida como model checking, consiste em descrever um dado software na forma de um modelo que é construído com base nas especificações do software em termos matemáticos com o objetivo de eliminar qualquer tipo de ambiguidade. Para verificar se o modelo satisfaz, ou não, as especificações utiliza-se uma ferramenta de verificação de modelo, chamada model checker, a qual realiza uma exploração exaustiva e sistemática de todos os possíveis cenários que o modelo pode apresentar.

\subsubsection{Definição de Model Checking}

Model checking (MC) é uma técnica que permite o desenvolvimento de ferramentas (model checkers) para automação do processo de verificação formal de um dado sistema. Em termos gerais, a metodologia de MC toma as especificações das funcionalidades de um dado sistema e as traduz em termos de expressões lógicas (também chamadas de propriedades do modelo). Em seguida, realiza uma exploração exaustiva do espaço de estados passíveis de serem atribuídos às expressões, a fim de determinar se elas podem, ou não, serem satisfeitas [M.11].

\footnotetext{
${ }^{4}$ As linguagens mais utilizadas para sistemas sequenciais são $Z, B$ e $V D M$. CCS e CSP são usadas para sistemas concorrentes. Para sistemas móveis, $\pi-$ calculuss [S.08, dS08].

${ }^{5}$ Uma discussão mais ampla da técnica de model checking é apresentada na Seção 2.3.1.
} 
Se, ao término da exploração, for constatado que todas as propriedades foram satisfeitas, podese concluir que o MC forneceu provas da conformidade entre sistema e especificações [B.99]. Mas, se ocorrer a violação de alguma propriedade no modelo, admite-se que há uma não conformidade entre o sistema e as especificações o que, em última análise, representa que um erro pode ter sido localizado[CP08, M.11]. Nesta situação, o MC fornece um trace para identificar qual caminho levou a violação. Logo, se ocorre satisfação de propriedade é possível afirmar que:

$$
\psi, t \models p
$$

Sendo $\psi$ uma função temporal que relaciona um estado $t$ a uma propriedade $p$.

Por outro lado, se

$$
\psi, t \not=p
$$

Isto indica que ocorreu uma violação da propriedade $p$.

Para que o processo de verificação via MC seja possível, um dos primeiros passos a adotar é a representação do software na forma de um autômato temporal ${ }^{6}$, o qual é definido pela tupla [B.99]:

$$
K=\left(S_{m}, S_{0}, T, L\right)
$$

sendo:

- $S_{m}$ é o conjunto de estados do modelo;

- $S_{0}$ é o conjunto dos estados iniciais do sistema tal que $S_{0} \subseteq S$;

- $T$ é o conjunto de relações de transição, no qual para cada $s \in S_{m}$ existe um $s^{\prime} \in S_{m}$ tal que $\left(s, s^{\prime}\right) \in T$

- $L: S_{m} \rightarrow 2^{A P}$, é uma função que mapeia um dado estado do modelo em relação a uma dada propriedade do modelo, sendo $A P$ um conjunto contável de proposições atômicas.

Um autômato temporal é apresentado na Figura 2.1

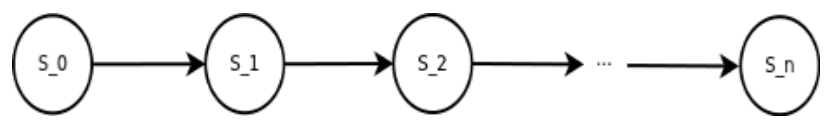

Figura 2.1: Autômato Temporal

O autômato representa uma sucessão de estados no tempo. Cada estado ocorre em um tempo $t$ de modo que $t_{i} \neq t_{j}$ se $i \neq j$, o que implica que não ocorrem estados simultâneos. O intervalo de tempo decorrido entre dois estados sucessivos é constante. Isto implica que o autômato temporal não opera com base em tempo real, mas em uma abstração [NA71]. Por fim, em termos práticos, é interessante que um autômato temporal possua um estado final, pois isso aumenta a proximidade entre o modelo do sistema e o sistema. Contudo, em termos teóricos, esta restrição não necessita ser observada [M.11]. Uma sequência de estados em um autômato temporal é definida como caminho, (path), o qual é formalmente definido como:

$$
c=\left(s_{0}, s_{1}, s_{2}, \ldots, s_{i}, s_{i+1}\right) .
$$

Sendo $P$ o conjunto de todos os caminhos em um autômato $K$, define-se:

$$
P(K, s) \text {. }
$$

\footnotetext{
${ }^{6}$ Estrutura de Kripke.
} 
como o conjunto de todos os paths em $P$ que possuem como estado inicial $s$ para $s \in S_{m}$ [FFE09].

A exploração dos estados, no modelo, é feita com base em uma sequência de transições (caminho $c$ em $\mathrm{P}$ ) definidas por $T\left(s_{i}\right)=s_{i+1}$ tais que

$$
s_{0} \rightarrow s_{1} \rightarrow s_{2} \rightarrow s_{3} \rightarrow \ldots \rightarrow s_{n} .
$$

se, para cada estado da sequência, temos que $s=\sigma$ para toda propriedade $\sigma$ tal que $\sigma \in L$ então admitimos que temos um trace dado por

$$
L\left(s_{0}\right) L\left(s_{1}\right) L\left(s_{2}\right) L\left(s_{3}\right) \ldots L\left(s_{n}\right) .
$$

o que implica que se $c \in P$ e $c$ é um caminho no qual não ocorrem violações dizemos que $c$ é um trace de $P$. Isto equivale a admitir que o caminho $c$ corresponde a uma execução valida. Por outro lado, se $s_{i} \not \models \sigma$ para $\sigma \in L$ temos que o caminho $c$ é uma execução não valida, o que resulta em um trace parcial dado por

$$
L\left(s_{0}\right) L\left(s_{1}\right) L\left(s_{2}\right) L\left(s_{3}\right) \ldots L\left(s_{i-1}\right) .
$$

no qual $T\left(s_{i-1}\right)=s_{i}$ que é o estado que viola a propriedade $\sigma$.

Um segundo passo consiste em definir as propriedades que se deseja verificar no modelo em termos de Lógica Temporal[B.99, PJ08]. A Lógica Temporal(LT) é uma extensão da Lógica Modal (LM) que tem por objetivo fornecer ferramentas para que se possa expressar, de forma precisa, raciocínios que envolvem a dimensão do tempo e para que se possa especular sobre a natureza do tempo [NA71]. Tempo, em LT, é um parâmetro utilizado na atribuição do valor-verdade a uma dada proposição, o que implica que uma dada proposição temporal pode ser verdadeira, ou falsa, mediante o momento no tempo em que ela é enunciada.

Logo, para:

$$
\sigma, s_{1}=k
$$

ao passo que em:

$$
\sigma, s_{2} \not \models k
$$

Isso equivale a afirmar que $k$ é verdadeira em $s_{1}$, mas falsa em $s_{2}$. Sendo $\sigma$ uma função temporal, $s_{1}$ e $s_{2}$ os estados e $k$ uma propriedade.

Outra característica importante da LT, que justifica o seu uso na modelagem de propriedades, é o fato dela permitir que estados sejam interconectados por meio de uma Relação de Acessibilidade (RA), do inglês accessibility relation[M.11], a qual permite navegar de um estado a outro. Uma RA tem a propriedade de garantir que dados dois estados $s_{1}$ e $s_{2}$, se $s_{1} R s_{2}$ então ocorrerá alguma coisa em $s_{2}$, se e somente se, ocorreu alguma coisa em $s_{1}$ que leva a $s_{2}$. Suponha que em $s_{i}$ tenha-se $\psi=$ reator superaquecido e $s_{j}$ tenha-se $\phi=$ reator explode. Em LT é possível estabelecer que $s_{i} R s_{j}$ o que implica, em termos de tempo, que em algum momento após o reator estar superaquecido, tal reator irá explodir. Ou seja, $s_{j}(\phi)$ se e somente se $s_{i}(\psi)$, para $i \wedge j \in T^{7}$ e $j \geq i$.

Vale colocar que a noção de "navegação" entre estados da LT tem por base a ideia de linearidade, ou seja, o estado que sucede $w_{i}$ será $w_{i+1}$ bem como o estado antecessor será $w_{i-1} \cdot{ }^{8}$. Em LT a relação de acessibilidade é expressa por meio de operadores temporais. Estes operadores são apresentados abaixo ${ }^{9}$ :

\footnotetext{
${ }^{7} T$ é o conjunto de todos os momentos em uma linha do tempo. Para todos os fins, assume-se $T$ como o conjunto dos números Naturais [NA71].

${ }^{8}$ A LT é uma extensão da Lógica Topológica [M.11] [NA71] na qual a propriedade que define o sistema pode ser métrica, cartesiana, etc.

${ }^{9}$ A Notação utilizada para os operadores temporais é a mesma utilizada para os operadores modais.
} 
- próximo, $\bigcirc \phi, \phi$ é verdadeira no momento imediatamente seguinte;

- sempre, $\square \phi, \phi$ é verdadeira para todos os momentos futuros;

- algum, $\diamond \phi, \phi$ é verdadeira em algum momento futuro;

- enquanto, $\phi U \psi, \phi$ é verdadeira até que em um momento futuro $\psi$ se torne verdadeira;

- até que, $\phi W \psi, \phi$ é verdadeira em todos momentos futuros a menos que $\psi$ se torne verdadeiro.

Os operadores $\bigcirc, \square$ e $\diamond$ são unários, ao passo que os operadores $U$ e $W$ são binários.

Além dos operadores acima descritos, a LT admite um operador inicial (start) caso seja possível garantir que existe um mundo/estado inicial. Com base no que foi colocado, é possível definir os elementos da sintaxe da LT como sendo:

$$
\phi::=\text { true } \mid \text { false }|a \in A P| \neg \phi\left|\phi_{1} \vee \phi_{2}\right| \phi_{1} \wedge \phi_{2}\left|\phi_{1} \rightarrow \phi_{2}\right| \phi_{1} \equiv \phi_{2}\left|\phi_{1} \cup \phi_{2}\right| \bigcirc \phi|\square \phi| \diamond \phi
$$

\subsubsection{Semântica}

A LT é uma extensão da LM que incorpora o tempo como um parâmetro na definição do valorverdade de uma dada proposição. A valoração de uma proposição depende de qual é o momento em que ela está sendo formulada. Desta forma, um modelo $T$ para LT pode ser expresso como uma tripla, como apresentado abaixo:

$$
T=(S, R, \pi)
$$

Onde, $S$ é o conjunto de estados em que cada $s \in S$ representa um momento no tempo, $R$ é uma relação de acessibilidade que define como a transição entre estados pertencentes a $S$ ocorre $^{10}$, e $\pi$ representa a função que mapeia cada elemento de $S$ a uma dada proposição em $T,(\pi: S \mapsto T)$.

Dadas as propriedades de $R$, o modelo $T$ pode ser simplificado se for assumido que:

$\forall s_{i} \in S$ se $i \geq 0$ então o próximo estado acessível será $s_{i+1}{ }^{11}$

O que permite escrever $T$ como sendo:

$$
T=(S, \pi)
$$

Isto implica que, dada uma proposição $\psi \in T^{12}$, então tem-se que

$$
t:(T \times \psi) \mapsto B
$$

para $B=\{$ True, False $\}$

Onde $t$ é uma função que mapeia o par definido por um modelo temporal e uma proposição a um dado valor true ou false em $B$.

Logo, dado um modelo temporal e um índice que identifica um estado no modelo, é possível definir se este modelo satisfaz uma dada proposição.

Formalmente:

$$
\left(T, s_{i}\right) \models p
$$

\footnotetext{
${ }^{10}$ Para a LT, $R$ descreve uma relação linear, discreta e que possui um estado inicial, $s_{0}$

${ }^{11}$ Podemos desconsiderar o valor de tempo decorrido entre $s_{i}$ e $s i+1$ de forma que entre dois estados há sempre um intervalo constante de tempo $c$

${ }^{12} \psi$ é uma proposição bem formada
} 
Desta forma a semântica de uma proposição temporal pode ser formalmente definida como:

$$
\left(T, s_{i}\right) \models p \text { se e somente se } p \in \pi(i)
$$

Deriva dessa formulação a semântica dos operadores temporais como apresentada a seguir,

- start: $(T, i) \models$ start, se e somente se $i=0$, logo $s_{i}$ é um estado inicial,

- $\bigcirc \psi:(T, i) \models \bigcirc \psi$ se e somente se $(T, i+1) \models \psi, \psi$ é satisfeita no próximo estado acessível partindo-se de $s_{i}$ que é $s_{i+1}$.

- $\diamond \psi:(T, i) \models \diamond \psi$ se e somente se existe $j$ tal que $j \geq i$ e $(T, j) \models \psi, \psi$ é satisfeita em algum momento existe um $s_{j}$ futuro,

- $\diamond^{+} \psi$ : $(T, i) \models \diamond \psi$ se e somente se existe $j$ tal que $j>i$ e $(T, j) \models \psi, \psi$ é satisfeita em algum momento $s_{j}$ futuro tal que $s_{j}$ não é estado atual ${ }^{13}$,

- $\square \psi:(T, i) \models \square \psi$ se e somente se para todo $j \geq i$ então $(T, i) \models \psi, \psi$ é satisfeita para todo os momentos que sucedem $s_{j}$ inclusive o estado presente,

- $\square^{+} \psi$ : $(T, i) \models \square \psi$ se e somente se para todo $j>i$ então $(T, i) \models \psi, \psi$ é satisfeita para todo os momentos que sucedem $s_{j}$,

- $\phi U \psi:(T, i)=\phi U \psi$ se e somente existe $j$ tal que $j \geq i$ e $(T, j) \models \psi$ sendo que para todo $k$ tal que $i \leq k<j$ então $(T, k) \models \phi, \phi$ é satisfeita até o momento em que $\psi$ é satisfeita.

- $\phi W \psi$ : $(T, i) \models \phi W \psi$ se e somente se $(T, i) \models \phi U \psi$ ou $(T, i) \models \square \phi, \phi$ é satisfeita até que $\psi$ ocorra ou $\phi$ é sempre verdadeira.

\subsubsection{Computation Tree Logic}

A LT apresentada até este momento é muitas vezes definida como Lógica Temporal Linear (LTL) pois apresenta um único futuro possível. Porém, existe uma variante da LT linear que aceita mais de um futuro possível. A Lógica em Ramos (Branching Time)[NA71] ou Computation Tree Logic (CTL) [B.99] permite representar fenômenos no tempo nos quais mais de um futuro é passível de ocorrer. Sua representação é apresentada na 2.2:

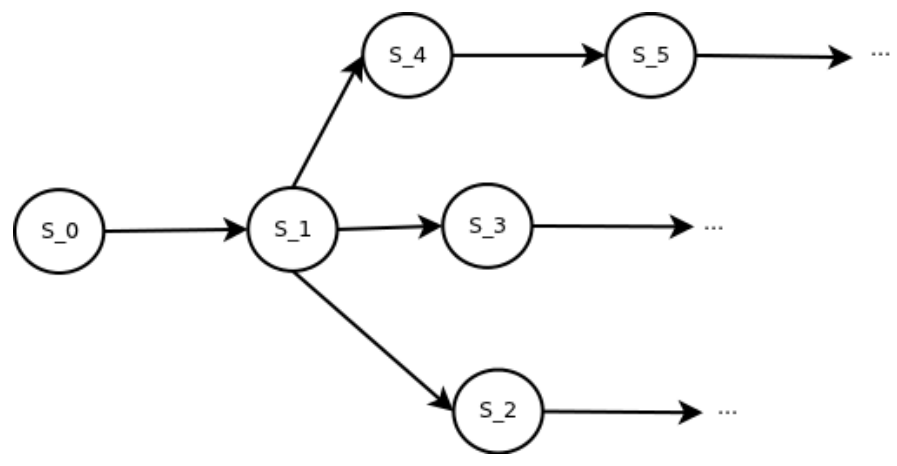

Figura 2.2: Representação de uma $C T L$

Partindo de um ponto inicial no tempo, um estado $s_{0}$, a cada estado pode ocorrer uma ramificação. Cada momento, representado por um nó na árvore, leva a um futuro possível representado pelo nó filho. A CTL agrega ao conjunto de operadores da LT dois operadores de caminho, que são:

\footnotetext{
${ }^{13} \diamond^{+} \psi \equiv \bigcirc \diamond \psi$
} 
- $A \psi$, em todos os caminhos $\psi$ é satisfeita,

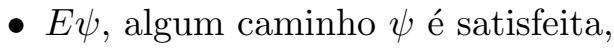

Estes operadores podem ser combinados com os operadores temporais conforme apresentado abaixo:

- $A \bigcirc \psi$, em todos os caminhos partindo do próximo momento em relação ao atual então $\psi$ é satisfeita,

- $E \bigcirc \psi$, algum caminho partindo do próximo momento em relação ao atual então $\psi$ é satisfeita,

Os operadores de caminho permitem verificar três propriedades em um dado modelo. São elas:

- Safety Property: descreve que um dado comportamento não ocorrerá em nenhum caminho.

- Invariance Property: descreve um comportamento que se deseja que ocorra em todos os caminhos.

- Liveness Property: descreve que eventualmente alguma coisa boa acontecerá [PJ08].

O uso de LT em ferramentas de MC varia de ferramenta para ferramenta. Há model checkers que utilizam LTL ou CTL, e mesmo ferramentas que incorporam ambas as abordagens. Dentre as variantes de MC podemos destacar:

- Explicit model checking: modelagem é feita com base em LTL ou CTL, o espaço de estados é explicitamente representado, e a busca pela violação ocorre por um caminho completo que vai da origem até o último estado (forward exploration) ou até que uma violação ocorra, $\left(s_{i}, s_{f}\right)$.

- Direct Model Checking: uma extensão dos conceitos apresentados pelo Explicit model checking, se vale de heurísticas de busca (Busca em Pronfundidade, Busca em Largura, $A^{*}$ etc.) para aumentar a eficiência na análise do modelo.

- Symbolic Model Checking: segunda geração de model checking, usa ordered binary decision diagrams (BDD) para representar estados e funções. Sua grande vantagem frente às outras metodologias é a de poder representar espaços de estado significativamente maiores.

- Bounded Model Checking: terceira geração de model checking, opera por meio de uma reformulação do modelo a ser analisado em termos de um problema de satisfação de restrições permitindo o uso de técnicas de SAT-solver [JP04].

Apesar do número de variantes de MC, todas elas possuem o mesmo objetivo: determinar se um dado modelo satisfaz uma dada propriedade em análise, fornecendo provas ou demonstrando a violação da propriedade via contra-exemplos.

\subsubsection{Limites da Verificação Formal}

A técnica de verificação formal, por prova de sistema ou por prova de modelo, possui duas grandes vantagens

- fornece provas da corretude de um dado software; e,

- é passível de total automação.

Contudo, apresenta grandes desvantagens [CP08]

- é uma técnica mais apropriada para verificação de sistemas com baixa manipulação de dados. 
- a verificação é feita apenas em relação aos requisitos estabelecidos (stated requirements), não há garantia de completude. A validade de propriedades que não são verificados não pode ser avaliada.

- a descrição do modelo ou sistema em termos formais é complexa e exige alto grau de capacitação do desenvolvedor; e,

- a representação do modelo ou sistema pode introduzir características que não existem no software original acarretando em erros detectados no modelo ou sistema que não estão presentes no software.

- O número de estados necessários para modelar um SUT com precisão pode exceder a quantidade disponível de memória (state-space explosion problem) num sistema computacional real. Apesar do desenvolvimento de vários métodos muito eficazes para combater este problema, modelos de sistemas reais ainda podem ser impossíveis de serem armazenados.

\subsubsection{Verificação Formal e Comportamento Excepcional}

A possibilidade de tratar do comportamento excepcional de um software agrega, à técnica de verificação formal, a vantagem de verificar a ocorrência de violações de propriedades em partes do código que, via de regra, são ignoradas. Além disso, as possíveis representações do sistema tornamse mais precisas e completas, pois incorporam os elementos referentes à manipulação de exceções. Indo além, é possível estudar violações de propriedades que se referem ao próprio comportamento excepcional, ou seja, é possível verificar se o modelo realmente dá o correto tratamento a exceções quando da ocorrência de uma.

\subsection{Conclusão}

O tratamento de exceções está presente na maioria das linguagens modernas. Este tratamento visa dotar o software de robustez a fim de que ele possa se recuperar, caso ocorra uma exceção. Apesar das estruturas de tratamento de exceção serem comuns na maioria dos códigos de grandes aplicações, elas são normalmente negligenciadas quando da realização de testes ou da construção de modelos formais. Isso implica que grande porções de código não são analisadas a fim de determinar a existência de erros.

Motivadas por esta constatação, várias pesquisas têm buscado integrar o teste de software e/ou verificação formal à análise do comportamento excepcional. A grande vantagem de tal integração é o aumento do conhecimento do comportamento do software no tocante ao tratamento de exceções propriamente dito, e um melhor e maior conhecimento do funcionamento do software em termos gerais. Isto leva a uma redução na ocorrência de erros. 


\section{Capítulo 3}

\section{Tratamento de Exceções}

Apresentaremos a seguir os principais conceitos do Tratamento de Exceções a fim de definir o que é uma exceção em termos de hardware/software e o modo como diferentes linguagens de programação implementam estratégias distintas com o objetivo de manipularem, propagarem ou definirem estruturas de manipulação e desativação de exceções.

\subsection{Comportamento Excepcional}

Exceção é uma situação inesperada e indesejável que ocorre em um programa durante sua execução. A maior parte dos computadores modernos possui um hardware capaz de detectar estas situações ${ }^{1}$. Porém, se a linguagem, na qual foi escrito o programa que está sendo executado não oferecer nenhum tipo de manipulação, essa exceção leva o hardware a, em termos gerais, abortar a execução do programa e retornar o controle para o sistema operacional o qual fornece algum tipo de listagem que identifique o erro que gerou a interrupção da execução. Vale notar que nem toda exceção é identificada pelo hardware. Um exemplo é a faixa de subscrito de matriz que, via de regra, só pode ser identificada pelo software [W.06]. Desta forma, o papel do hardware é identificar a exceção mas não efetivamente realizar sua manipulação dentro do contexto do programa que está sendo executado. Esta manipulação só pode ser implementada pela linguagem de programação e intencionalmente utilizada pelo desenvolvedor.

Assim, para garantir que exceções detectáveis por hardware ou por software recebam tratamento adequado, a maioria das linguagens modernas de programação oferece mecanismos manipulação de exceção que permitem:

- identificar a exceção que foi ativada,

- identificar o agente no código responsável pela ativação da exceção,

- identificar o agente no código responsável pela desativação da exceção,

- definir uma estratégia de propagação da exceção do agente que a ativou até chegar ao agente responsável por sua desativação, se este existir,

- definir estruturas de manipulação de exceções que possam ser utilizadas pelo desenvolvedor tanto na definição de novas situações excepcionais quanto na definição do tratamento efetivo de uma dada exceção.

O objetivo que se deseja alcançar, quando uma dada linguagem oferece um conjunto de manipuladores de exceção, é garantir que o código, escrito nessa linguagem, possua robustez. Robustez é a capacidade de um dado software se recuperar e retornar ao seu processamento normal após a ativação de uma dada exceção.

\footnotetext{
${ }^{1}$ estouro de pilha, estouro de número real, divisão por zero etc.
} 
Por exemplo, suponha um programa com alto custo de processamento (transações financeiras de um banco). Será extremamente custoso se todo um processamento for abortado devido à ativação de uma exceção. Se o programa tiver capacidade de se recuperar dessa exceção, então ocorrerá uma real economia em termos de tempo de processamento e de custos agregados. Outro exemplo, são os sistemas critícos (aviônica) nos quais uma exceção não tratada pode gerar perdas de vidas e de recursos.

Por outro lado, a desvantagem do uso de manipuladores de exceção tem por base o aumento na complexidade da linguagem de programação considerando que, normalmente, novas estruturas sintáticas são necessárias além de uma maior sobrecarga em termos de compilação dado que o compilador passa a ter a tarefa de verificar situações que possam produzir exceções, bem como deve operar sobre as estruturas de manipulação. Some-se a isso uma potencial diminuição da legibilidade do código, o que pode ser produzido devido às estruturas de tratamento.

\subsection{Conceitos Vinculados à Manipulação de Exceções}

Como já foi colocado, uma exceção é um comportamento errôneo e indesejável que pode ocorrer durante a execução de um programa. Este comportamento pode ser detectado tanto por hardware quanto por software. Sendo as unidades de código definidas para tratar deste comportamento definidas como manipuladores de exceção. Para cada exceção há, normalmente, um manipulador apropriado. Desta forma, um manipulador responsável pela identificação de um estouro de pilha seria diferente do responsável pela identificação de um arquivo não encontrado ${ }^{2}$.

Porém, é possível realizar uma manipulação de exceções sem necessariamente promover a implementação de estruturas dedicadas a isso. A Linguagem $C$ implementa uma embrionária manipulação de exceções. O processo se dá por meio da troca de parâmetros entre o método que realiza a chamada e o que é chamado. Se o método chamado ativa uma exceção ele altera o valor de um parâmetro auxiliar[W.06] de acordo com o tipo de exceção ativada. Esse parâmetro informa ao método que realizou a chamada que ele deverá manipular uma exceção.

A manipulação de exceção, por sua vez, pode ser feita por meio de manipuladores que são segmentos de código ou por unidades de programa [W.06]. No primeiro caso, o código é diretamente incorporado ao código da unidade que pode gerar a exceção. No segundo caso, o manipulador pode ser inserido diretamente no escopo do código que pode gerar informação ou pode haver uma troca de parâmetros entre o código que gera a exceção e o manipulador.

Outro fundamento importante relacionado à manipulação de exceções diz respeito à forma como a exceção é vinculada ao seu manipulador. Nesse caso, duas abordagens são possíveis. Na primeira, define-se um manipulador específico para cada instrução que possa lançar uma exceção. Se duas exceções lançarem a mesma exceção, cada uma possuirá seu próprio manipulador. Por outro lado, na segunda abordagem, a vinculação se dá de modo a que um manipulador possa ser usado por várias instruções diferentes que ativem a mesma exceção. Além disso, a vinculação entre exceção e manipuladores deve tratar da propagação de uma exceção. Se uma exceção não encontra um manipulador adequado no escopo no qual foi ativada, ela pode ser repassada para outro escopo até que encontre um manipulador. Se não ocorrer propagação, todo o código necessário para o tratamento deve ser escrito no local da ativação. Isso pode acarretar uma diminuição na legibilidade do código, caso existam muitos manipuladores para serem definidos. Por outro lado, a propagação pode fazer com que uma única unidade de programa seja responsável pelo tratamento de muitas exceções. A desvantagem de tal abordagem está no potencial aumento no tempo de execução de um programa desse tipo.

Quando um manipulador apropriado é encontrado e o programa este é executado, a fim de tratar dada exceção a qual é dedicado, podem ocorrer duas coisas, ou o fluxo de execução é passado do corpo do manipulador para uma parte do código do programa que se encarrega de continuar a execução ou a execução é finalizada. O conceito de continuação expressa essas duas possibilidades.

\footnotetext{
${ }^{2}$ apesar de ser uma orientação de projeto, nem toda linguagem segue esta orientação no seu sentido restrito. Um exemplo é a classe Exception da linguagem java que permite instanciar objetos que manipulam qualquer exceção.
} 
A escolha mais simples neste tocante é a de finalizar o programa e pode ser aplicada a um enorme número de exceções. Porém, em situações nas quais o erro pode ser superado por meio de uma redundância ${ }^{3}$. Disso implica definir o lugar para onde o fluxo de controle deve ser desviado pelo manipulador. Nesse caso o controle poderia retornar para a própria instrução que gerou a exceção, poderia ser passada para uma instrução imediatamente após a exceção ou ainda ser desviada para um escopo diferente do escopo da instrução que gerou a exceção.

Outro fundamento importante da manipulação de exceções diz respeito à definição de exceções feita pelo desenvolvedor e às exceções que são pré-especificadas pela linguagem. Na maior parte dos casos, as linguagens que permitem ao desenvolvedor definir exceções são declaradas no escopo no qual as exceções podem ser geradas. No caso das exceções pré-definidas ou incorporadas, há duas abordagens usualmente implementadas: ou toda exceção, pré-definida pela linguagem, deve ser tratada pelo desenvolvedor nos possíveis locais nos quais estas exceções podem ocorrer, ou a própria linguagem fornece manipuladores que monitoram a execução e são ativados quando uma exceção é lançada.

Por fim, as questões que envolvem a manipulação de exceções devem definir o grau de controle que a linguagem permite ao desenvolvedor sobre a manipulação. Por exemplo, um desenvolvedor pode ser capaz, ou não, de desativar a verificação de determinados tipos de exceção. Isso é muito útil se houver certeza absoluta de que tal exceção não vai ocorrer. O desenvolvedor pode, ou não pode, explicitamente ativar uma exceção no sistema de uma determinada condição de programação. Esse fundamento é útil pois, por meio dela, o desenvolvedor pode definir condições específicas que deverão ser tratadas, caso ocorram.

Exemplos do modo como diferentes linguagens de programação tratam da implementação de manipuladores serão apresentados na seção 3.3

\subsection{Linguagens de Programação e Manipulação de Exceções}

\subsection{1 $\quad \mathrm{PL} / \mathrm{I}(\mathrm{ANSI})$}

A linguagem PL/I(ANSI) [W.06] foi pioneira no fornecimento de estruturas para manipulação de exceção. Sua principal inovação foi a de permitir que o código do desenvolvedor pudesse manipular, de forma direta, um conjunto de exceções pré-defindas pela linguagem, além de fornecer exceções definidas pelo próprio desenvolvedor. Os manipuladores são construídos pelo usuário no formato de blocos e podem ser inseridos em qualquer parte do código. Como a estrutura de manipulação se dá na forma de bloco, o desenvolvedor deve inserir no escopo do bloco a instrução para a exceção cujo bloco deve fornecer tratamento.

PL/I implementa uma vinculação dinâmica entre a exceção lançada e seu respectivo manipulador. Por meio da instrução $O N$ um dado manipulador é definido para uma dada exceção. Um bloco pode conter quantas instruções $O N$ forem necessárias e cada uma pode especificar um manipulador para diferentes tipos de exceções ou várias instruções que podem gerar a mesma exceção. Uma instrução $O N$ se mantém ativa no sistema até que outra instrução $O N$ seja gerada ou até que o bloco da instrução seja finalizado.

A continuação da execução da exceção é definida de forma flexível em PL/I. Nas situações definidas pelo sistema nas quais o controle de fluxo retorna à exceção na qual ocorreu promovem a ativação da exceção; em outros casos, a execução do programa é abortada. O desenvolvedor pode ainda especificar um ponto de retorno desejado que não seja a instrução que gerou a exceção.

\subsubsection{Ada}

Um dos elementos fortes da linguagem Ada é sua capacidade de manipular exceções [W.06, INF]. Isto faz de Ada uma linguagem muito utilizada em sistemas critícos nos quais há baixa tolerância a erros. A primeira característica da manipulação de exceções feita em Ada é a de que os

\footnotetext{
${ }^{3}$ se um socket não estiver disponível, uma redundância seria a indicação de um socket auxiliar.
} 
manipuladores são definidos localmente, ou seja, no mesmo escopo do código no qual se espera que ocorra uma exceção. A palavra reservada when seguida do nome da exceção que se está monitorando pode ser escrita em qualquer parte do código e ainda pode ser agrupada em um conjunto de exceções a serem monitoradas por meio da palavra reservada exception. Neste caso, o bloco de exceções é escrito como o último conjunto de instruções do bloco do programa no qual se encontram.

Aqui, a vinculação entre exceção e manipulador é estática. Se não houver um manipulador apropriado para exceção ativada esta é propagada até encontrar um bloco de tratamento adequado. A peculiaridade do processo de propagação em Ada repousa no fato de essa propagação depender do tipo de entidade que a propaga. Se uma exceção for lançada por um procedimento que não lhe dá tratamento, então a exceção é propagada para a entidade que fez a chamada do procedimento no ponto exato em que tal chamada foi feita. Dessa forma, a propagação em Ada se dá em direção ao ancestral dinâmico e não ao estático. O processo se repete até que um ancestral forneça um tratamento ou até que o programa seja abortado.

Por outro lado, se a exceção for gerada no corpo de um pacote e este não possuir nenhum manipulador, a exceção é propagada para seção de declaração da unidade que contém a declaração do pacote[W.06]. Se esse pacote for uma biblioteca, o programa é abortado.

Do ponto de vista da execução do programa, o bloco que gerou a exceção, bem como todos os blocos para os quais a exceção foi propagada mas não recebeu tratamento, são finalizados. Desta forma, o controle de execução não retorna para o bloco que gerou a exceção.

\subsection{3 $C++$}

A linguagem $C++$ especifica um conjunto de blocos definidos pelas palavras reservadas try e catch. Sendo que um bloco try é sempre seguido por um ou mais blocos catch. Um bloco try pode conter qualquer instrução que possa, ou não, lançar uma exceção e sua função é a de monitorar se tal lançamento ocorre. Por sua vez, os blocos catch são definidos pela passagem de um parâmetro que identifica para qual exceção fornecem tratamento. O parâmetro definido no bloco pode ser qualquer tipo de dado, um integer, ou uma exceção específica. Além disso, $C++$ permite a declaração de um parâmetro geral, (...), o qual captura qualquer tipo de exceção.

Quando uma exceção é lançada em bloco try, todas as instruções posteriores à instrução que lançou a exceção não são executadas e o controle de execução passa para os blocos catch vinculados ao bloco try. Se nenhum bloco fornecer tratamento, o controle de fluxo é passado para entidade que fez a chamada do bloco e essa propagação continua até que o devido manipulador seja encontrado ou até que o programa seja finalizado. O fluxo de controle nunca retorna à instrução que ativou a exceção. Ela retorna para primeira instrução após o bloco try e o seu último bloco catch é definido pelo desenvolvedor.

\subsubsection{Smalltalk-80}

A linguagem Smalltalk-80[FFAJ01] é conhecida por ser totalmente orientada ao objeto. Exceções em Smalltalk-80 são vistas como objetos do tipo selector. Cada exceção é vinculada a um método que, por sua vez, é definido em uma classe. Quando uma exceção é lançada ocorre uma troca de mensagens entre a entidade que a lançou, o método, e o método que fornece o tratamento. Esta troca de mensagem se dá sempre no escopo da classe do objeto que lançou a exceção, ou seja, Smalltalk-80 não propaga exeções para o método que realizou a chamada. Após a definição do manipulador correto, Smalltalk-80 permite dois tipos de ação. A primeira é a interrupção da execução e a segunda é um retorno ao ponto de lançamento de exceção a fim de tentar novamente sua execução. Os desenvolvedores podem definir este retorno fornecendo valores alternativos a serem usados a fim de garantir que a exceção não seja novamente ativada.

\subsubsection{Eiffel}

O tratamento de exceções em Eiffel segue as linhas gerais do projeto que é baseado em contratos entre entidades. Cada entidade, classe, define um conjunto de condições pré, pós e invariantes que 
devem ser observadas após a execução. Se alguma destas condições contratadas não for respeitada, uma exceção é lançada. Caso a entidade que lançou a exceção não forneça um tratamento então ocorre uma propagação da exceção pelos ancestrais ativos do método que ativou a exceção. Eiffel permite que o programa continue por meio de uma nova execução da entidade que gerou a exceção, com novos parâmetros pré-defindos, ou então que aborte a execução.

\subsubsection{Guide}

Exceções em Guide são definidas como símbolos que podem receber parâmetros durante o processo de ativação de uma exceção [W.06]. Dessa forma, informações podem ser agregadas para especificar qual tipo exceção está sendo lançada. Toda exceção que pode ser lançada por uma classe deve ser declarada na interface desta classe. Uma particularidade dos manipuladores em Guide é o fato de não ocorrer tratamento local. Toda exceção é propagada para o método que realizou a chamada. Porém, se o método que realizou a chamada não fornece um tratamento então uma mensagem Uncaught_Exception é gerada. Após a manipulação da exceção, o fluxo de controle retorna para a instrução imediatamente posterior a instrução que lançou a exceção.

\subsubsection{Java}

$\mathrm{Java}^{4}$ [W.06] é uma das primeiras linguagens modernas na qual tratamento de exceções está presente como um dos elementos primários do projeto da linguagem. Apesar de ter sido originalmente baseada no $C++$, o tratamento de exceções em Java foi desenhado para ser mais adequado ao paradigma de programação conhecido como Orientação ao Objeto [W.06]. Em Java todas as exceções são representadas como objetos pertencentes à classe Throwable, a qual possui duas subclasses definidas como Error e Exception [Orab, Oraa].

A classe Error e suas subclasses representam exceções que ocorrem no interpretador Java e não são, portanto, manipuladas diretamente pelo usuário. As exceções representadas por esta classe são definidas como assíncronas. Podem ocorrer em qualquer ponto do código, dado que são geradas pela Java Virtual Machine (JVM). Por outro lado, a classe Exception possui duas subclasses definidas como RuntimeException e IOException. A primeira trata de exceções geradas pelo usuário, enquanto a segunda trata de exceções geradas por operações de entrada e de saída [Oraa]. As exceções representadas por estas duas classes são definidas como síncronas, pois ocorrem em pontos específicos do programa. Elas são geradas por meio de avaliação de expressões (atribuição de null), chamadas de métodos ou, ainda, geradas explicitamente por meio da instrução throw.

As exceções definidas como síncronas podem ser classificadas como:

- Checked: são verificadas pelo compilador Java. Se o compilador identificar alguma situação na qual uma exceção pode ser lançada, então ele impõe ao programador a utilização de alguma estrutura de captura de exceção para garantir o tratamento apropriado;

- Unchecked: não são verificadas pelo compilador Java;

- Implícitas: são lançadas por uma chamada a uma sub-rotina ou pelo ambiente de execução; e,

- Explícitas: são lançadas pelo usuário via comando throw.

As estruturas de tratamento das exceções em Java, por sua vez, são compostas por cinco tipos de instruções, denominadas como

- try

- catch

\footnotetext{
${ }^{4}$ Java será explorada em mais detalhes pois é a técnica de instrumentação para verificação e validação de comportamento excepcional de software que será aplicada em códigos escritos nessa linguagem nessa pesquisa.
} 
- finally

- throw

- throws

Para exemplificar o uso e o efeito de cada uma das instruções acima listadas, apresentamos a Listagem 3.1 que será usada ao longo deste trabalho como modelo para outras explanações.

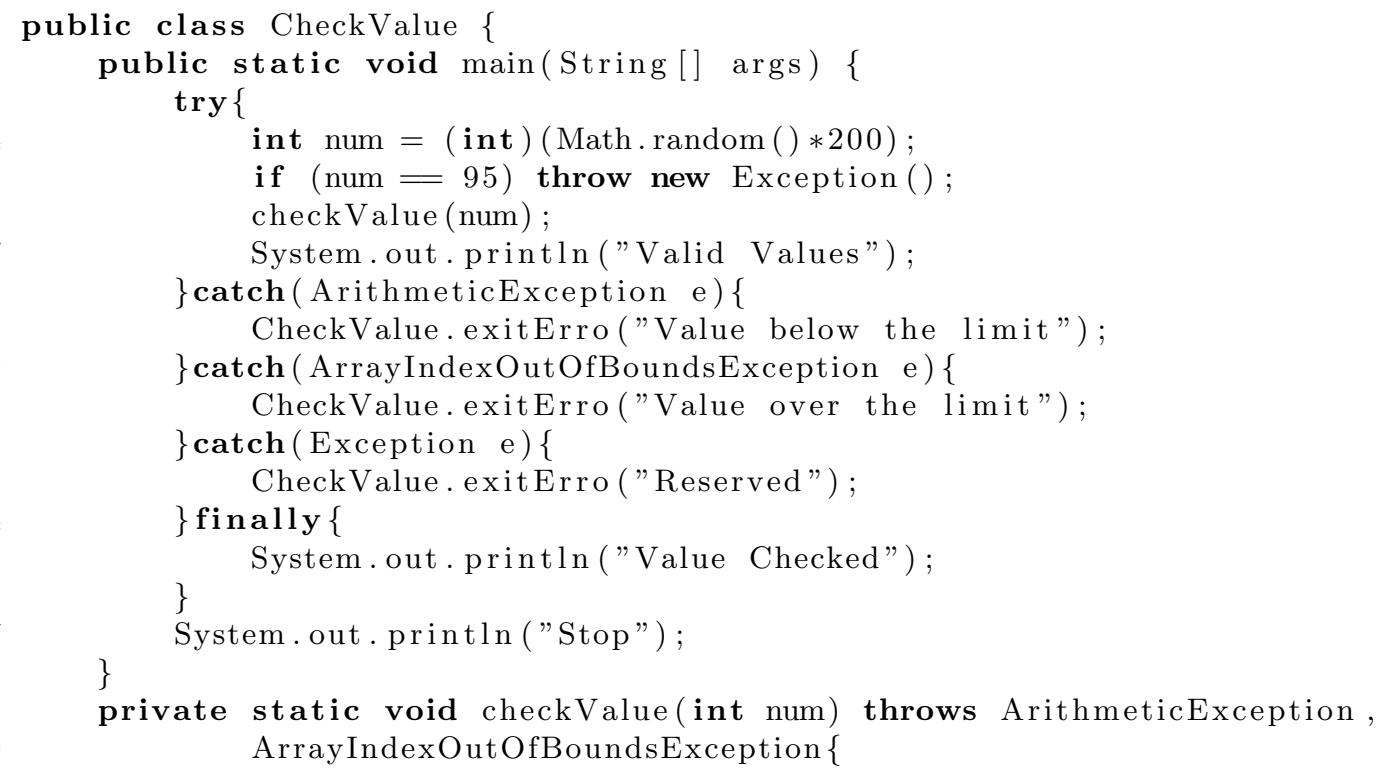

Listagem 3.1: Programa CheckValue

- try/catch/finally: o bloco try agrupa os comandos que podem gerar uma exceção. Ele é seguido por zero ou mais blocos catch e/ou por zero ou um bloco finally. Se nenhum bloco catch for definido, o último bloco depois do bloco try deve ser um bloco finally. Se uma exceção é lançada no bloco try, os blocos catch são percorridos na ordem de declaração até 
que o bloco catch, que fornece o tratamento apropriado à exceção, seja encontrado. No bloco try todos comandos que estão após o comando que lançou a exceção não são executados. O código de cada bloco catch lida com um tipo específico de exceção. Uma sintaxe opcional introduzida pela versão Java 7 permite a um único bloco catch capturar exceções que, apesar de diferentes, podem receber o mesmo tratamento [Orac]. O bloco finally é sempre executado com ou sem lançamento de uma exceção [Orab], e normalmente é utilizado para liberar recursos do sistema. Exemplos das estruturas acima descritas são apresentados no programa apresentado na Listagem 3.1. O bloco try é limitado pelas linhas 3 e 8. Há três blocos catch imediatamente depois do bloco try, os quais são limitados pelas linhas 8-10, 10-12 e 12-14, respectivamente. É possível notar que cada bloco catch declara com qual exceção ele lida na primeira linha do bloco. O bloco finally é o último bloco da estrutura e é limitado pelas linhas 14 e 16. É possível estabelecer uma analogia entre os blocos try/catch/finally e a estrutura de decisão switch/case/default. Se assumirmos que o bloco try opera da mesma forma que o comando switch, o bloco catch possui a mesma finalidade que o comando case e o bloco finally tem função análoga ao comando default, então é possível argumentar que o bloco try/catch/finally opera como uma estrutura de decisão no código de forma similar à estrutura switch/case/default.

- A cláusula throws é especificada depois da declaração dos parâmetros do método e antes do corpo do método. Ela sinaliza que uma ou mais exceções podem ser lançadas pelo método [Orab] mas esse método não fornece tratamento para estas exceções. A linha 19 da Listagem 3.1 apresenta o uso da cláusula throws. Há duas exceções que podem ser geradas pelo método checkValue, e que não são tratadas por ele.

- A instrução throw é usada para definir exceções que podem ser lançadas em tempo de execução [Orab]. Frequentemente é associada com um ponto de decisão inserido diretamente pelo programador. A Listagem 3.1 apresenta três estruturas que implementam a instrução throw. Elas são limitadas pelas linhas: 5, 34-36 e 42-44. Este tipo de estrutura é muito importante, pois permite ao programador decidir onde e como uma exceção pode ser lançada dentro de um código.

\subsubsection{Tratamento de uma Exceção Lançada em Java}

Definidas as estruturas que realizam o tratamento de exceções em Java, é possível discutir, com base na Listagem 3.1, como o tratamento ocorre após o lançamento de uma exceção.

$\mathrm{Na}$ Listagem 3.1 há três possíveis pontos de lançamento de exceções ${ }^{5}$ : linhas 6,35 e 43 . A exceção da linha 6 só é lançada se o valor da variável num for igual a 95. Se isto ocorrer, então o bloco catch, responsável pelo tratamento da exceção, será o bloco definido na linha 12. Toda exceção lançada e tratada no mesmo método é definida como intraprocedural. Vale notar que, se a exceção da linha 6 for lançada, todas as linhas posteriores à linha 6 não serão executadas.

As exceções das linhas 35 e 43 ocorrem em métodos distintos, inferiorValue e upperValue respectivamente, e não recebem nenhum tratamento dos seus métodos de origem. Se ocorrer uma exceção em qualquer um destes dois pontos do código, o método que a gerou (inferiorValue ou upperValue) será finalizado e ocorrerá um backtracking no fluxo de controle até que um ponto de tratamento adequado seja encontrado. Neste caso, os pontos de tratamento das exceções serão os blocos catch do método main (linhas 8 e 10). O tipo de exceção cujo ponto de lançamento e tratamento não se encontram no mesmo método é denominada de interprocedural. Como no caso da exceção da linha 6 , o lançamento de qualquer uma das exceções interprocedurais acarreta na não execução de todas as linhas subsequentes.

Vale notar que o desvio do fluxo de controle, quando uma exceção ocorre, não retorna para o ponto de lançamento da exceção pois este é desviado para um ponto de tratamento adequado a fim de permitir à continuidade da execução. Se, no entanto, não existir nenhum manipulador

\footnotetext{
${ }^{5}$ Estas exceções são classificadas como explícitas, conforme definido na Seção 3.3.7.
} 
adequado à exceção lançada, o software é finalizado. Por fim, o bloco finally, linha 14, é executado com ou sem o lançamento de alguma exceção.

A linha 19 da Listagem 3.1, por sua vez, é sinalizado para o programa que o método checkValue lança duas exceções mas não as trata, como foi dito anteriormente. O interessante nesta construção é que qualquer exceção disparada no código, menos a da linha 6, passa pelo método checkValue que as repassa, dado que não possui nenhum tratamento disponível.

A apresentação do tratamento de exceções feito pela linguagem Java permite circunscrever quais tipos de exceção este trabalho buscará tratar. O foco de nossa técnica de exercício de comportamento excepcional serão as estruturas acima descritas e o uso destas pelos desenvolvedores. Isto se deve às seguintes razões:

- este tipo de exceção é muito frequente em código Java;

- apesar de frequentes, elas raramente são contempladas nas especificação de um software;

- são geralmente implementadas com base em escolhas pessoais do desenvolvedor;

- estudos indicam que são sujeitas a um grande número de más práticas de programação [BP07] que acarretam na ineficiência do tratamento de exceções, além de introduzirem erros; e,

- podem ser tratadas com técnicas de instrumentação relativamente simples.

\subsection{Conclusão}

O tratamento de exceções está presente na maioria das linguagens modernas. Este tratamento visa dotar o software de robustez a fim de que ele possa se recuperar, caso ocorra uma exceção. As principais questões que envolvem este tratamento dizem respeito à identificação das entidades que ativam as exceções, às entidades que desativam estas exceções, ao modo como essas entidades são vinculadas, ao modo como uma exceção é propagada pelo código e ao grau de acesso que um desenvolvedor pode ter a estas estruturas de manipulação de exceção.

Logo, o estudo dessas estruturas de manipulação é interessante pois permite avaliar tanto se as estruturas efetivamente atingem seu objetivo no tocante a fornecer robustez a uma aplicação, quanto por permitir identificar possíveis erros vinculados à essa exceção. Dessa forma, o estudo focado na verificação e validação de manipuladores de exceção é de grande interesse. No próximo capítulo apresentamos uma definição de para teste de software e verificação formal e a relevância destas técnicas no estudo de manipuladores de exceção. 


\section{Capítulo 4}

\section{Modelo de Comportamento Excepcional}

O teste de todos os possíveis valores de entrada de um programa é uma tarefa inviável [PJ08]. Logo, para que um software seja verificado é necessário definir normas que selecionam elementos do conjunto de entrada que possuem alta capacidade de manifestar defeitos [PJ08, P.12]. Tais normas são chamadas de Critérios de Teste [PJ08, MM08].

Nesse Capítulo apresentaremos os principais critérios de teste aplicáveis à verificação de exceções, o modo como esses critérios definem quais elementos em um SUT (System Under Test) são responsáveis pelo lançamento e o respectivo tratamento de exceções adequados a eles e como esses elementos podem ser relacionados de modo a definir um modelo que retenha essas informações. Por fim, usaremos esse modelo para orientar o processo de instrumentação de código escrito em Java a fim de exercitar exceções.

\subsection{Conceitos Preliminares}

Os critérios de teste, como apresentado no Capítulo 2, podem ser utilizados para identificar quais elementos do conjunto de inputs de um dado SUT possuem maior probabilidade de manifestar falhas. Além disso, estes critérios identificam quais estruturas do código devem ser exercitadas. Dentre os critérios de teste mais utilizados [ECM07], podemos destacar o critério de Definição e Uso de variáveis e/ou objetos. Esse critério é associado ao teste de fluxo de dados [PJ08] cujo foco não está na execução da linha de código, teste de fluxo de controle, e sim na utilização das variáveis/objetos (dados) existentes no código.

Estes conceitos preliminares constituem um elemento importante do modelo que será utilizado para orientar o desenvolvimento de uma técnica aplicada no execício do comportamento excepcional de um SUT.

\subsubsection{Conceitos de teste fluxo de dados}

O teste de fluxo de dados tem por base a noção de que a computação de um valor incorreto leva a uma falha apenas no momento em que este valor é usado [MM08]. Logo, o foco do teste está no fluxo de dados que pode ser entendido como a relação estabelecida entre a definição da variável e seu uso. Essa relação permite uma análise de cobertura do código na qual se pretende identificar se cada definição de variável possui um respectivo uso e se esse uso resulta em um comportamento correto, ou seja, especificado pelo software. Uma definição de variável e seu respectivo uso constituem um par de definição e uso chamado de par definição-uso ou def-use. Logo, uma variável é dita definida/usada quando ${ }^{1}$ apresenta:

Definição 1 (Definição e Uso de Variáveis).

\footnotetext{
${ }^{1}$ Definições retiradas dos trabalhos de Sinha e Harrold [SJ98, SH99].
} 
- Definição-Variáveis (V $V_{\text {def }}$ ): uma variável é definida quando é armazenada na memória[ECM0¥], esse armazenamento se dá nas seguintes situações: quando a variável está do lado esquerdo do comando de atribuição, em um comando de entrada ou em uma chamada de procedimento como valor de retorno.

- Uso-Variáveis ( $\left.V_{u s e}\right)$ : uma variável é usada quando a referência a ela não a está definindo [ECMO'7].

Se, entre uma definição e uso de uma variável, não ocorrer nenhuma nova definição então admitimos que há um caminho livre de definição entre a definição da variável e seu uso. Formalmente, um caminho é dito livre de definição quando²:

Definição 2 (Caminho Livre de Definição).

Uma variável $x$ definida na linha $i$ é usada na linha $j$ e existe um caminho $p$ tal que $p=$ $\left(i, n_{1}, n_{2}, \ldots, n_{n}, j\right) \geq 0$ no qual, em nenhuma linha $n$, ocorre uma redefinição de $x$ então $p$ é um caminho livre de definição [ECMOク].

Por fim, utilizando as definições 1 e 2, temos que um par é dito par de definição e uso quando ${ }^{3}$ :

Definição 3 (Par de definição e uso).

Entre a linha $i$, na qual uma variável é definida ( $\left.V_{\text {def }}\right)$, e a linha $j$, na qual é usada ( $\left.V_{\text {use }}\right)$, existe um caminho livre de definição, então a linha $i$ e $j$ formam um par de definição e uso para variável $V$. O par du é formalmente representado pela tripla,

$$
<i, x, j>
$$

Na qual, $x$ representa a variável, $i$ representa a linha de definição da variável $x$ e $j$ representa a linha de seu uso.

As definições apresentadas acima (1, 2 e 3) são aplicáveis aos programas escritos em linguagens orientadas a procedimentos (C, Cobol, etc.) [W.06] nas quais a execução do programa ocorre por meio da passagem de dados entre subprogramas ou bibliotecas de subprogramas na forma de parâmetros [W.06]. Cada subprograma é responsável pelo processamento dos dados ou por seu envio para um subprograma que o faça.

Por sua vez, as linguagens que dão suporte à programação orientada a objetos estão baseadas na definição de tipos de dados abstratos chamados objetos e todo processamento destes objetos se dá por meio de subprogramas a eles associados [W.06].

Além disso, as linguagens orientadas a objetos possuem um conjunto de características particulares tais quais encapsulamento, herança, polimorfismo e vinculação dinâmica. Essas características, por sua vez, introduzem um novo conjunto de erros. Some a isso, o fato de, nesses casos, exceções serem tratadas por linguagens Java-like, como objetos.

Para abarcar esse novo conjunto de erros, as definições 1, 2 e 3 necessitam ser expandidas [PXC97, VSF10] a fim de tornar os critérios de teste de fluxo de dados adequados a linguagens orientadas a objetos [VSF10] e ao tratamento de exceções que são definidas como objetos. Logo, um objeto é dito definido/ usado $^{4}$ :

Definição 4 (Definição e Uso de Objetos).

- Definição-Objeto: se e somente se é inicializado ou atualizado. Há três situações sintáticas nas quais um objeto é definido: quando o construtor do objeto é invocado, quando um valor é explicitamente atribuído a um atributo do objeto ou quando um método que inicializa ou atualiza um atributo é invocado.

\footnotetext{
${ }^{2}$ Definições retiradas dos trabalhos de Sinha e Harrold [SJ98, SH99].

${ }^{3}$ Definições retiradas dos trabalhos de Sinha e Harrold [SJ98, SH99].

${ }^{4}$ Definições retiradas dos trabalhos de Sinha e Harrold [SJ98, SH99].
} 
- Uso-Objeto: um objecto é usado quando um dos seus atributos é utilizado em um predicado ou em um cálculo, quando um método que usa um valor de atributo é invocado ou quando um objeto é passado como parâmetro em uma chamada de método.

Uma exceção, por sua vez, pode tanto ser definida como um objeto quanto como uma variável [SJ98]. Logo, uma exceção é dita um objeto ou variável quando ${ }^{5}$ :

Definição 5 (Exceções: objetos e variáveis ).

- Objeto de Exceção: Corresponde a uma instância de uma classe de exceção. Representada por eobji sendo $i$ a linha na qual a classe foi instanciada. (Ex: throw new Exception();)

- Variável de Exceção: Expressa uma variável cujo tipo é um tipo de Exceção. (Ex: Exception ex;)

- Variáveis Temporárias: Expressa variáveis de exceção associadas a alguma cláusula throw. Representada por evar ${ }_{i}$ onde i representa a linha da instrução throw. (Ex: throw new Excep$\operatorname{tion}() ;)$

- Objeto de exceção ativo: É um objeto de exceção lançado por uma cláusula throw. Representado por evar active.

Os elementos apresentados na Definição 5 representam todas as possíveis ocorrências sintáticas de uma exceção em uma linguagem como Java [SJ98, VSF10]. Com base na Definição 5 é possível determinar quais são as situações em que uma exceção é definida/usada e ativada/desativada. Uma exceção é dita definida ou usada quando ${ }^{6}$ :

Definição 6 (Exceções: definição e uso).

1. Exceção-Definição

(a) Expressa um valor associado a uma variável de exceções (Ex: Exception ex $=$ new Exception();)

(b) Em um catch um valor é associado a uma variável ex e evar active é associado a null. (Ex: $\operatorname{catch}($ Exception ex))

(c) Em um throw é feita uma associação e $e_{v a r}$.(Ex: throw new Exception();)

(d) Em um throw é feita uma associação evaractive.(Ex: throw e;)

2. Exceção-Uso

(a) Uma variável de tipo exceção é acessada. (Ex: System.out.println(ex);)

(b) O valor evar active é acessado. (Ex: catch(ex))

(c) Corresponde a um nó throw com uma variável temporária de exceção. (Ex:throw new Exception())

Por sua vez, uma exceção é dita ativada ou desativada quando ${ }^{7}$ :

Definição 7 (Exceções: ativação e desativação).

1. Exceção-Ativação: Neste tipo de ativação, é determinado de forma explícita pelo programador em quais condições uma exceção é lançada. Este lançamento é feito via instrução throw a qual está no escopo do código fonte que está sendo analisado.

\footnotetext{
${ }^{5}$ Definições retiradas dos trabalhos de Sinha e Harrold [SJ98, SH99].

${ }^{6}$ Definições retiradas dos trabalhos de Sinha e Harrold [SJ98, SH99].

${ }^{7}$ As definições 7.1.a e 7.2.a foram retiradas dos trabalhos de Sinha e Harrold [SJ98, SH99]. A definição 7.1.b é de autoria dessa dissertação.
} 
(a) Ativação-Sícrona: Neste tipo de ativação, foi definido no código fonte do programa que se está verificando uma estrutura de tratamento, ver próximos itens, na qual pode ocorrer lançamento de exceção mas o método que lança a exceção não pertence ao código fonte da aplicação que se está verificando. Neste caso, o que se tem é um método que pertence a uma biblioteca. Como, neste estudo não trabalhamos com bytecode, assumimos que os pontos de ativação são os blocos definidos dentro do próprio código fonte.

i. Via instrução throw.

(b) Ativação-Assincrona

i. Via declaração throws que anuncia que uma variável evar ${ }_{p}$, no corpo do método, pode ativar uma exceção.

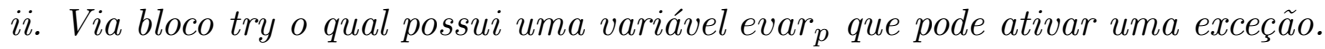

2. Exceção-Desativação

(a) Uma exceção é desativada via instrução $\operatorname{catch}^{8}$.

Análoga à Definição 2, um Caminho é dito Livre de Ativações quando:

Definição 8 (Caminho Livre de Ativações).

uma exceção é ativada em uma linha $i$ e desativada em linha $j$ e existe um caminho $p$ tal que $p=\left(i, n_{1}, n_{2}, \ldots, n_{n}, j\right) \geq 0$ no qual, em nenhuma linha $n$, ocorre ativação de uma nova exceção, então $p$ é um caminho livre de ativações.

Com base na Definição 7, um par é dito de ativação/desativação de exceções (e-du) quando ${ }^{9}$ :

Definição 9 (Par de ativação/desativação de exceções (e-du)).

Entre a linha $i$, na qual uma exceção é ativada, e uma linha $j$, na qual é desativada, existe um caminho livre de ativação, então a linha $i$ e $j$ formam um par de ativação e desativação da exceção e. $O$ e-du é formalmente representado pela tripla,

$$
<i, e, j>
$$

Na qual, e representa a exceção ativada, $i$ representa a linha de ativação e $j$ a linha de desativação.

Definidos os elementos que constituem definição/uso e ativação/desativação de objetos e exceções é possível apontar quais são os critérios de teste de fluxo de dados especificamente relacionados a esses elementos. Um critério de teste de fluxo de dados é dito específico para a cobertura de definição/uso e ativação/desativação de objetos e exceções quando ${ }^{10}$ :

Definição 10 (Critérios de Cobertura de Objetos e Exceções).

1. all-du-pairs: todos os pares de definição e de uso, ver definição 3, são exercitados.

2. all-throw: todos os comandos throw são exercitados.

3. all-catch: todos os comandos catch são exercitados.

4. all-e-defs: todas as definições, associadas a pelo menos um uso, são exercitadas.

5. all-e-use: todas os pares de definição/uso (e-du) são exercitados.

6. all-e-act: todas exceções ativadas, ver definição 6, relacionadas a pelo menos uma desativação devem ser exercitadas.

\footnotetext{
${ }^{8}$ A desativação também pode ocorrer por meio de um comando finally, return, break, continue ou new throw.

${ }^{9}$ Definições retiradas dos trabalhos de Sinha e Harrold [SJ98, SH99].

${ }^{10}$ Estes critérios foram retirados dos trabalhos de Sinha e Harrold [SJ98, SH99].
} 
7. all-e-deact: todos os pares de ativação/desativação (e-du), ver definição 7 e 8, devem ser exercitados.

A satisfação dos critérios, Definição 9, exige a criação de casos de teste para cobrir, ou para exercitar, todos os objetos e exceções que formam pares p-du e e-du [VSF10]. A identificação desses objetos e exceções se dá com base na construção de um GFC. Na Seção 4.3, definimos as características de um GFC que permite identificar os elementos responsáveis pela ativação/desativação de exceções.

\subsection{Estudo do Modelo do Comportamento Excepcional em Pro- gramas Java}

Sinha e Harrold [SJ00] propõem um modelo para representação do comportamento excepcional de um programa Java baseado na construção de um grafo de fluxo de controle (GFC). Nele são apresentados os efeitos do tratamento de exceções como caminhos no grafo. Esses caminhos são compostos por todos os nós e arestas que se tornam viáveis no momento da ocorrência de uma exceção.

Para exemplificar o modelo a ser utilizado, usaremos o programa CheckValue2 ${ }^{11}$ (Listagem 4.1), um programa escrito em Java cujo objetivo é determinar se um valor atende um conjunto de especificações.

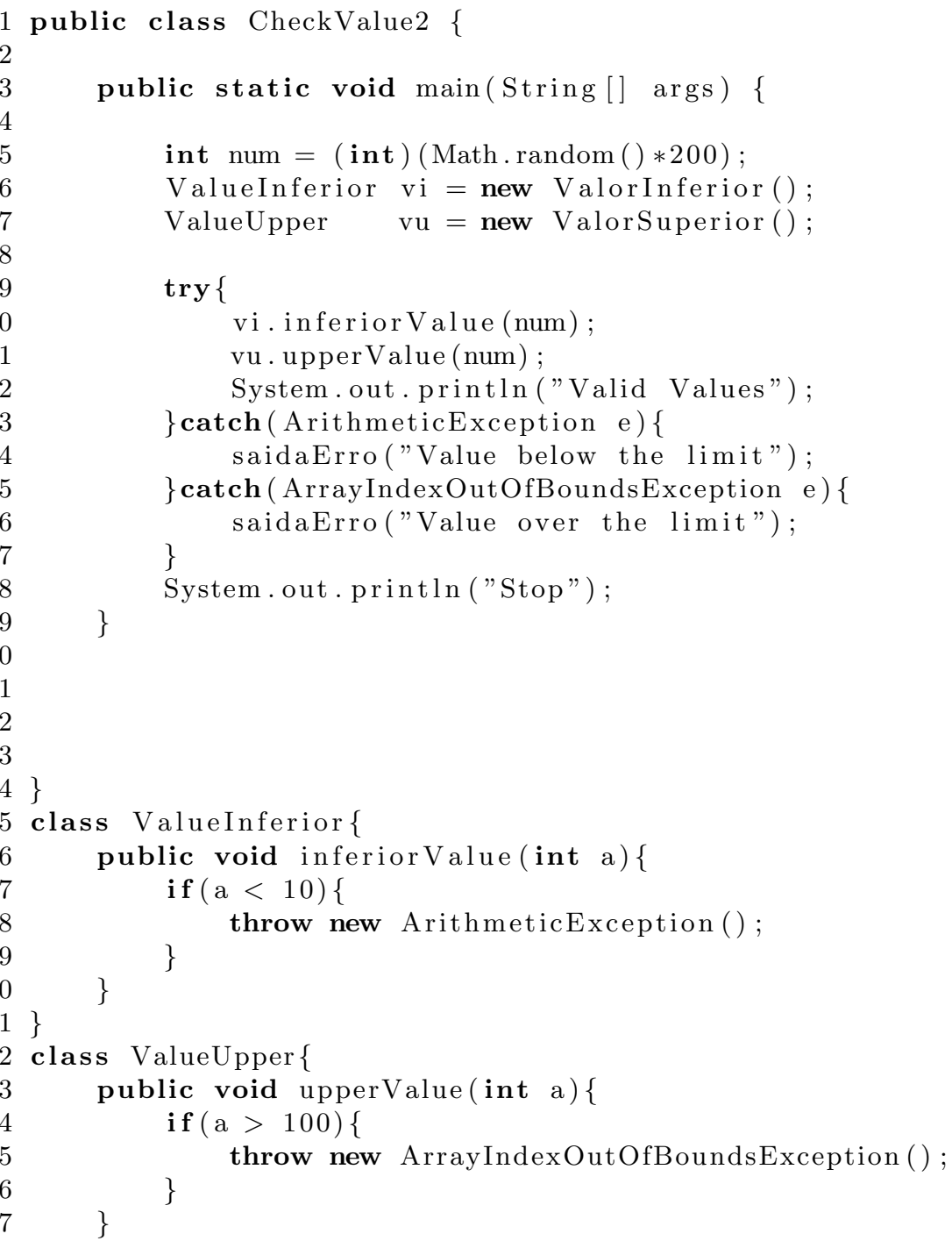

${ }^{11}$ Versão simplificada do programa CheckValue apresentado na Seção 3.3.7 
$38\}$

\section{Listagem 4.1: Exemplo de Modelagem de Exceções}

A variável num recebe um valor inteiro. Esse valor deve estar limitado à faixa entre $10<$ num $<$ 100. Se ocorrer uma violação do limite inferior, o método in feriorValue gera uma exceção do tipo ArithmeticException que ele não trata. Por outro lado, se ocorrer uma violação de limite superior, o método upperValue gera uma exceção do tipo ArrayIndexOutOf BoundsException a qual ele, também, não dá tratamento. Todas as exceções que forem geradas no programa são tratadas pela classe CheckValue2, e todas elas são explicitamente geradas. Isso implica que todo tratamento de exceção é interprocedural, ou seja, o método que gera a exceção não a trata, delegando essa tarefa a outro método. Esta situação é complexa pois, como será apresentado, o desvio de fluxo interprocedural de tratamento de exceções é um problema não trivial de modelagem.

A Figura 4.1 apresenta o GFC da Listagem 4.1. Neste GFC cada nó representa uma instrução que é identificada pelo número da linha no código fonte. As arestas representam o fluxo de controle que é transferido de uma instrução para outra. Os nós que possuem um rótulo \#a representam nós nos quais ocorre uma chamada para um dado método. Os nós que possuem rótulo \#b representam os nós de retorno da chamada anterior. Por exemplo, os nós $10 a$ e $10 b$ representam um desvio no fluxo devido a uma chamada de método e seu respectivo retorno.

O GFC não permite identificar o comportamento excepcional do programa, pois os nós representantes de instruções que geram as exceções são conectados diretamente às suas saídas de método. Este é o caso do nó 35 na classe ValueUpper e do nó 28 na classe ValueInferior. Os nós que representam os pontos de tratamento de exceção, os blocos catch, estão desconectados do GFC pois não podem ser acessados a menos que uma exceção seja lançada, o que implica que estes nós estão em um caminho excepcional do grafo.

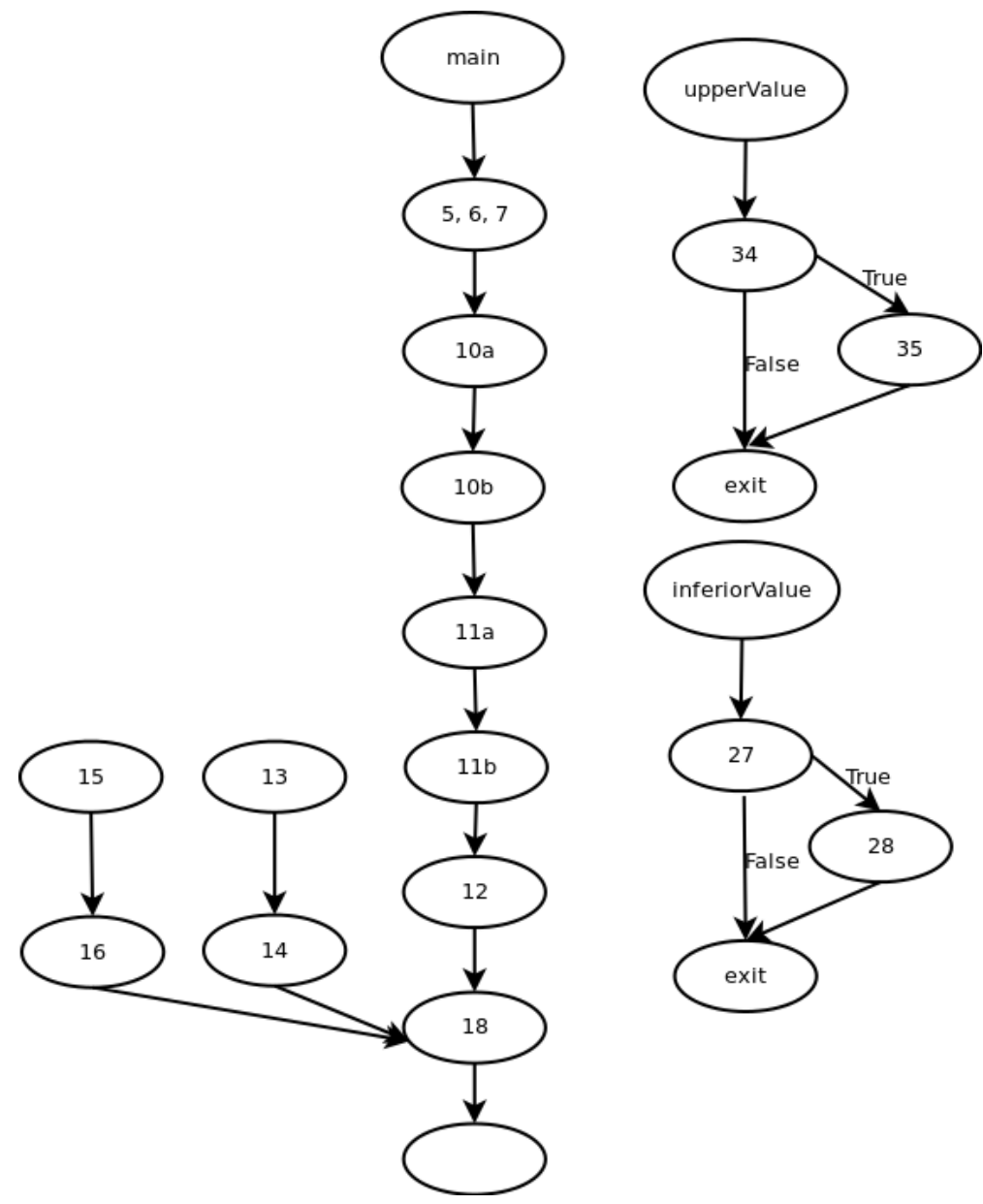

Figura 4.1: Fluxo de Controle da Listagem 4.1 
Sinha e Harrold [SJ00] propõem reconstruir o GFC da Figura 4.1 de modo a permitir a representação do comportamento excepcional de um programa. O processo de reconstrução do GFC é constituído por três etapas:

1. inferir o tipo de exceção, para determinar quais podem ser geradas por um dado nó, e criar uma aresta no nó de cada exceção;

2. atribuir um rótulo a cada aresta que identifique a qual exceção ela está relacionada;

3. ligar cada aresta de exceção a um nó de saída excepcional (exception-exit).

O resultado da reconstrução pode ser observado na Figura 4.2.

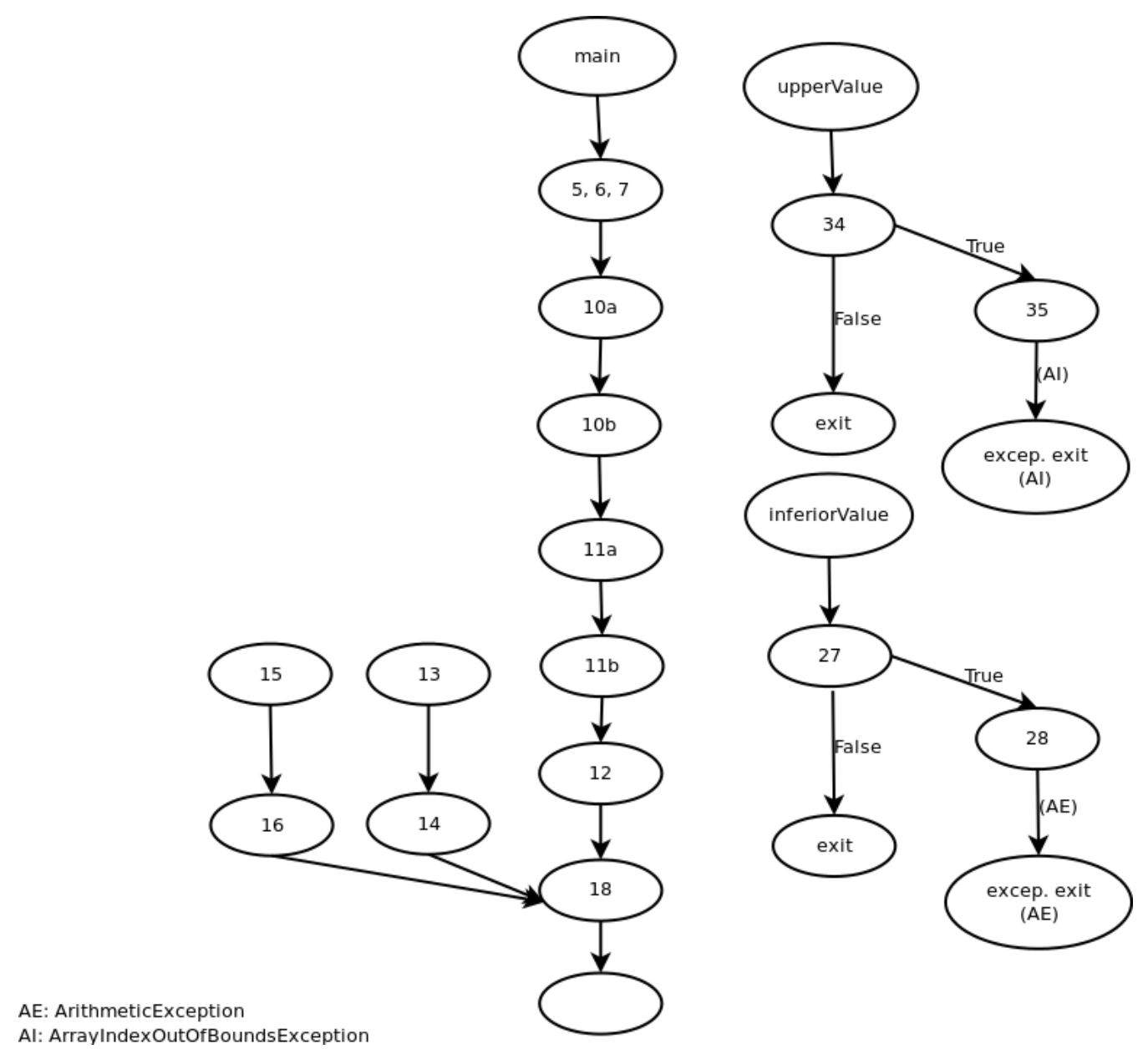

Figura 4.2: Fluxo de Controle da Listagem 4.1 Alterado 
Para que a representação do comportamento excepcional da Listagem 4.1 fique completa é necessário introduzir as arestas que representam os desvios de fluxo interprocedural normal e excepcional. A Figura 4.3 apresenta o resultado da introdução das arestas de fluxo interprocedural expresso por meio de um Grafo de Fluxo de Controle Interprocedural (GFCI). A inserção das arestas é feita com base no tipo de exceção que é disparada e em sua respectiva propagação através do GFC até encontrar um método que lhe forneça o tratamento adequado. Por exemplo, o método inferiorValue dispara uma exceção que é propagada até o método main, que a trata. A aresta que representa esse caminho é originada no nó de saída excepcional do método inferiorValue e se conecta ao nó que representa o bloco catch o qual fornece o tratamento, no caso, o nó 13, ver Figura 4.3 .

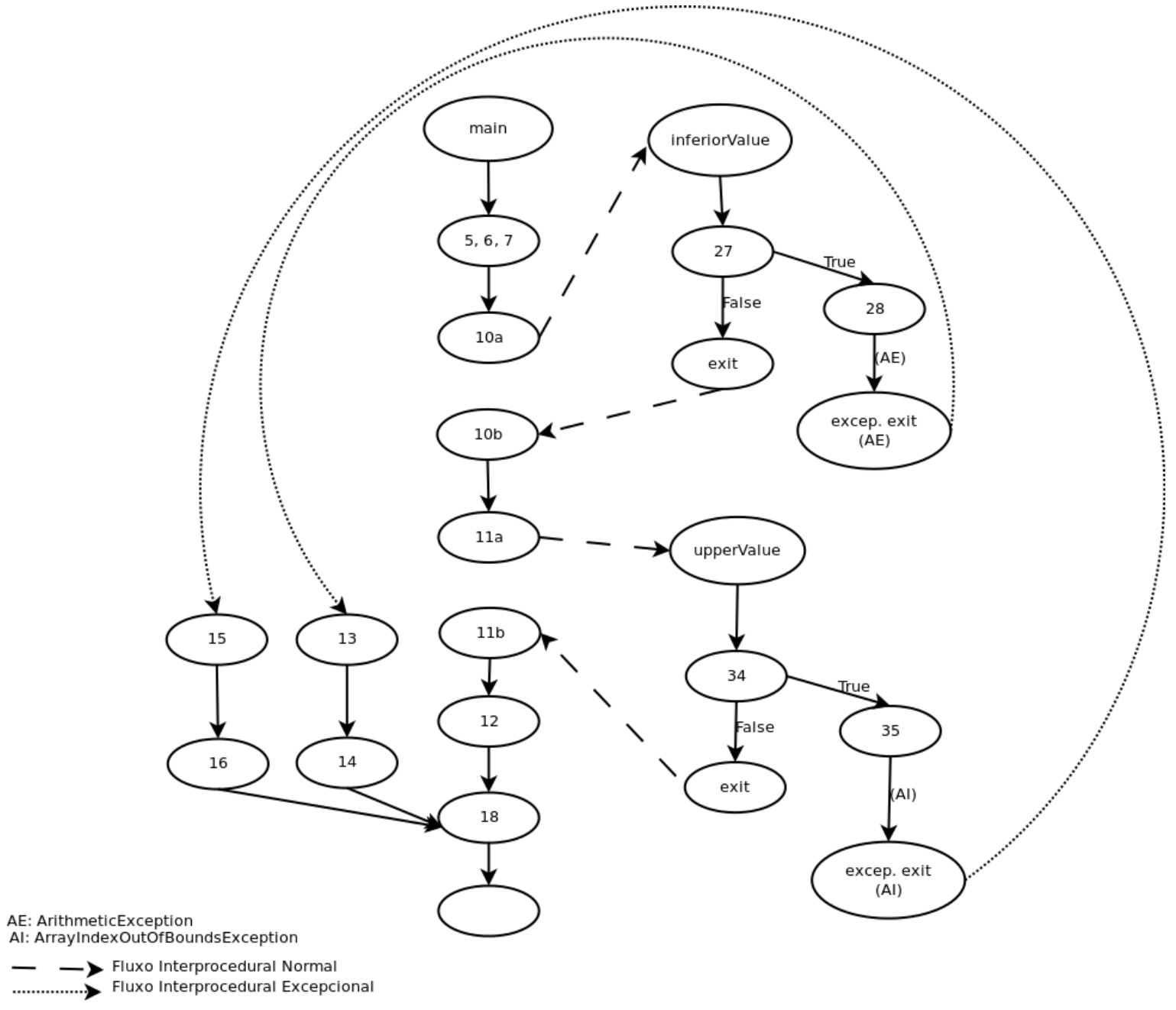

Figura 4.3: Fluxo de Controle Interprocedural da Listagem 4.1 
A inserção das arestas da Figura 4.3 é feita com base no algoritmo apresentado na Listagem 4.2 .

1 algorithm ConstructICFG

2 input CFG : control-flow graph for procedure $\mathrm{P}$

3 output ICFG : interprocedural control-flow graph for $\mathrm{P}$

4 declare worklist: methods that are processed iteratively

5

6 begin ConstructICFG

initialize worklist with methods in $\mathrm{P}$

while worklist is not empty

remove method $\mathrm{N}$ from worklist

foreach call in method $\mathrm{M}$ that calls $\mathrm{N}$

create call edge, return edge

foreach exceptional-exit node in the $\mathrm{CFG}$ of $\mathrm{N}$

add finally-call nodes, exceptional-exit node to

the CFG of $M$, if required

create exceptional-exit node added to the CFG of $M$

if exceptional-exit node added to the CFG of $M$

add $M$ to worklist

endif

endfor

endfor

endwhile

end ConstructICFG

Listagem 4.2: Algoritmo para construção de GFCI desenvolvido por Sinha e Harrold[SJ00]

O algoritmo inicializa uma lista de métodos (linha 4) contendo todos os métodos do software. Cada elemento da lista é removido até que a lista fique vazia (linhas 8 a 21). Para cada método $\mathrm{N}$ removido da lista determina-se quais métodos fazem uma chamada para N (linhas 10 a 20). Para cada método $\mathrm{M}$ que chama $\mathrm{N}$ é estabelecida uma aresta de chamada e uma aresta de retorno entre os métodos (linha 11). Se ocorrerem exceções em $\mathrm{N}$ que são indiretamente propagadas por $\mathrm{M}$, não há tratamento em M, então o algoritmo insere no GFC um nó de saída excepcional para o tipo de exceção gerada indiretamente por M (linha 13). Se um nó de saída excepcional for adicionado a M, então $\mathrm{M}$ é devolvido à lista para ser reprocessado(linhas 16 e 17).

\subsubsection{Considerações sobre o Modelo de Sinha e Harrold}

A modelagem proposta por Sinha e Harrold [SJ00], acima apresentada, é baseado em uma análise estática do código. Possui a propriedade de identificar os elementos do código responsáveis pela geração das exceções e por seu tratamento.

Além disso, o modelo está sustentado no conceito de que um GFC pode ser utilizado para representar o processo de execução de um software e bem como representar quais elementos estruturais deste software são exercitados. O modelo demonstra que um GFC pode ser estendido a fim de abarcar elementos do comportamento excepcional de um software.

Porém, o modelo proposto apenas trata de estruturas excepcionais vinculadas ao lançamento de exceções via instrução throw não abarcando outras estruturas extremamente comuns no tratamento de exceções tais como blocos try, catch e declaração throws. Isto ocorre pois toda exceção é gerada explicitamente por uma instrução throw. Para dar um exemplo, a Listagem 4.3 apresenta uma situação na qual uma exceção pode ser lançada pela operação de remoção de um elemento da pilha, objeto st, feita pela chamada do método pop. O código fonte do método pop da classe Stack possui uma instrução throw que lança explicitamente a exceção EmptyStackException. Logo, o Grafo baseado no modelo de Sinha e Harrold deve incluir a classe Stack e o método pop como elementos do fluxo de controle. Porém, isto implica considerar código pertencente a uma biblioteca que está fora do escopo da aplicação que está sendo desenvolvida, no caso a classe Main. Além disso, em termos práticos, é possível não se ter acesso a estas bibliotecas tanto em termos de código fonte (não disponível) como em termos de bytecode (obscurecido). 


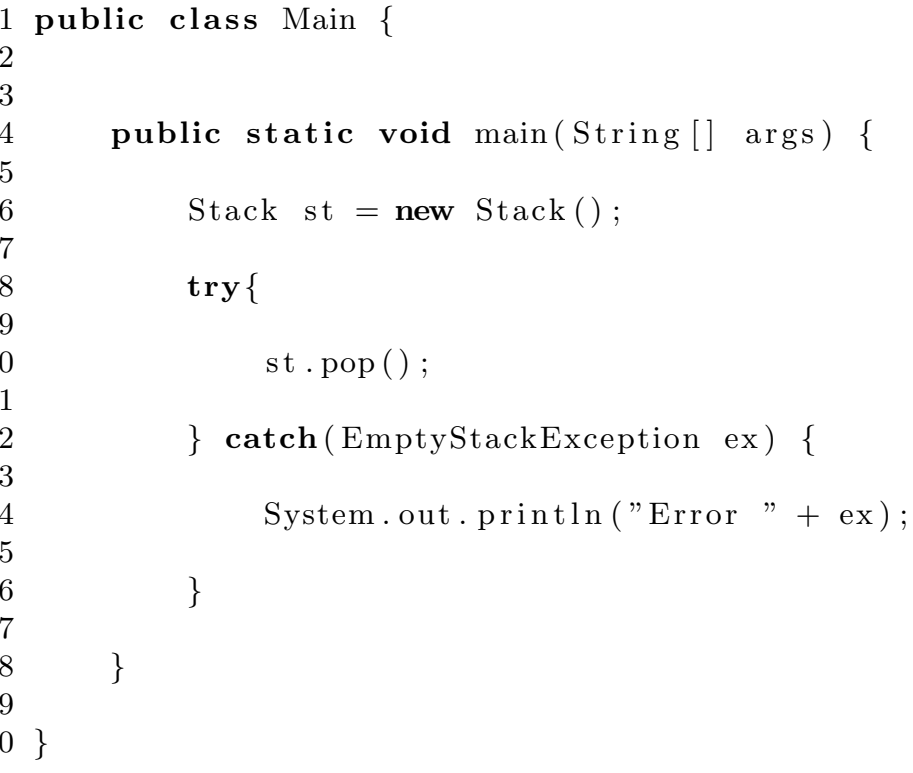

Listagem 4.3: Apenas Código Fonte Disponível

Com base nesses limites, propomos um modelo de comportamento excepcional baseado no conceito de pares de definição e uso (def/use) de objetos para identificar, com precisão, quais objetos são responsáveis pela ativação de exceções e quais os objetos, relacionados com os primeiros, são responsáveis por sua desativação. Com base nessas definições, propomos implementar um processo de inserção automática de código que permita o exercício desses pares e, dessa forma, manifestar o comportamento excepcional de um determinado SUT. Este modelo será baseado nas estruturas excepcionais encontradas no código fonte da aplicação que se deseja verificar, não levando em conta chamadas de biblioteca nas quais o código fonte não se encontra disponível e/ou não faz parte da aplicação.

\subsection{Novo Modelo de Comportamento Excepcional}

A ocorrência de uma exceção em uma aplicação Java ativa um conjunto de estruturas de tratamento de exceções [W.06]. Estas estruturas visam garantir que o lançamento de uma exceção não comprometa a funcionabilidade da aplicação [W.06, Orab, MJ03]. Para caracterizar as situações nas quais estas exceções ocorrem apresentamos uma classificação em termos de Estados. Um Estado é o conjunto de condições (objetos, instruções, variáveis, estrutura de tratamento de exceções, etc.) que leva ao lançamento ou tratamento de uma exceção. Posteriormente, usaremos esta classificação para definir os nós que compõem um grafo de ativação/desativação de exceções.

Os Estados associados ao lançamento/tratamento de exceções são:

- Exceção Programada $\left(E_{p r}\right)$ : um estado no qual existem um ou mais objetos definidos pelo desenvolvedor que lançam uma exceção via instrução throw, como apresentado na listagem 4.4. O bloco if representa o lançamento intencional de uma exceção dada a ocorrência de uma situação específica, no caso, o valor da variável $a$ ser maior que 5 . A linha 7 identifica um possível uso da instrução throw no qual o lançamento da exceção é explicitamente feito caso o fluxo de execução exercite esta linha.

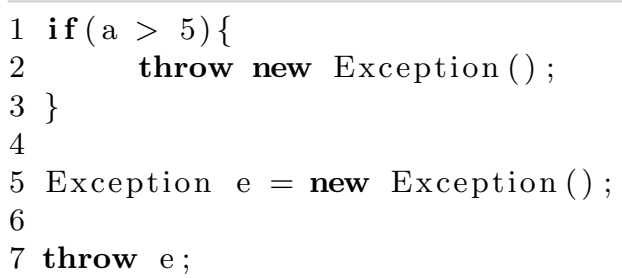


Listagem 4.4: Exceção Programada

- Exceção Monitorada $\left(E_{m}\right)$ : um estado no qual há probabilidade de ocorrer uma exceção. Exemplos de exceções lançadas neste estado são: arquivos não encontrados, acessos não autorizados, servidores não encontrados, problemas no fechamento de arquivos, remoção de dados em estruturas vazias etc.. As instruções vinculadas a esse estado são aquelas que se encontram delimitadas em blocos de tratamento de exceções. Em linguagens como Java e $\mathrm{C}++$ tais estruturas são representadas pelos blocos try. A inserção de uma instrução em um bloco try depende da escolha de projeto pertinente a cada linguagem. A linguagem Java exige que determinados tipos de instruções, que podem gerar exceções, sejam inseridas em um bloco try. Elas são definidas como exceções verificadas. As exceções não verificadas podem, ou não, ser escritas dentro de um bloco try, ficando a cargo do desenvolvedor a escolha do tipo de implementação a ser feita. Por outro lado, a linguagem $\mathrm{C}++$ não impõe nenhuma forma obrigatória de monitoramento de exceções ficando a cargo do desenvolvedor decidir se utiliza, ou não, blocos try na codificação.

- Exceções Anunciadas $\left(E_{a}\right)$ : Uma exceção anunciada representa uma condição na qual uma instrução lança uma exceção e impõe a todos que a usam o fornecimento de tratamento. A instrução throws da linguagem Java representa esse estado. Um método que implementa a instrução throws exige que todos os elementos do código que o instanciam forneçam tratamento ou repassem a informação de que uma exceção pode ser lançada.

- Tratamento $(H)$ : um estado no qual uma exceção lançada é tratada. Estruturas relacionadas a estes estados são blocos catch e finally. Vale notar, que nem toda linguagem implementa estruturas específicas de tratamento. A linguagem Smalltalk é um exemplo de linguagem que fornece tratamento de exceções sem, contudo, possuir algum tipo de estrutura de captura específica.

- $\operatorname{Normal}(N)$ : um estado que não lança nem trata exceções.

- $\perp$ : estado indefinido. Um estado que é acessado após a ativação de uma exceção mas que não corresponde a um tratamento para a exceção lançada. Dessa forma, a exceção lançada possui um local desconhecido do tratamento correspondente.

Os estados, acima definidos, podem ser relacionados aos critérios de teste definidos na Seção 4.1.1 a fim de permitir especificar quais objetos, que se encontrem nesses estados, configuram ativações/desativações de exceções.

Com base na Definição 7 e nos estados excepcionais definidos na Seção 4.3, propomos uma nova definição de ativação e de desativação de exceções que estende a definição proposta por Sinha e Harrold [SH99] e, dessa forma, pretendemos abarcar todas as possíveis situações nas quais uma exceção pode ocorrer em código escrito em linguagem Java.

Logo, dizemos que uma Exceção é Ativada quando:

Definição 11 (Ativação de Exceções).

Ocorrerem Estados de Exceções Programadas, Anunciadas ou Monitoradas.

Dessa forma, toda possível situação na qual a ativação de exceções, síncrona ou assíncrona (ver Definição 7), bem como as estruturas sintáticas pertinentes a estas situações (instrução throw, throws e bloco try, possam ocorrer é delimitada e determinada.

Por sua vez, dizemos que ocorre uma Desativação de Exceções quando:

Definição 12 (Desativação de Exceções).

Ocorrer um Estados de Tratamento. 
Conforme a Definição 7 subitem 2.a, a desativação de uma exceção se dá, sintaticamente, por meio da instrução catch a qual, conforme definida nesta Seção, também permite identificar um estado de Tratamento de exceções $(H)$.

Com base nas Definições 11 e 12 dizemos que Pares de Ativação/Desativação de Exceções são definidos quando:

Definição 13 (Pares de Ativação/Desativação de Exceções).

Uma exceção é ativada em um Estado de Exceção Programado, Anunciada ou Monitorada e é desativada em um estado de Tratamento de Exceção. Nesse caso temos um par de ativação e desativação definido pela tripla:

$$
<E, x, H>
$$

Na qual,

- E é o estado de ativação,

- $x$ a excȩão ativada, $e$

- H o estado de tratamento.

Sendo que, se

1. E for um Estado de Exceção Programada então temos que $\left.\left\langle E_{p}, x, H\right\rangle=<l_{p}, x, l_{h}\right\rangle$, sendo $l_{p}$ a linha na qual se encontra a instrução de ativação (throw) e $l_{h}$ a linha na qual se encontra a instrução de desativação.

2. E for um Estado de Exceção Anunciada então temos que $\left\langle E_{a}, x, H>=<\left(l_{i}, l_{f}\right), x, l_{h}>\right.$, sendo sendo $l_{i}$ a primeira linha de definição do escopo do método que declara throws, $l_{f}$ a última linha do escopo do método que declara throws e $l_{h}$ a linha na qual se encontra a instrução de desativação (catch).

3. E for um Estado de Exceção Monitorada então temos que $\left\langle E_{m}, x, H>=<\left(l_{i}, l_{f}\right), x, l_{h}>\right.$, sendo $l_{i}$ a primeira linha de definição do bloco de monitorização (bloco try), $l_{f}$ a última linha do escopo do bloco de monitorização e $l_{h}$ a linha na qual se encontra a instrução de desativação (catch).

Por fim, com base nas Definições 11 e 12, podemos estabelecer dois novos critérios de teste de fluxo de dados específicos aos elementos apontados acima os quais são somados ao critério all-throw apresentado na Definição 10 item 2.

Para tanto, ampliando a Definição 10, temos dois novos critérios de cobertura de pares de ativação e desativação de exceções que definimos como:

Definição 14 (Critério de Cobertura de Exceções).

1. all-throws: todas as declarações throws são exercitadas.

2. all-try: todos os blocos try são exercitados.

A Tabela 4.1 sintetiza as relações estabelecidas entre os elementos de ativação e desativação de exceções. 
Tabela 4.1: Relação Estados e Critério de Ativação/Desativação de Exceções

\begin{tabular}{cccc}
\hline Estado & Par de Ativação/Desativação & Instrução & Definição ${ }^{12}$ \\
\hline \hline$E_{p}$ & $<l_{p}, x, l_{c}>$ & throw & 13.1 \\
$E_{a}$ & $<\left(l_{i}, l_{f}\right), x, l_{h}>$ & throws & 13.2 \\
$E_{m}$ & $<\left(l_{i}, l_{f}\right), x, l_{h}>$ & try & 13.3 \\
$H$ & $<l_{a}, x, l_{h}>,<\left(l_{i}, l_{f}\right), x, l_{h}>$ & catch & - \\
$N$ & - & - & - \\
$\perp$ & - & - & - \\
\hline
\end{tabular}

\subsubsection{Identificação de ativação e desativação}

A Tabela 4.1 identifica quais estados estão relacionados com os Estados de ativação/desativação de exceções definidos nesta Seção. Por meio desta relação, é possível apontar qual objeto no estado é responsável pela ativação/desativação de uma exceção.

A Tabela 4.1 identifica que só existem três situações nas quais é possível identificar pares de ativação/desativação de exceções. Há três estados distintos que lançam exceções mas apenas um estado que fornece tratamento. Por fim, há apenas uma situação na qual é possível determinar com precisão qual objeto lança a exceção $\left(E_{p}\right)$ e duas situações $\left(E_{a}, E_{m}\right)$ nas quais $x$ se encontra no escopo do método (declaração throws) ou no escopo do bloco (bloco try) nos quais uma exceção pode ser lançada.

A Tabela 4.1 pode ser usada para identificar quais pares devem ser exercitados a fim de que o comportamento excepcional de um SUT seja manifestado. Neste processo, os pares são identificados por meio de uma modelagem baseada nos conceitos e nas definições apresentados neste capítulo que produz o GFC. Cada nó do grafo representa um conjunto de instruções vinculadas a uma definição ou ao uso de um objeto ou a uma exceção. De maneira similar, é possível utilizar os pares identificados no grafo para inserir instrumentação a fim de exercitar os caminhos excepcionais de um SUT. Para tanto, apresentamos as modelagens das Listagens 4.5, 4.6 e $4.7 \mathrm{com}$ a respectiva identificação dos pares de ativação e desativação apresentados na Tabela 4.1.

\section{Modelagem par $<E_{p r}, x, H>$}

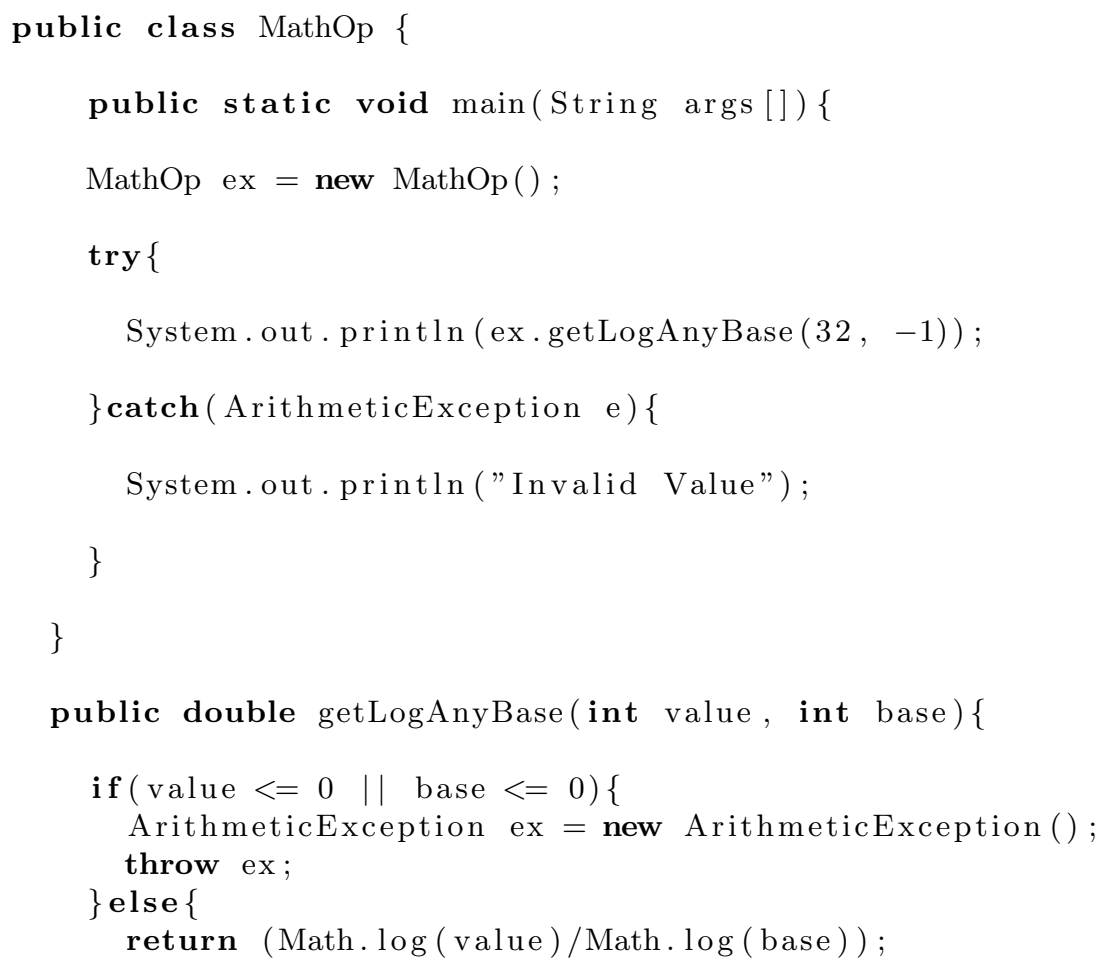




$\left.\left.\begin{array}{l}26 \\ 27 \\ 28 \\ 29 \\ 30\end{array}\right\} \quad \begin{array}{l} \\ \{\end{array}\right\}$

Listagem 4.5: Identificação do par $\left\langle E_{p r}, x, H>\right.$

Dada a Listagem 4.5, temos, com base nos elementos identificados na Tabela 4.1,

- $E_{p}$ é representado no código pela linha 22 da Listagen 4.5 , na qual uma exceção foi programada para ser lançada caso algum parâmetro assuma valor menor ou igual a zero.

- O objeto $x$ assume o valor do objeto ex que, por sua vez, pertence à classe ArithmeticException. Esse objeto, ao ser executado, é responsável pela ativação da exceção programada. Vale colocar que como apresentado na Seção 4.3 a instrução throw configura o lançamento intencional da exceção que é feito na linha 23.

- $H$ é representada pela linha 11 na qual a exceção será desativada.

Logo, temos que para listagem 4.5 o par de ativação/desativação é apresentado abaixo:

$$
<E_{p r}, x, H>=<23, e x, 11>^{13}
$$

2. Modelagem par $<E_{a}, x, H>$

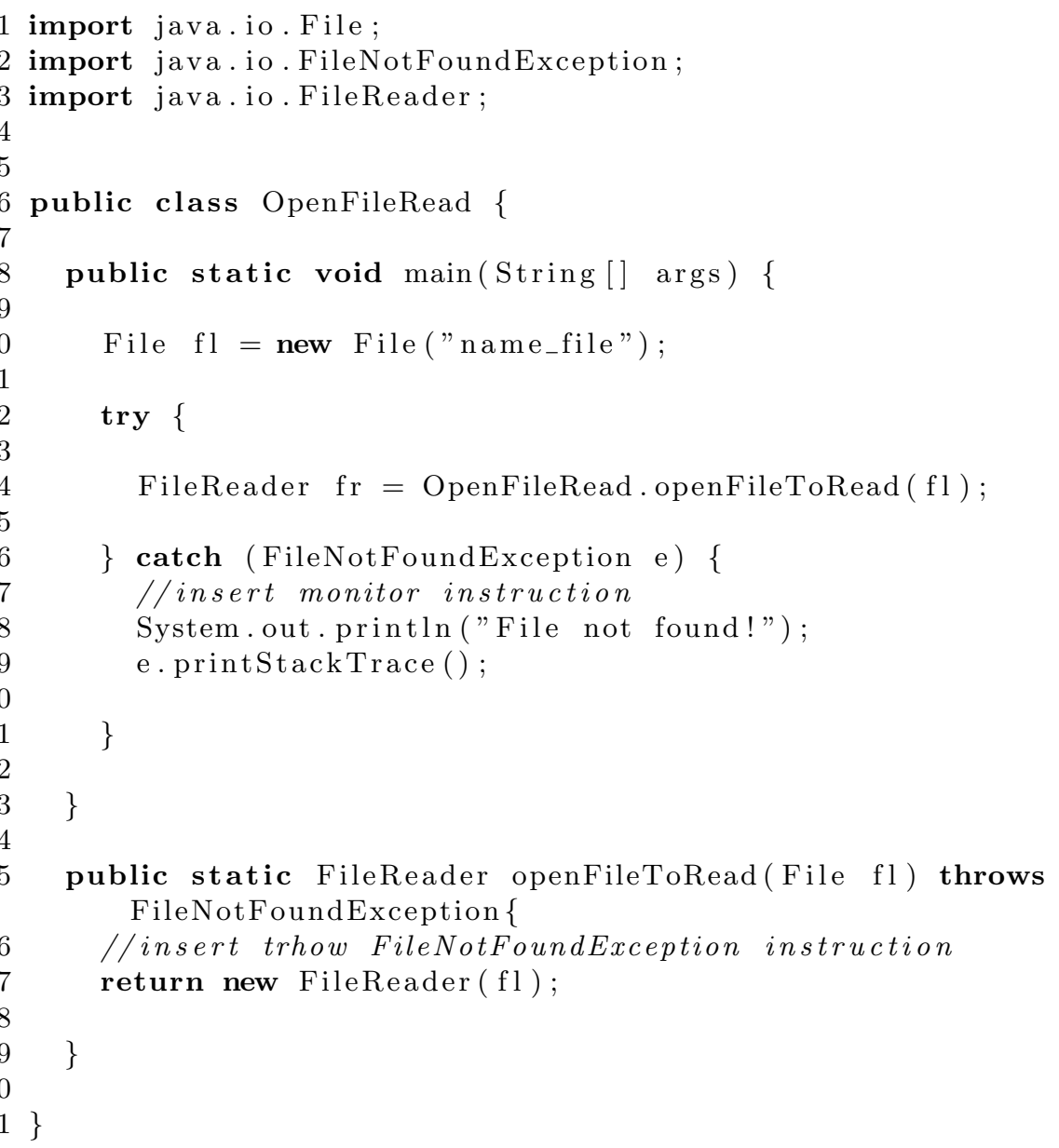

Listagem 4.6: Identificação do par $\left\langle E_{a}, x, H>\right.$

\footnotetext{
${ }^{13} 23$ e 11 representam os números das linhas nas quais a exceção é ativada e desativada respectivamente.
} 
Dada a Listagem 4.6, temos, com base nos elementos identificados na Tabela 4.1, que:

- $E_{a}$ é representado no código pelas linhas 25 a 29, Listagen 4.6, na qual uma exceção foi anunciada para ser lançada caso algum parâmetro assuma valor menor ou igual a zero.

- O objeto $x$ é do tipo FileNotFoundException e é declarado no corpo do método, ver definição 7. O lançamento desta exceção está vinculado à execução do método openFileToRead. Vale colocar que, como apresentado na Seção 4.3, a instrução throws anuncia que uma exceção pode ser lançada pelo método openFileToRead mas esse método delega a quem realizou a chamada a obrigação de fornecer o tratamento a exceção.

- $H$ é representada pela linha 16 na qual a exceção será desativada.

Logo, temos que para listagem 4.6 o par de ativação/desativação é apresentado abaixo:

$$
<E_{p r}, x, H>=<25, \text { FileNotFoundException e, } 16>^{14}
$$

3. Modelagem par $<E_{m}, x, H>$

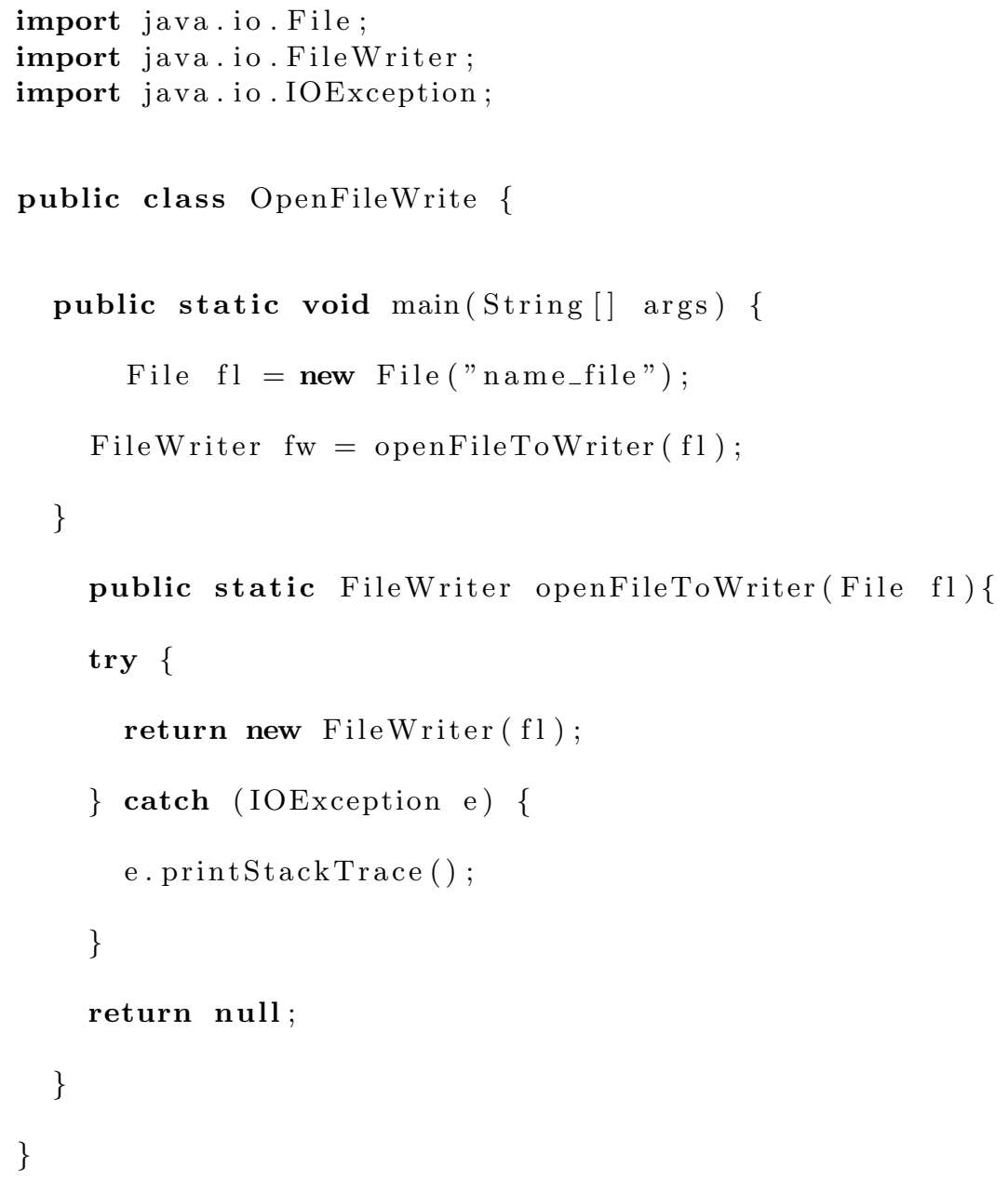

Listagem 4.7: Identificação do par $\left\langle E_{m}, x, H>\right.$

Dada a Listagem 4.7 , temos, com base nos elementos identificados na Tabela 4.1,

- $E_{m}$ é representado no código pelas linhas 19 a 23, Listagen 4.7. Nesta situação, temos um estado de monitoramento, ver Seção 4.3, no qual uma exceção assíncrona, não programada pelo desenvolvedor, pode ser lançada.

\footnotetext{
${ }^{14} 25$ e 16 representam os números das linhas nos quais a exceção é ativada e desativada respectivamente.
} 
- Uma exceção do tipo IOException pode ser lançada por algum elemento contido no bloco try, ver Definição 7, desta forma assumimos que $x$ é um objeto do tipo IOException.

- $H$ é representada pela linha 23 na qual a exceção será desativada.

Logo, temos que para listagem 4.7 o par de ativação/desativação é apresentado abaixo:

$$
<E_{m}, x, H>=<19, \text { IOException ex }, 23>^{15}
$$

\subsubsection{Grafo de Ativação/Desativação}

A identificação dos pares de ativação/desativação de uma exceção pode ser feita por meio da criação de um grafo no qual o controle de fluxo do SUT é representado por nós (cada nó representa uma instrução ou conjunto de instruções) e arestas (cada aresta representa a transição entre instruções ou bloco de instruções durante a execução do programa). Nesta Seção, introduzimos um grafo de fluxo de controle específico para a identificação de pares de ativação/desativação de exceções, ver Definição 10, o qual denominamos eXceptions Activation Deactivation ControlFlow Graphs (XADCFG).

Desta forma, um grafo de fluxo de controle é dito um XADCFG quando ${ }^{16}$ :

Definição 15 (Representação grafos de fluxo de programa).

Seja $P$ um programa escrito em linguagem orientada ao objeto, $C$ o conjunto de classes de $P, M$ o conjunto de métodos pertencente à classe em $C$, ex uma exceção $P$ e

- $N$ é o conjunto de nós que representam instruções que ativam ou desativam uma exceção ex em um programa $P$. Dado $n \in N$ então $n$ identifica uma linha do código fonte (número da linha) que corresponde a uma ativação ou desativação de ex, ver Definição $\%$.

- CE é o conjunto de arestas de controle que representam o fluxo de controle de uma exceção ex definida em um método $m$. Dado $n_{i}$ e $n_{j} \in N$, temos que ce $=\left(n_{i}, n_{j}\right) \in C E$ conecta um nó $n_{i}$ a um nó $n_{j}$ e ce representa um caminho de exceção do método $m \in M$.

Considerando a representação de elementos dos grafos apresentados na Definição 15, dizemos que um eXceptions Activation Deactivation Control-Flow Graphs (XADCFG) para uma dada exceção ex é

\section{Definição 16 (eXceptions Activation Deactivation Control-Flow Graphs).}

Um grafo orientado e conectado [Cor02] definido como $G=(S N, E)$, no qual $S N$ representa o conjunto de supernós e $E$ o conjunto arestas de passagem de mensagem (p-m) para uma exceção ex em $P$, de modo que:

- Um supernó $s n_{i}=\left(N_{i}, C E_{i}\right) \in S N$ representa o fluxo de controle de uma exceção ex pertencente ao método $m$ de um programa $P$ o qual possui a ativação ou desativação de ex $\left(N_{i} \subseteq N\right.$ e $\left.C E_{i} \subseteq C E\right)$.

- Uma aresta de passagem de mensagem $m_{e}=\left(n_{k}, n_{t}\right) \in E$ conecta o nó $n_{k}$ para um nó $n_{t}$ pertencente a um supernó $s n_{j}$ de modo que $n_{k}$ possui uma chamada de método (passagem de mensagem (pm))

Como um XADCFG representa o tempo de vida de uma exceção temos que este grafo pode percorrer várias classes de $P$. O XADCFG pode abranger supernós (métodos) de diferentes classes. Isto implica que os supernós representam o controle de fluxo interno do próprio método (intramétodo) enquanto o grafo XADCFG pode abranger o controle de fluxo entre métodos (intermétodo)

\footnotetext{
${ }^{15} 19$ e 23 representam os números das linhas nos quais a exceção e ativada e desativada respectivamente.

${ }^{16}$ Esta definição tem por base os trabalhos de Sinha e Harrold [SJ98, SH99]. Porém, se diferencia daqueles por focar apenas os elementos específicos à ativação e desativação de exceções e por tratar de estruturas como blocos try e declarações throws, o que os trabalhos acima citados não abarcam.
} 
de uma mesma classe ou de classes diferentes. Na Seção 4.5 apresentaremos algoritmos que permitem a construção de um XADCFG e, com base neste grafo, a identificação dos pares de ativação e desativação. No programa, o grafo é armazenado na forma de uma lista de pares sendo que cada par possui a informação sobre o método e estrutura que ativa a exceção (throw, throws ou try) e o método e estrutura que desativa a exceção (catch).

\subsubsection{Representação Gráfica}

Para a representação gráfica do XADCFG, definimos os seguintes nós e $\operatorname{arestas~}^{17}$ :

Nós

- Nó simples: um retângulo que contem uma linha de código e um número que representa o número da linha na qual a instrução se encontra no código fonte.

- Supernó: um retângulo contendo nós simples identificados pelo nome do método que representam.

Arestas

- Setas cheias: ligam dois nós que estão dentro do mesmo supernó.

- Setas vazadas: ligam dois nós de diferentes supernós.

- Setas pontilhada: ligam dois nós. O primeiro nó, origem, possui a instrução de ativação da exceção $e x$ o segundo contem a instrução de desativação de $e x$.

\subsection{Exemplos de Construção do XADCFG}

\subsubsection{Exemplo 1 - Exceção ocorre dentro de um Bloco try}

Fornecemos ao Algoritimo 1 a Listagem $4.8 \mathrm{e}$

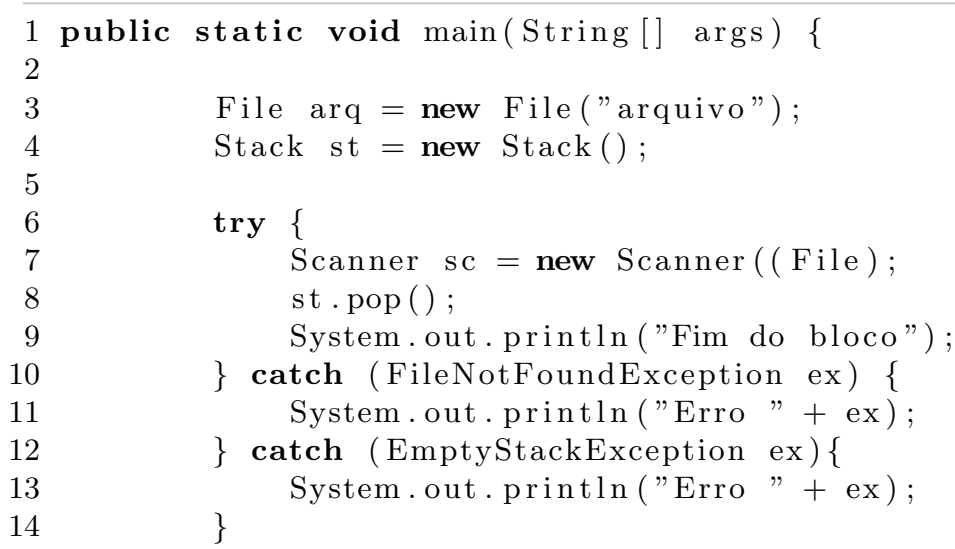

\section{Listagem 4.8: Exemplo 1}

obtemos como saída o Grafo representado pela Figura 4.4.

\footnotetext{
${ }^{17}$ A representação do grafo foram feitas manualmente. Uma implementação será feita na ferramenta Ocongra [VSF10] utilizando o framework JGraph.
} 


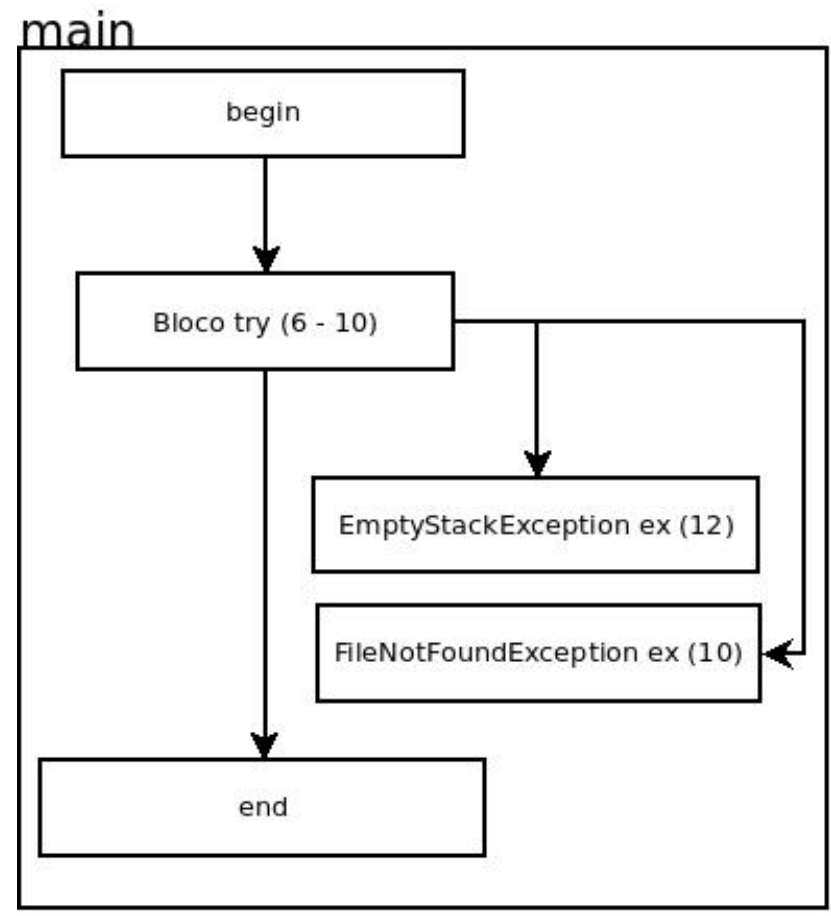

Figura 4.4: Exemplo 1

O XADCFG é posteriormente fornecido como entrada do Algoritmo 2 e retorna o Grafo representado pela Figura 4.5 no qual as arestas pontilhadas indicam uma relação de ativação/desativação entre dois nós de XADCFG

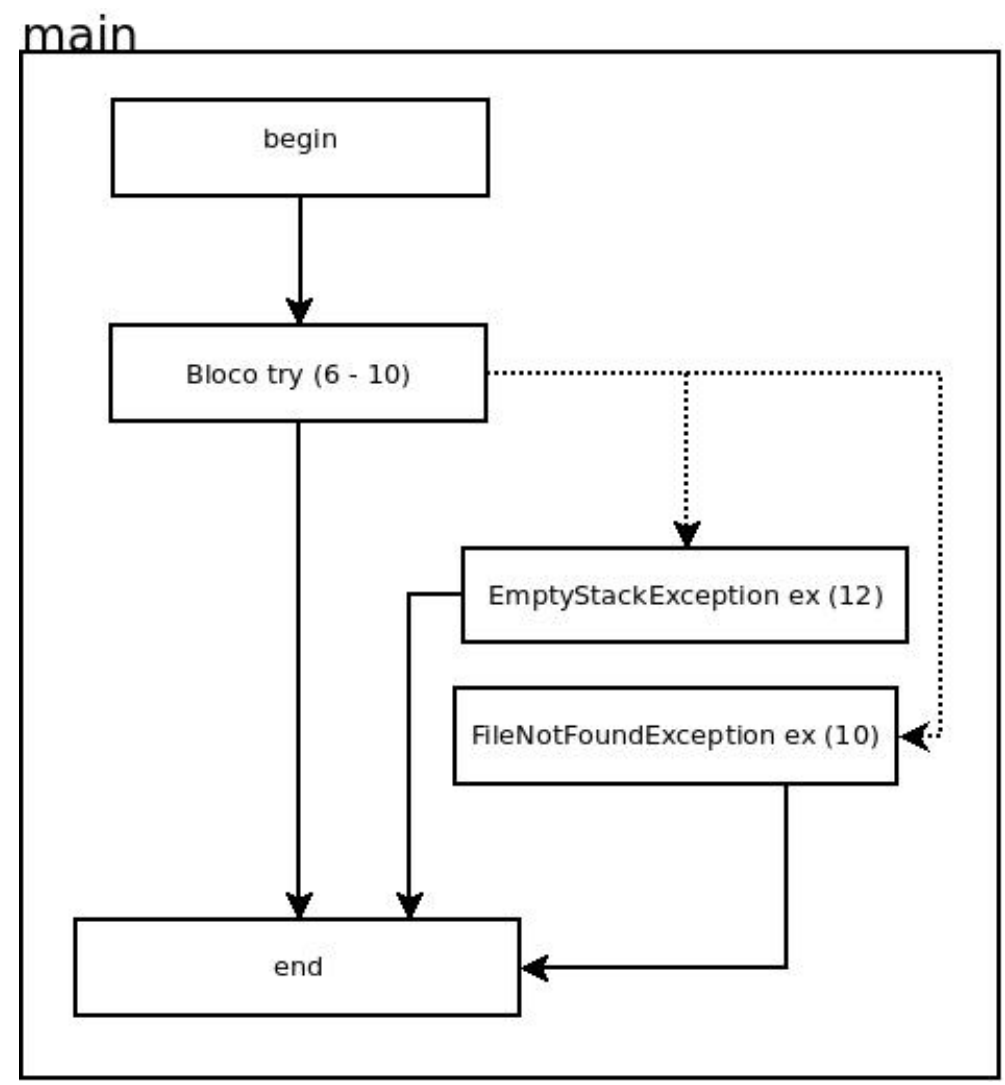

Figura 4.5: Exemplo 1 
Com base na Figura 4.5 identificamos dois pares de ativação/desativação que são:

- $k_{1}=<E_{m}, e x, E_{h_{1}}>=<(6,10), e x_{1}, 10>\mathrm{e}$

- $k_{2}=<E_{m}, e x, E_{h_{2}}>=<(6,10), e x_{2}, 12>$

Logo, para Listagem 4.8 há dois pares de ativação e desativação de exceções. Vale ressaltar, que o tipo de exceção assumido por $e x_{1}$ e $e x_{2}$ não pode ser identificado diretamente pelo código fonte contido no bloco try. Logo, assumimos que o par é formado pelo bloco try, que possui uma instrução de ativação de exceções não identificada, e um respectivo bloco catch que fornece um tratamento, ver definição 7 .

Por fim, há apenas um único supernó, main, pois o programa possui apenas um método que contem todas as instruções pertinentes a ativação/desativação de exceções.

\subsubsection{Exemplo 2 - Exceção ocorre dentro de um método que declara throws}

Fornecemos ao Algoritimo 1 a Listagem 4.9 e

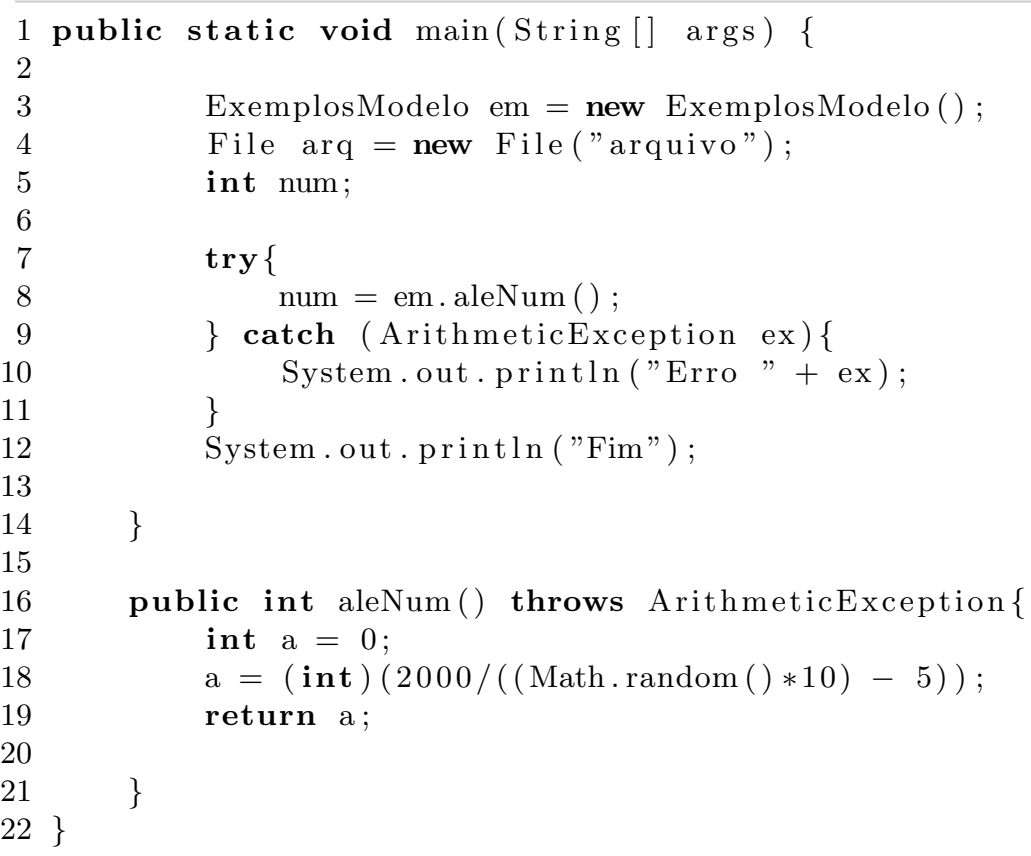

Listagem 4.9: Exemplo 2

obtemos como saída o Grafo representado pela Figura 4.6.

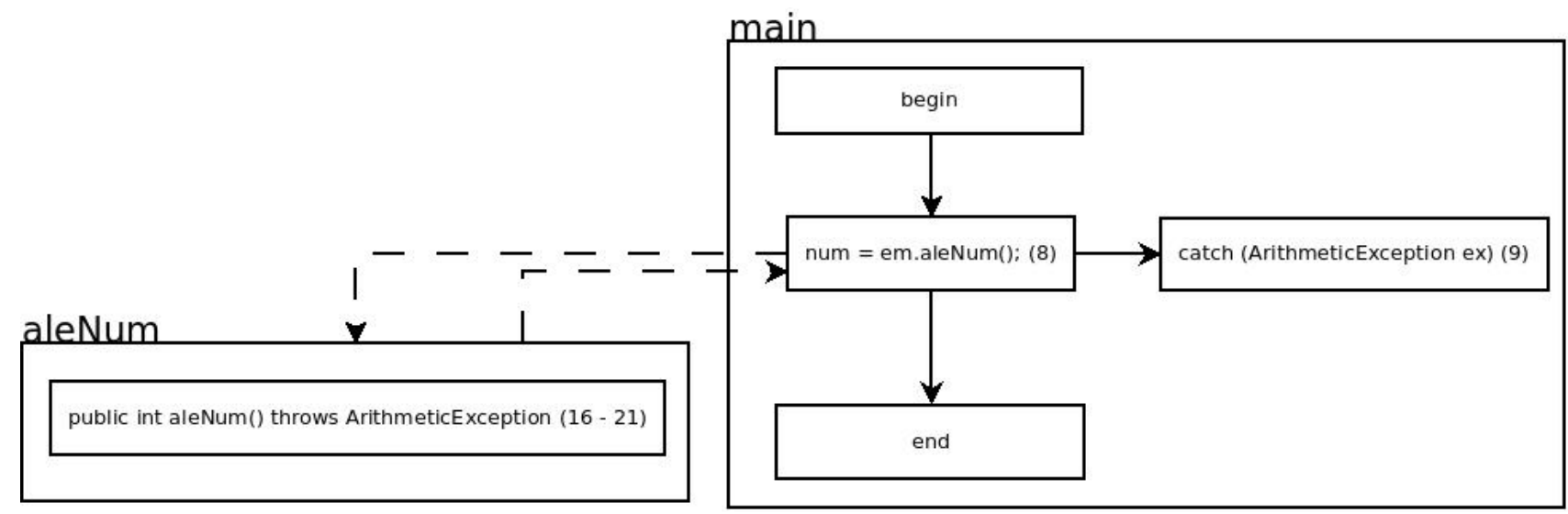

Figura 4.6: Exemplo 2 - Fluxo de Controle Normal 
O XADCFG é posteriormente fornecido como entrada do Algoritmo 2 e retorna o Grafo representado pela Figura 4.7 na qual as arestas pontilhadas indicam uma relação de ativação/desativação entre dois nós de XADCFG

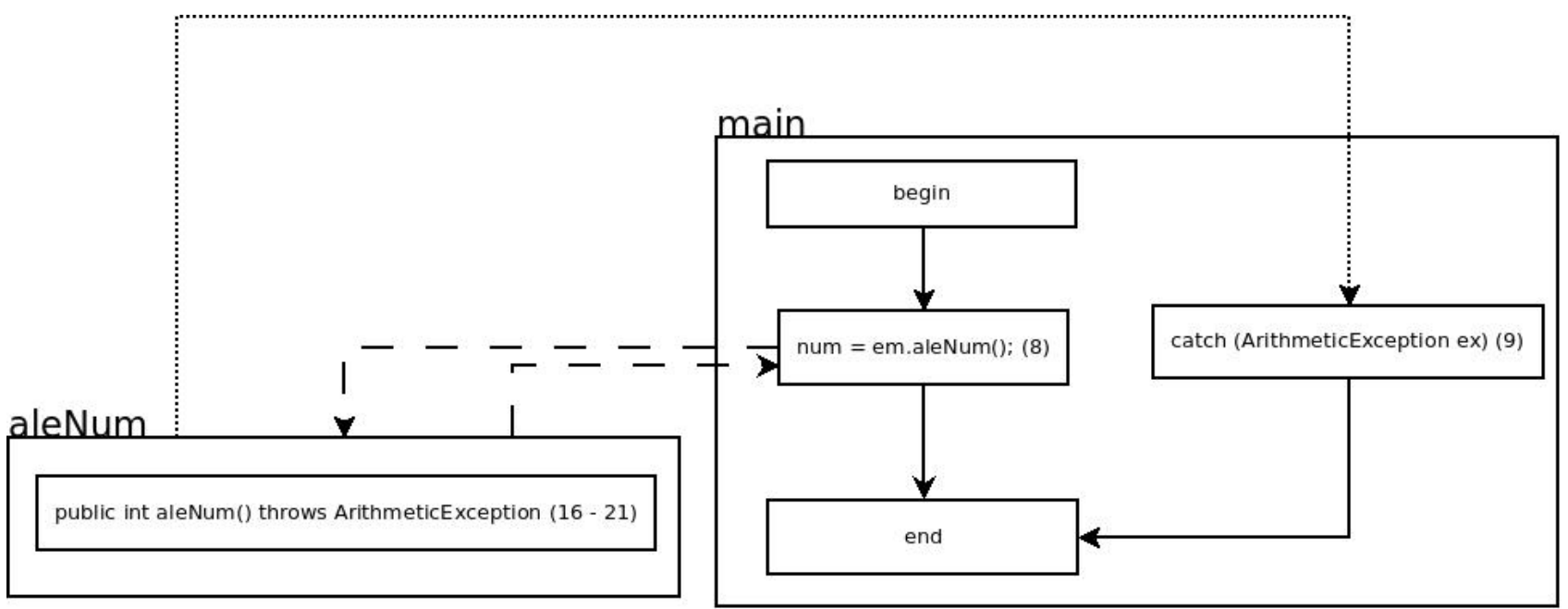

Figura 4.7: Exemplo 2 - Pares de Ativação/Desativação Estabelecidos

Com base na Figura 4.5 identificamos um par de ativação/desativação:

- $k_{1}=<E_{a}, e x, E_{h}>=<(16,21), e x, 9>$

Logo, para Listagem 4.9 há um par de ativação e desativação de exceções. O tipo de exceção assumido por $e x_{1}$ não pode ser identificado diretamente pelo código fonte contido no método aleNum. Esta informação é obtida da declaração throws no corpo do próprio método. Logo, assumimos que o par é formado pelo bloco corpo do método aleNUM e por um respectivo bloco catch que fornece um tratamento, ver Definição 7 e Tabela 5.1.

\subsubsection{Exemplo 3 - Exceção Programada}

Fornecemos ao Algoritimo 1 a Listagem 4.10 e

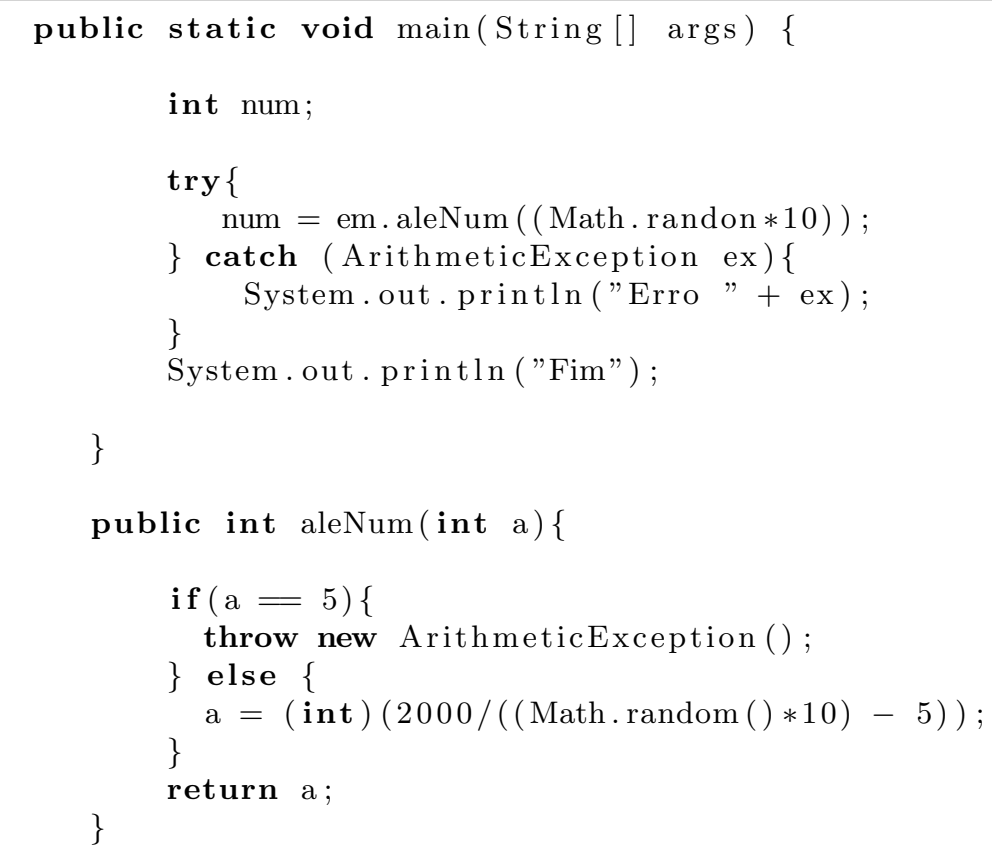

Listagem 4.10: Exemplo 2 reescrito 


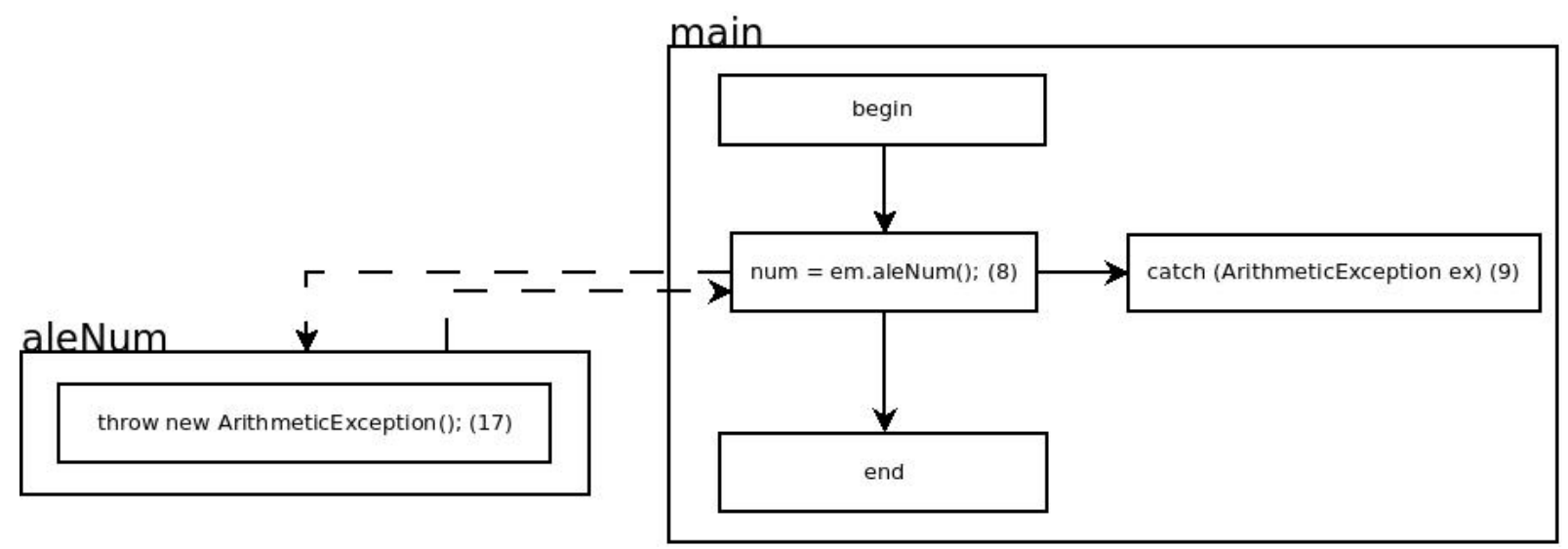

Figura 4.8: Exemplo 3

obtemos como saída o Grafo representado pela Figura 4.8.

O XADCFG é posteriormente fornecido como entrada do Algoritmo 4.10 e retorna o Grafo representado pela Figura 4.9 no qual as arestas pontilhadas indicam uma relação de ativação/desativação entre dois nós de XADCFG

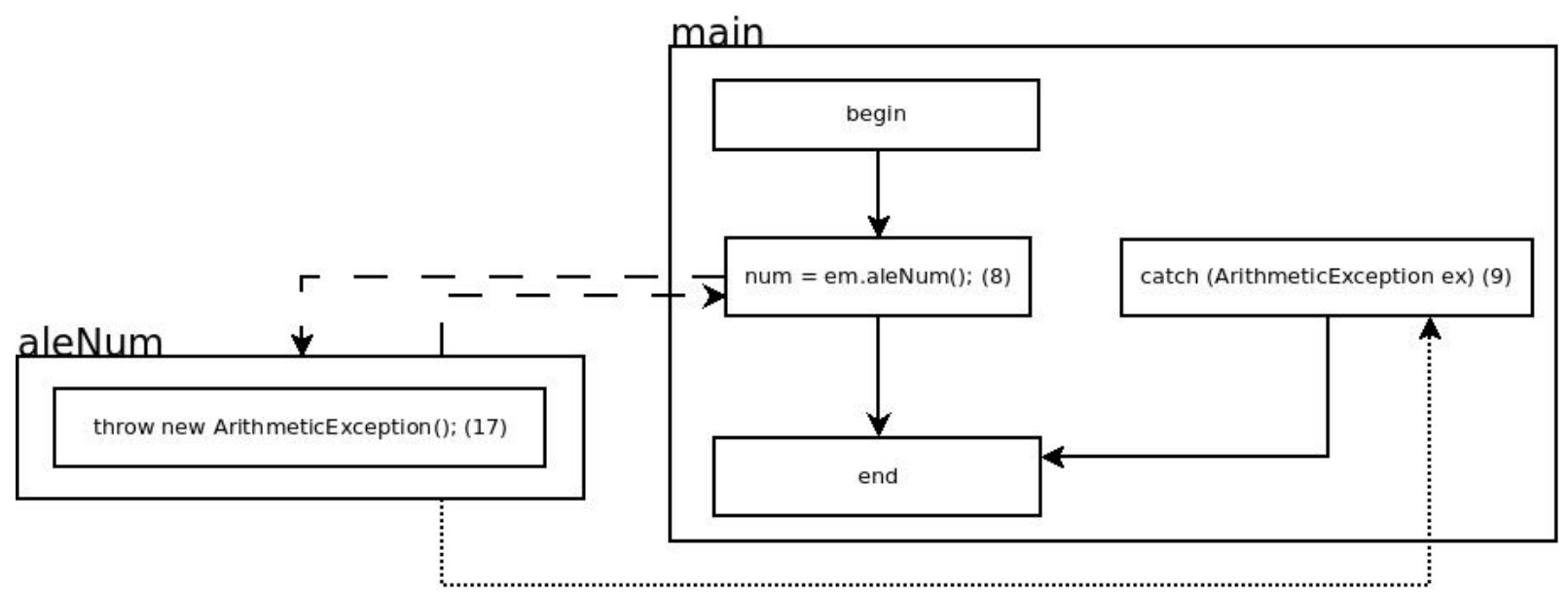

Figura 4.9: Exemplo 3

Com base na Figura 4.5 identificamos um par de ativação/desativação:

- $k_{1}=<E_{p r}, e x_{1}, E_{h}>=k_{1}=<17, e x, 9>$

Na Listagem 4.9 há um par de ativação e desativação de exceções. Vale colocar, que o tipo de exceção assumido por $e x$ pode ser identificado diretamente pelo código fonte contido no método aleNum. Esta informação é obtida da instrução throw no corpo do próprio método que explicitamente ativa $e x$.

\subsection{Algoritmos para de Construção do XADCFG e Identificação de Pares de Ativação e Desativação de Exceções}

A construção de um XADCFG de ativação/desativação de uma dada exceção ex (Definição 10) em uma classe $C_{i}$ é iniciada com a construção de supernós para cada método $m$ que possui uma instância de ex. O Algoritmo 1 descreve os principais passos na construção de um XADCFG para cada método enquanto o Algoritmo 2 descreve os pares de ativação/desativação. 


\subsubsection{Construção do Grafo}

No Algoritmo 1, o função buildSuperNode constrói o supernó vinculado a um dado método $m$ e posteriormente expande o grafo para criar novos supernós com a correspondente aresta de passagem de mensagem (p-m) se uma chamada de método for encontrada no fluxo de execução da exceção $e x$.

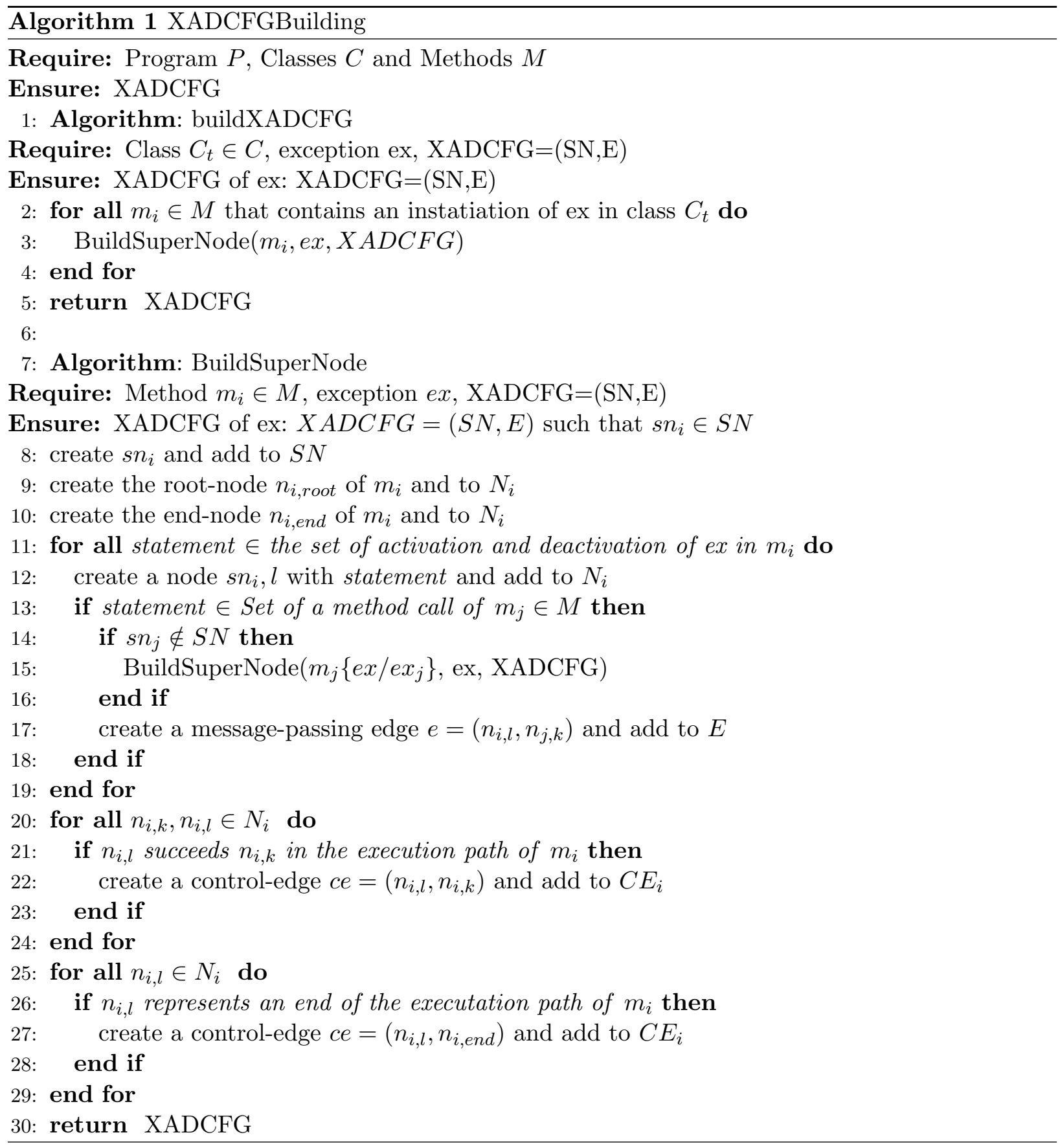

\subsubsection{Definição dos Pares}

O Algoritmo 2 identifica todos os pares de ativação/desativação, all-e-deact, para uma dada exceção ex. Ele recebe como entrada o grafo XADCFG e retorna o conjunto de pares de ativaçãodesativação para uma exceção.

O Algoritmo 2 percorre o Grafo identificando instruções nas quais uma dada exceção ex é ativada, ver Definição 7. Identificada a instrução de ativação no XADCFG, o Algortimo 2 inicia 


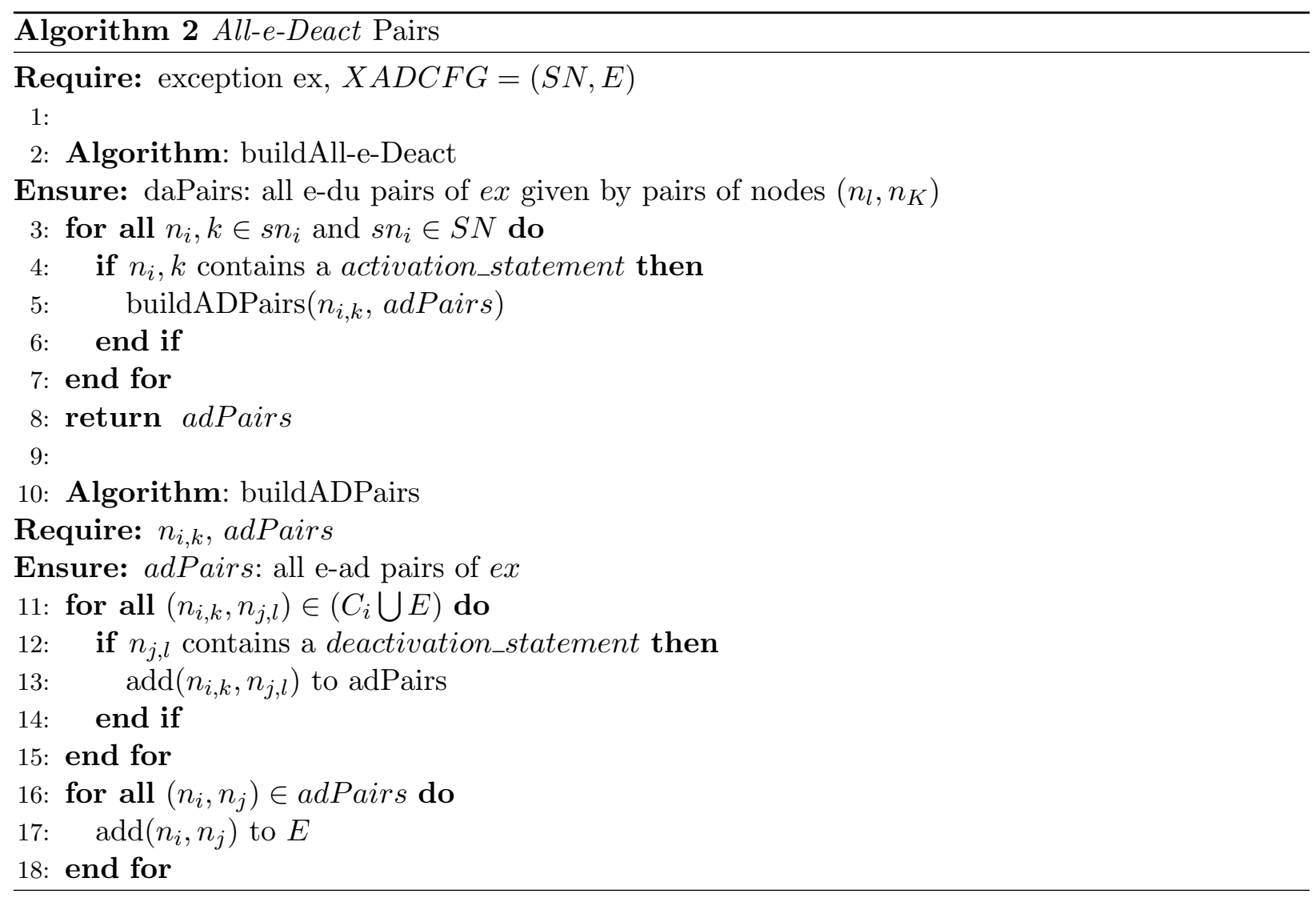

uma busca por uma instrução de desativação. Vale ressaltar que, ao contrário dos demais critérios de teste, para cada exceção $e x$ ativada, bem como para cada ativação de $e x$, existe apenas uma única instrução de desativação. Isto ocorre pois os mecanismos de lançamento de exceções da linguagem Java não permitem que uma mesma exceção seja relançada. Além disso, a instrução de desativação, se existir, também será única e necessariamente se encontra no fluxo de controle da exceção lançada em bloco catch, ver Capítulo 3.

Por fim, para cada par de nós que representam uma ativação/desativação de uma exceção ex é inserida uma aresta ligando estes dois nós em XADCFG.

Na Seção 4.6, são apresentados exemplos de construção do XADCFG e de identificação de pares de ativação e desativação para uma da exceção ex baseados nos Algoritmos 1 e 2.

\subsection{Conclusão}

As estruturas de tratamento de exceções introduzem ao código uma complexidade particular pois desviam o fluxo de controle do software para os conjuntos de instruções que são apropriadas ao tratamento da exceção lançada.

Os conceitos vinculados a cada uma destas estruturas permitem construir um modelo de comportamento excepcional o qual representa, de forma precisa, o comportamento excepcional de um dado SUT.

Uma vez identificado o comportamento excepcional é possível utilizar um conjunto de técnicas (construção de Grafo de Fluxo de Controle de objeto/exceções e pares de ativação e desativação de exceções) para localizar, no código fonte, quais instruções efetivamente são responsáveis pela ativação e desativação de exceções. Essas estruturas, por sua vez, são classificadas em termos de pares de ativação e desativação de exceções.

No próximo Capítulo, apresentaremos um conjunto de regras de inserção de código, instrumentação de código fonte, que utilizará as informações oriundas do modelo de comportamento excepcional para orientar um processo de verificação de comportamento excepcional de um dado 
SUT. 


\section{Capítulo 5}

\section{Instrumentação para o Exercício do Comportamento Excepcional}

A instrumentação de código permite monitorar o comportamento de um dado SUT e/ou introduzir instruções que causam a ocorrência de um dado efeito que se deseja observar. Esse é o caso do execício do comportamento excepcional, o qual pode ser observado por meio da introdução de código apropriado que, em tempo de execução, resulta no lançamento de exceções.

Desta forma, o proposito da manifestação do comportamento excepcional, via instrumentação, consiste em:

- verificar se o comportamento excepcional atende as especificação do programa;

- identificar estruturas excepcionais que estão presentes no código a ser verificado;

- identificar a relação entre estruturas de ativação e desativação de exceções (quais estruturas ativam uma dada exceção e quais desativam);

- identificar mau uso de estruturas de tratamento de exceção tais quais:

- blocos catch que não possuem nenhuma instrução;

- blocos catch que declaram tratamento para exceções genéricas;

- entre outros.

- permitir que ferramentas de teste e verificação formal tenham acesso as estruturas de tratamento excepcional.

Para tanto, é necessário definir em que locais do código fonte deve-se inserir a(s) instrução(ões), qual instrução(ões) deve ser inserida e qual é a provável estrutura de tratamento da exceção lançada. A Definição destas questões configura o processo de instrumentação sendo que o processo de Definição dos pontos de instrumentação para lançamento de exceções e a determinação dos prováveis locais de tratamento são equivalentes ao processo de determinar quais são os pares de ativação/desativação de exceções, como apresentado no Capítulo 4.

Nesse Capítulo, estipularemos Regras de instrumentação, baseadas nos critérios de ativação/desativação, para definir e implementar um processo de exercício do comportamento excepcional de um SUT e apresentaremos uma ferramenta para instrumentação do código.

\subsection{Objetivo das Regras de Instrumentação para Verificação de Comportamento Excepcional}

As Regras de Instrumentação para Verificação de Comportamento excepcional visam orientar o processo de inserção de código que, em tempo de execução, força um determinado SUT a exercitar seu comportamento excepcional, ver Capítulo 3. Para tanto, é necessário especificar 
- Em qual local do código fonte deve-se inserir o código de instrumentação,

- Qual instrução deve ser inserida e

- Qual o provável ponto de tratamento para a exceção lançada.

Com base no que foi definido na Seção 4.3, é possível utilizar os conceitos de ativação/desativação de exceções para postular Regras de instrumentação que respondam às questões acima listadas. Essas Regras, por sua vez, representam um padrão que tem por objetivo final orientar o processo de verificação do comportamento excepcional de um dado SUT. Para tanto, nas próximas seções definiremos as Regras de instrumentação que serão aplicáveis aos estados nos quais ocorrem ativação e desativação de exceções, ver Seção 4.3 e Tabela 5.1. Estas Regras são:

- Regra Geral (1)

- Regra da Exceção Programada $\left(E_{p r}\right)(2)$

- Regra da Exceção Anunciada $\left(E_{a}\right)(3)$

- Regra da Exceção Monitorada $\left(E_{m}\right)(4)$

Regra 1 (Regra Geral). Todos os elementos do código que formam pares que satisfazem o critério all-e-deact ${ }^{1}$ devem ser exercitados.

Deriva da Regra 1, as três outras Regras que abarcam cada estado excepcional identificado na Seção 4.3, são elas:

Regra 2 (Regra da Exceção Programada $\left(E_{p r}\right)$ ). Todo par $k=<E_{p r}, x, E_{h}>$, ver Tabela 5.1, representado no XADGFC pelos nós $n_{i}$ e $n_{j}$ tal que $k=<n_{i}, x, n_{j}>$ e $x$ é uma exceção ativada no nó $i$ e desativada no nó $j$, deve ser instrumentado de modo que:

- Para todo $x$ em $n_{i}$ inserimos a instrução s tal que s lança uma exceção do tipo $x$.

- Sintaticamente, a instrução s é inserida na primeira linha do escopo do método representado pelo nó $n_{i}$,

- A instrução de monitoramento deve ser inserida na primeira linha do bloco de tratamento, $E_{h}$.

Como apresentado na Tabela 5.1, $x$ é variável do tipo $e^{v a r} r_{a c t i v}$ ou $e_{v a r}$ sintaticamente vinculada à instrução throw. Desta forma, o nó $i$, que contem $x$, possui toda a informação necessária para a instrumentação do código em termos de ativação. O comportamento esperado para o par $k$ consiste em que uma exceção ativada em $E_{p r}$ deve ser tratada em $E_{h}$.

Regra 3 (Regra da Exceção Anunciada $\left(E_{a}\right)$ ). Todo par $k=<E_{a}, x, E_{h}>$, representado no $X A D G F C$ pelos nós $n_{i}$ e $n_{j}$ tal que $k=<n_{i}, x, n_{j}>$ e x é uma exceção ativada no nó $i$, exceção no escopo do método que declara throws, e $x$ é desativada no nó $j$, deve ser instrumentado de modo que:

- Para todo $x$ em $n_{i}$ inserimos a instrução s tal que s lança uma exceção do tipo $x$,

- Sintaticamente, a instrução s é inserida na primeira linha do escopo do método representado pelo nó $n_{i}$ (método que anuncia o lançamento da exceção) e

\footnotetext{
${ }^{1}$ ver Definiçãoo 14.
} 
Tabela 5.1: Pares de Ativação/Desativação e função dos Estados e Nós

\begin{tabular}{cccc}
\hline Par por Estado & Par por Nó & Variável & Instrução \\
\hline \hline$<E_{p r}, x, H>$ & $\left\langle n_{p r}, x, n_{h}\right\rangle$ & $x$ do tipo $e_{\text {var }}$ ou evar activ $_{\text {a }}$ & throw \\
$<E_{a}, x, H>$ & $\left\langle n_{a}, x, n_{h}\right\rangle$ & $x$ do tipo evar & throws \\
$<E_{m}, x, H>$ & $\left\langle n_{m}, x, n_{h}\right\rangle$ & $x$ do tipo evar & try \\
$H$ & - & - & - \\
$N$ & - & - & - \\
$\perp$ & - & - & - \\
\hline
\end{tabular}

- A instrução de monitoramento deve ser inserida na primeira linha do bloco de tratamento, $E_{h}$.

Como apresentado na Tabela 5.1, $x$ é variável do tipo $e_{p}$. Logo, a informação contida no nó $i$ diz respeito apenas ao escopo do método, à linha de início e de fim e ao tipo de exceção que pode ser lançada, declaração throws. Desta forma, consideramos que $x$ é uma abstração para todas as instruções no escopo e definimos $x$ como responsável pela ativação da exceção anunciada.

Regra 4 (Regra da Exceção Monitorada $\left(E_{m}\right)$ ). Todo par $k=<E_{a}, x, E_{h}>$, representado no $X A D G F C$ pelos nós $n_{i}$ e $n_{j}$ tal que $k=<n_{i}, x, n_{j}>$ e $x$ é uma exceção ativada no nó $i$, exceção no escopo de um bloco try, e $x$ é desativada no nó $j$, deve ser instrumentado de modo que:

- Para todo $x$ em $n_{i}$ inserimos a instrução s tal que s lança uma exceção do tipo $x$,

- Sintaticamente, a instrução s é inserida na primeira linha do escopo do bloco try representado pelo nó $n_{i}$ e

- A instrução de monitoramento deve ser inserida na primeira linha do bloco de tratamento, $E_{h}$.

Como apresentado na Tabela 5.1, $x$ é variável do tipo $e_{p}$. Logo, a informação contida no nó $i$ diz respeito apenas ao escopo do bloco, linha de início e fim, e não possui nenhuma informação sobre o tipo de exceção a ser lançada. Esta informação pode ser obtida no nó $j$ dado que há uma relação sintática entre o bloco try, em $E_{m}$, e os respectivos blocos catch em $E_{h}$. Vale colocar, assumimos que $x$, contido em $i$, é uma abstração para todas as instruções definidas no bloco try.

\subsubsection{Exemplo de Aplicação ds Regras de Instrumentação}

Para exemplificar a aplicação das regras de instrumentação, utilizamos os exemplos apresentados no Capítulo 4 inserindo nos corretos pontos de instrumentação linhas de comentários que identificam:

- Linha de ativação;

- Exceção a ser lançada; e

- Linha de desativação.

1. Instrumentação para Modelagem $<E_{p}, x, H>$ Listagem 4.5

Dada a Listagem 4.5, temos, com base nos elementos identificados na Tabela 4.1, que ocorre um Estado de Exceção Programada o que implica que a Regra 2 deve ser observada resultando na listagem 5.1. 


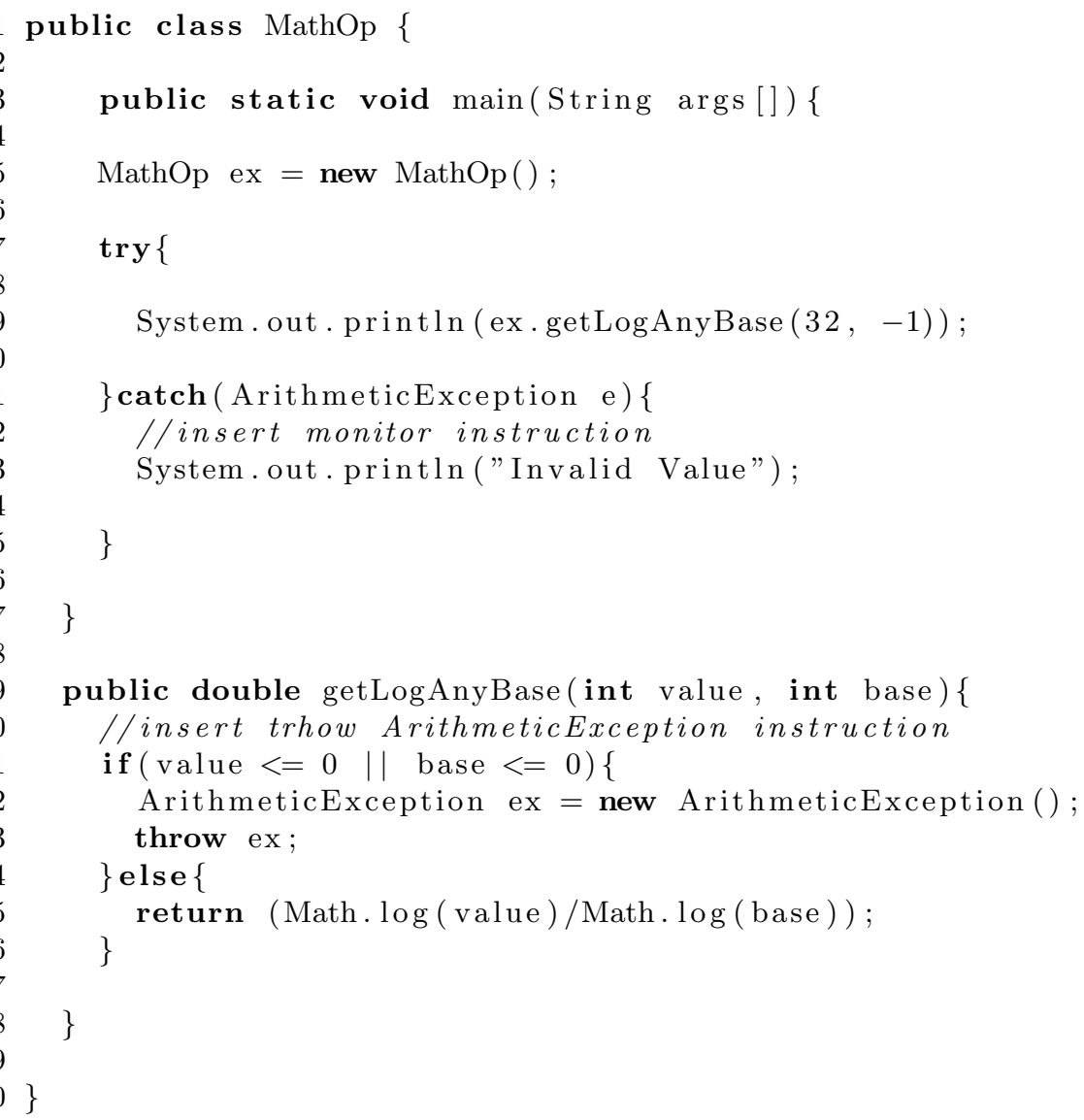

Listagem 5.1: Identificação do par $\left\langle E_{p}, x, H>\right.$

2. Instrumentação para Modelagem $<E_{a}, x, H>$ Listagem 4.6

Dada a Listagem 4.6, temos, com base nos elementos identificados na Tabela 4.1, que ocorre um Estado de Exceção Anunciada o que implica que a Regra 3 deve ser observada resultando na listagem 5.2.

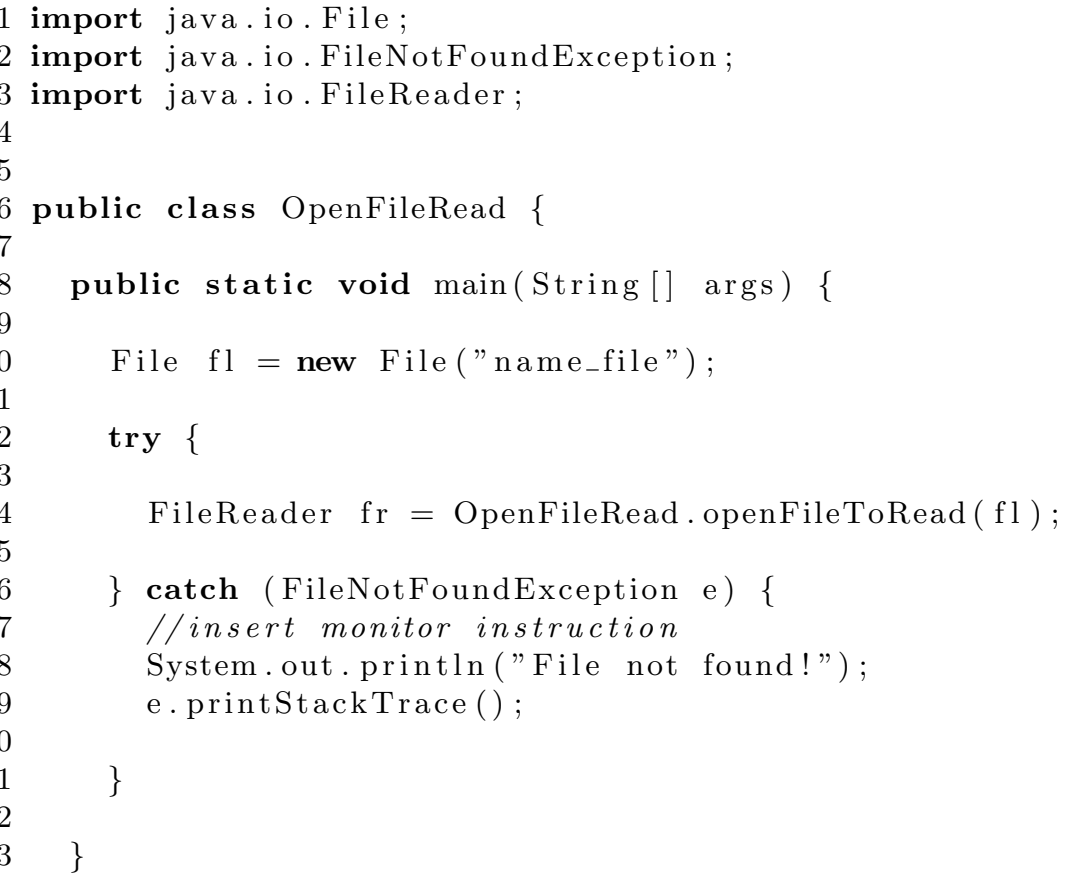




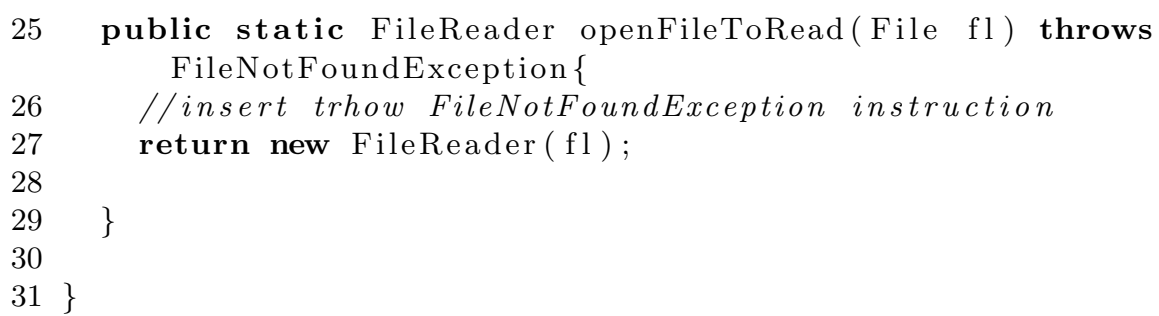

Listagem 5.2: Identificação do par $<E_{a}, x, H>$

\section{Instrumentação para Modelagem par $<E_{m}, x, H>$ Listagem 4.7}

Dada a Listagem 4.7, temos, com base nos elementos identificados na Tabela 4.1, que ocorre um Estado de Exeção Monitorado o que implica que a Regra 4 deve ser observada resultando na listagem 5.3.

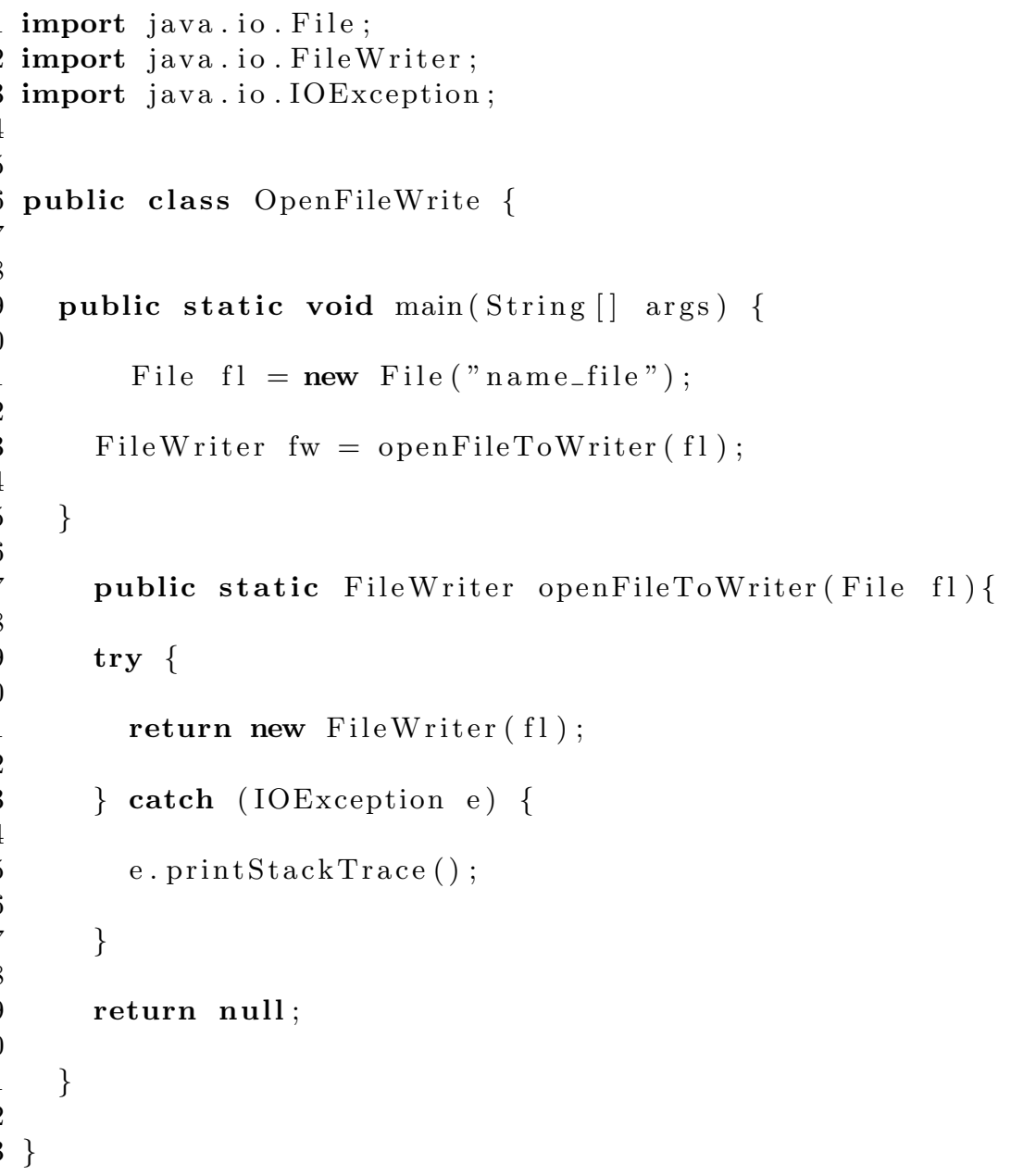

Listagem 5.3: Identificação do par $<E_{m}, x, H>$

Para os exemplos acima, é possível notar que mais de uma regra de instrumentação é aplicável. Porém, a guiza de exemplificar a aplicação de cada Regra a seu tipo específico foram omitidas as demais situações no código nas quais poderia haver aplicação de outras regras.

\subsection{Classe VerifyEx}

A classe VeryfyEx é escrita em código Java e implementa o Algoritmo 3, o qual recebe como entrada um rótulo (String) que representa o identificador da exceção que será lançada. Posterior- 
mente é verificado se este identificador já foi invocado ou não. Em caso negativo, a classe VeryfyEx lança a exceção, em caso positivo a exceção não é lançada e o fluxo do programa não é afetado.

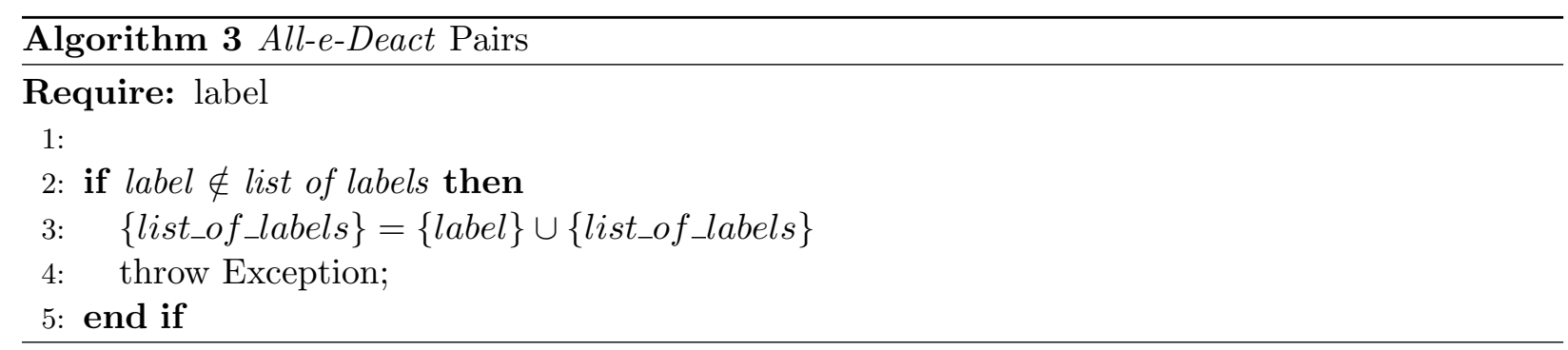

O Algoritmo 3 permite que para cada ponto de ativação de exceções ocorra apenas um lançamento. Desta forma, utilizando qualquer ferramenta ou método que permita realizar múltiplas execuções teremos o exercício de um único par de ativação e desativação de exceções, por execução, o que equivale a observar um único caminho excepcional ser exercitado por execução.

O código Java que representa a implementação do Algoritmo 3 é apresentado na Listagem 5.4,

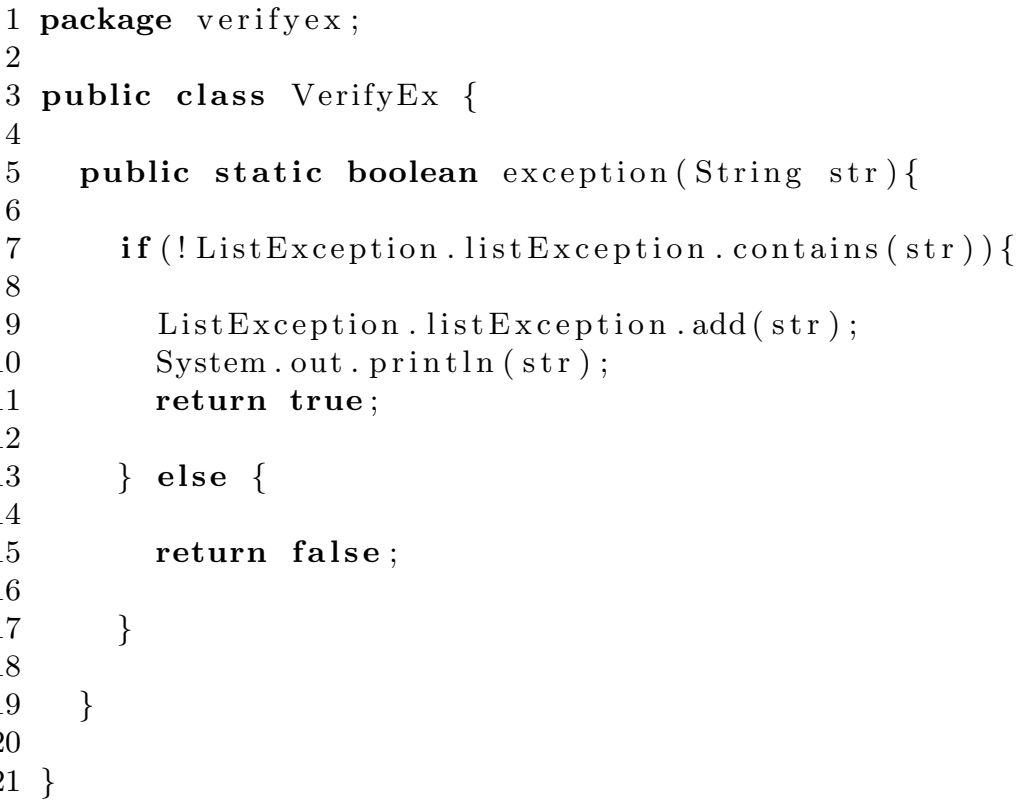

Listagem 5.4: Implementação da classe VerifyEx

O método verifyEX verifica se a exceção foi lançada ou não. Se a exceção não tiver sido lançada o método retorna true e lança a exceção que irá exercitar o caminho excepcional referente à instrumentação inserida. Caso contrário, a execução do SUT prossegue sem ser alterada.

Cada execução lançada é armazenada, linha 9 da Listagem 5.4. Este atributo pode ser usado ao término da execução para gerar um log de lançamento de exceções. O atributo monitor é inserido no ponto de desativação da exceção lançada, ver Definição 10 e permite determinar se o ponto de ativação e desativação condizem com os pares de ativação/desativação de exceções previamente determinados pela análise estática do código, ver Listagem 5.5.

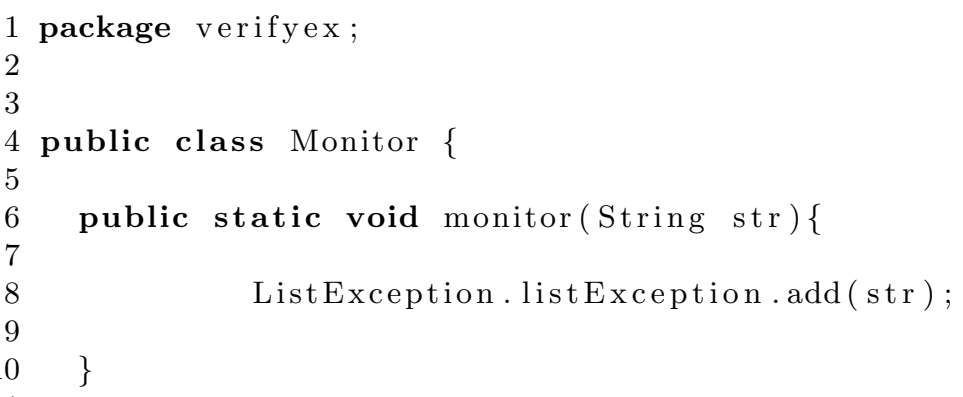


Listagem 5.5: Implementação da classe Monitor

A classe Monitor recebe um rótulo que identifica que uma determinada estrutura de tratamento foi acessada. Como após o lançamento de uma exceção a única outra estrutura que pode ser exercitada é uma estrutura de tratamento temos que para cada rótulo de exceção lançada haverá um rótulo de exceção tratada armazenado na lista, ver linha 8 Listagem 5.5.

Desta forma é possível gerar um log no qual identificamos qual exceção foi lançada, onde foi lançada e qual a estrutura responsável pelo seu tratamento, ver Capítulo 6.

\subsection{Ferramenta de Automação}

A inserção da instrumentação é feita de maneira automática por uma ferramenta construída em linguagem Java. Esta ferramenta recebe como entrada, um diretório que contém os arquivos fontes da aplicação a ser instrumentada e identifica, com bases nas regras acima listadas, os pontos de ativação e de desativação de exceções para cada arquivo. A ferramenta possui uma simples interface como apresentada na figura 5.1.

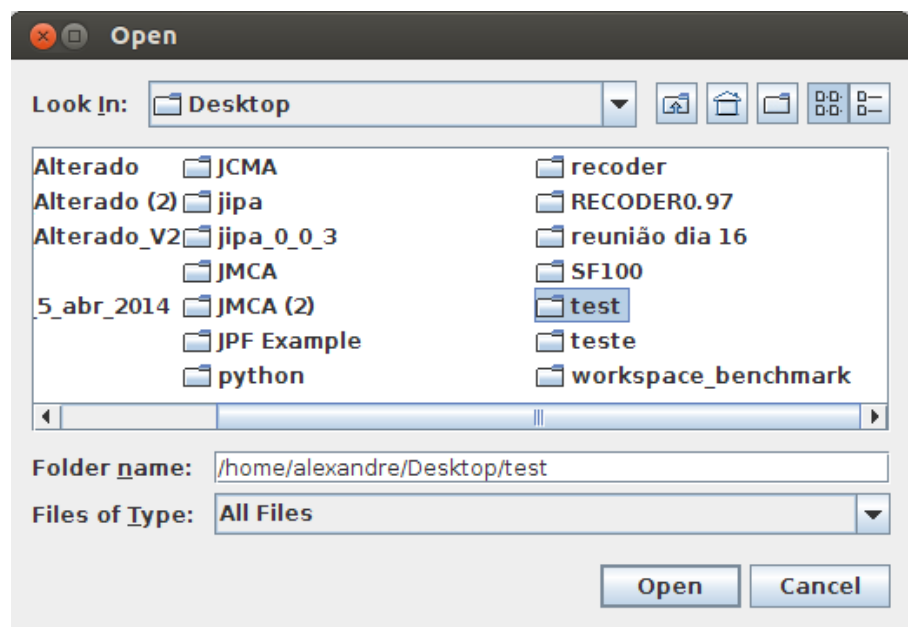

Figura 5.1: Interface de Instrumentação

No diretório test existe um arquivo Java (listagens 5.6). Ele foi elaborado seguindo as regras de instrumentação acima listadas.

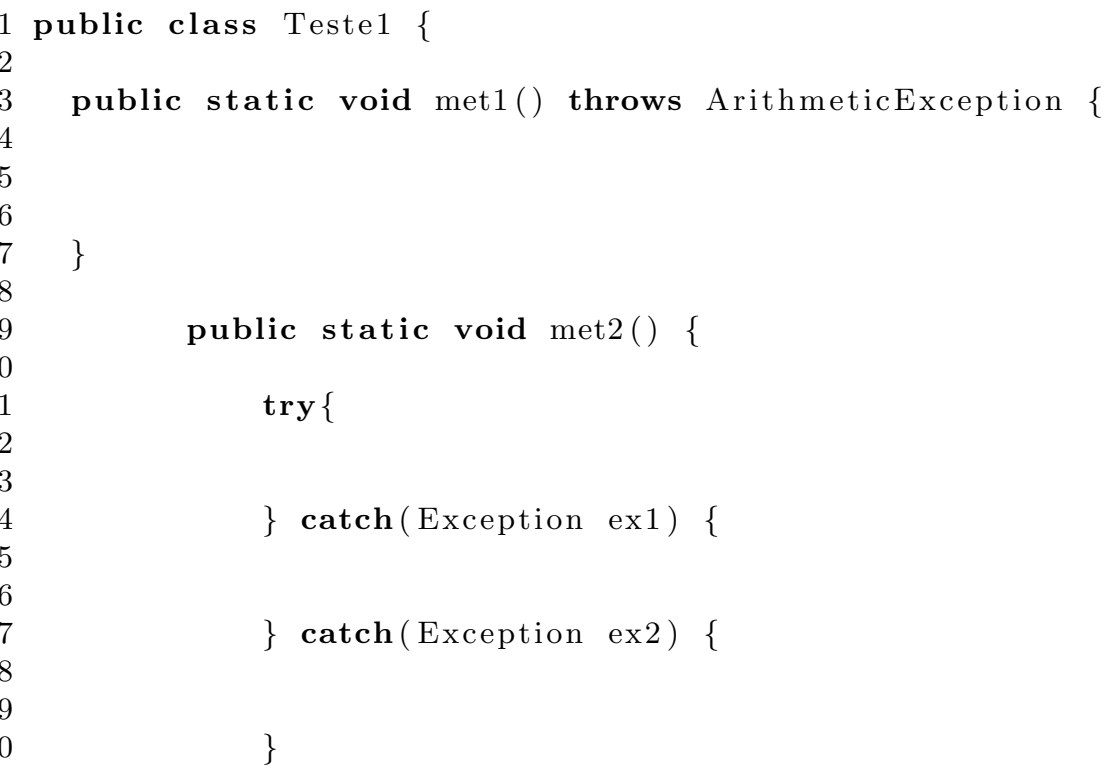




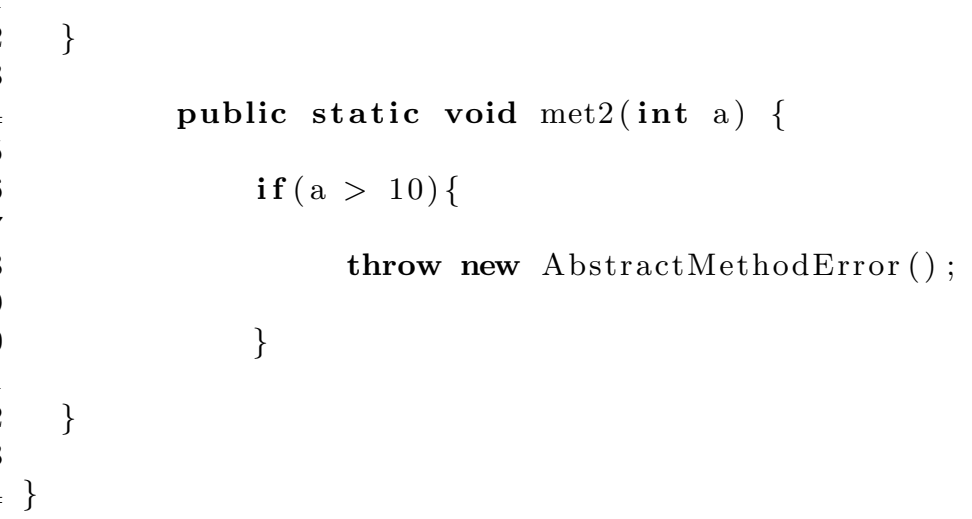

Listagem 5.6: Instrumentação Automática

O término do processamento gera o arquivo instrumentado apresentado na listagem 5.7

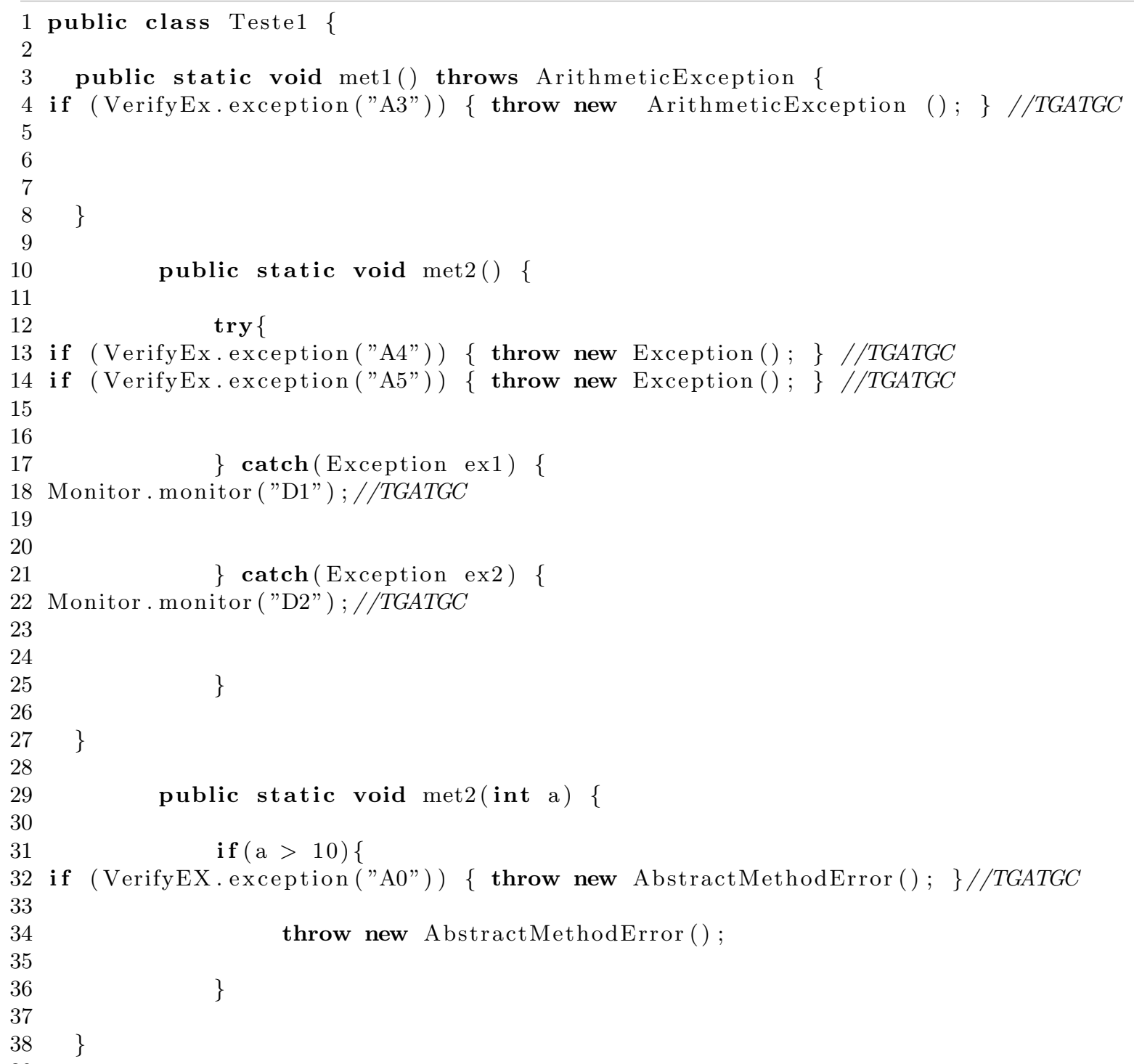

Listagem 5.7: Instrumentação Automática 


\subsection{Conclusão}

Por meio dos critérios de ativação/desativação de exceções, all-e-deact, é possível abstrair um modelo, XADGFC, de um SUT no qual são identificados os elementos envolvidos no lançamento de exceções e tratamento de exceções. Além disso, é possível estabelecer uma relação entre elementos que lançam (ativam) exceções e os que desativam exceções a fim de determinar pares. Tais pares, ao serem exercitados, manifestam o comportamento excepcional de um dado código. Esse comportamento envolve o lançamento de uma exceção e, espera-se, o seu correto tratamento.

Com base nesta relação, foi possível formular um conjunto de Regras que orienta a inserção de código que permite exercitar o caminhos excepcionais representados pelos pares de ativação/desativação de modo a forçar, em tempo de execução, que o comportamento excepcional do SUT seja manifestado.

Por fim, para viabilizar o exercício destes elementos apresentamos a classe VerifyEx Java que pode ser inserida em qualquer SUT ocasionando uma mínima interferência no comportamento deste. Ela permite lançar e monitorar exceções de modo a determinar, em tempo de execução, qual o comportamento de um dado SUT quando da ocorrência de uma exceção. No Capítulo 6, apresentaremos um estudo de caso no qual esta classe é usada para lançar e monitorar exceções. 


\section{Capítulo 6}

\section{Estudo de Caso - Vending Machine}

O exemplo apresentado nesse Capítulo supõe que a Listagem 6.1 já está representada como um grafo XADCFG, ver Definição 11. A representação foi feita pelo Algoritmo 1, sendo que a identificação dos pares de ativação e desativação foi realizada pelo Algoritmo 2, como apresentado na Seção 4.5. Uma vez identificados os pares de ativação/desativação implementamos o processo de instrumentação seguindo as Regras definidas no Capítulo 5.

\subsection{Vending Machine}

Dado o código ${ }^{1}$ apresentado na listagem 6.1 ,o processo de instrumentação tem início pela localização dos pares de ativação/desativação de exceções baseado no grafo XADCGF.

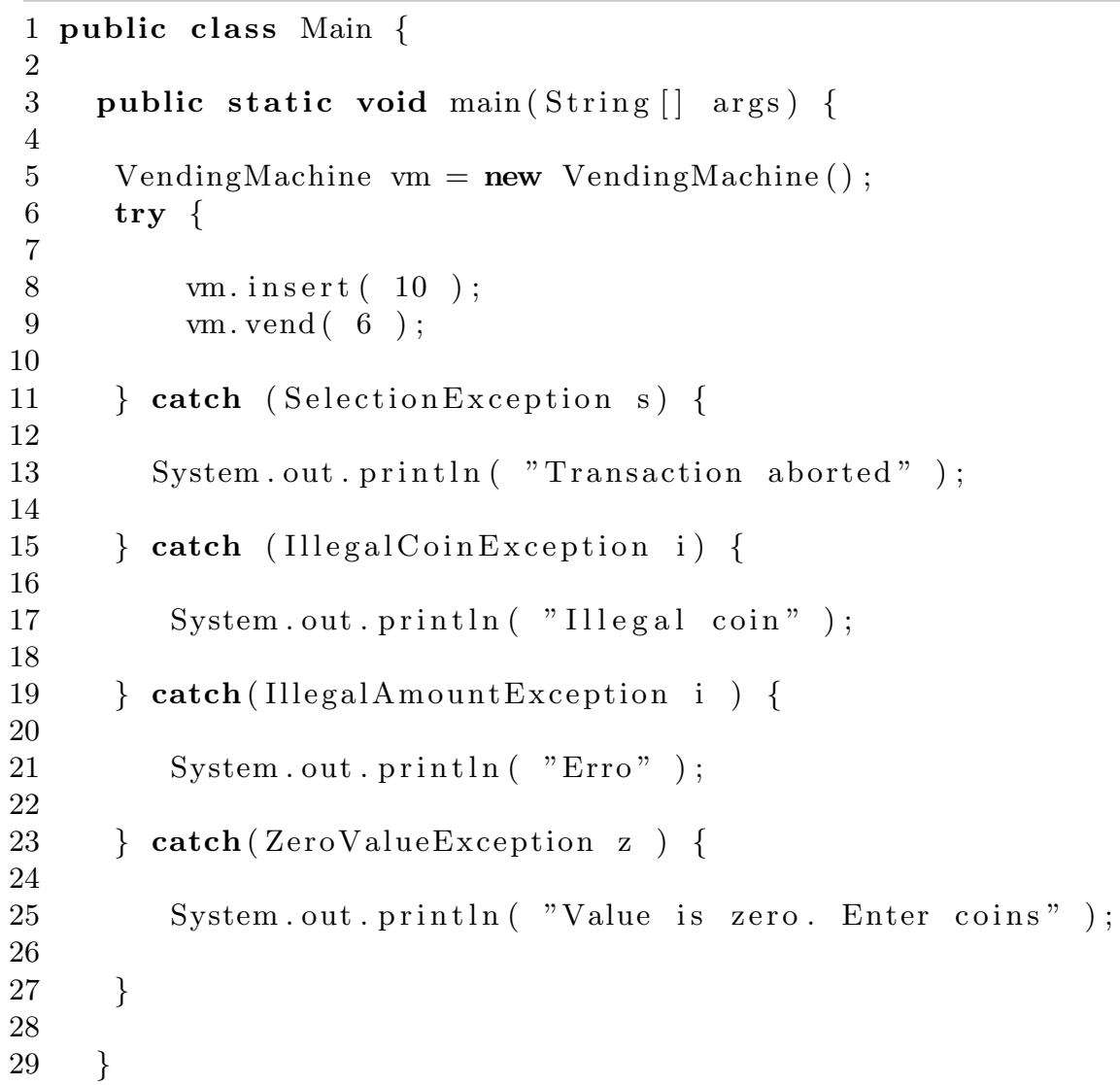

${ }^{1}$ este código foi extraído do trabalho de Sinha e Harrold [SJ98] e foi alterado para atender aos fins propostos por esse exemplo. 


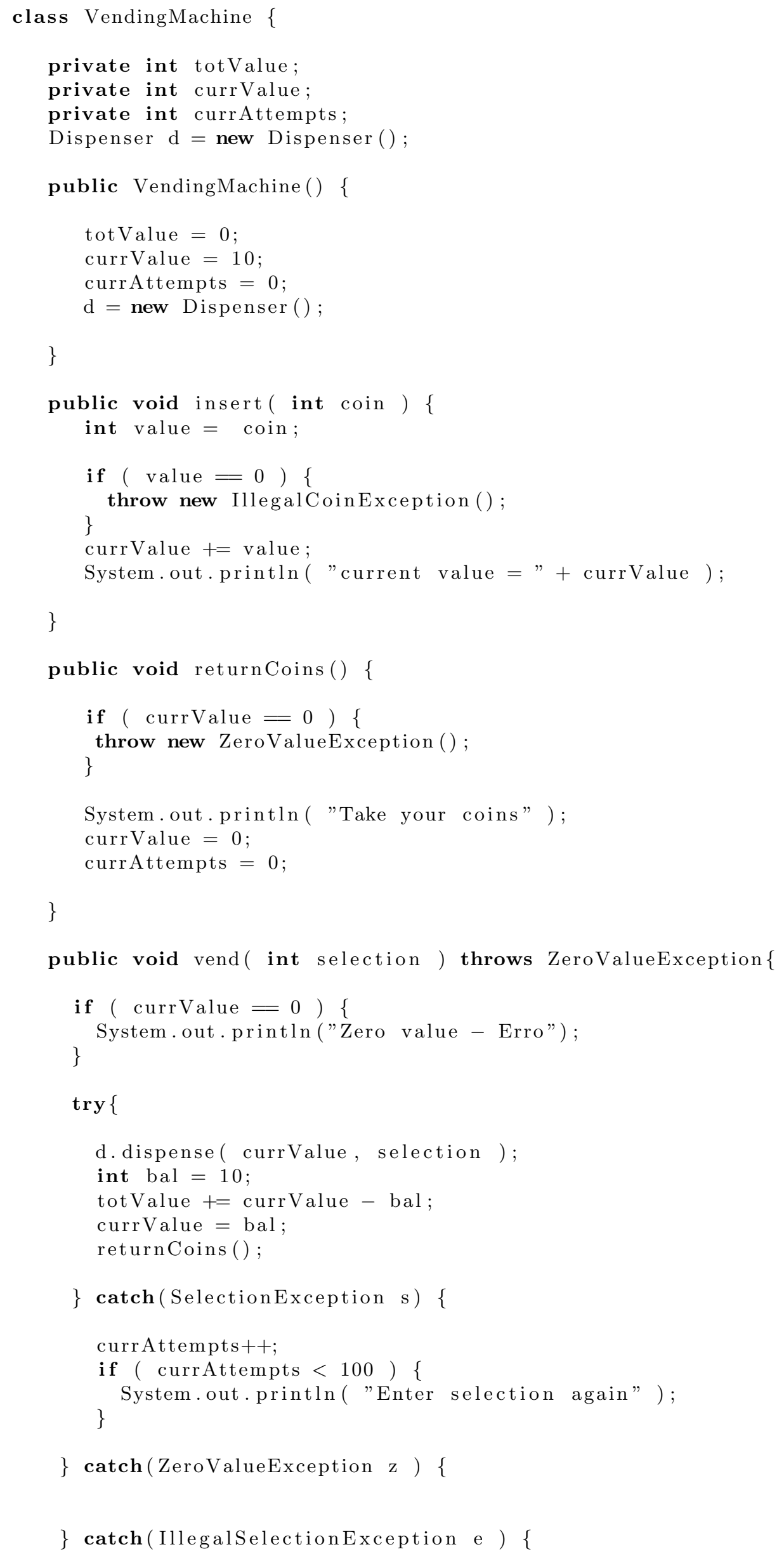


98

98
99
100

101

102

103

104

105

106

107

108

$109\}$

110

111

112

113

114

115

116

117

118

119

120

121

122

123

124

125

126

127

128

129

130

131

132

133

134

135

136

137

138

139

140

141

142

$143\}$

144

145 146

147

148

149

150

$151\}$

152

153

154

155

156

157

158

$159\}$

160

161 class IllegalSelectionException extends RuntimeException \{

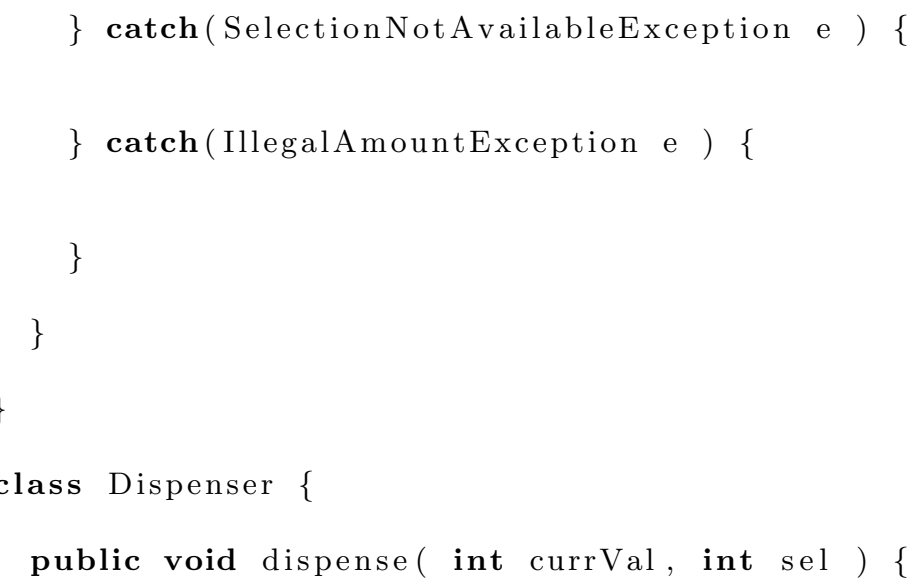




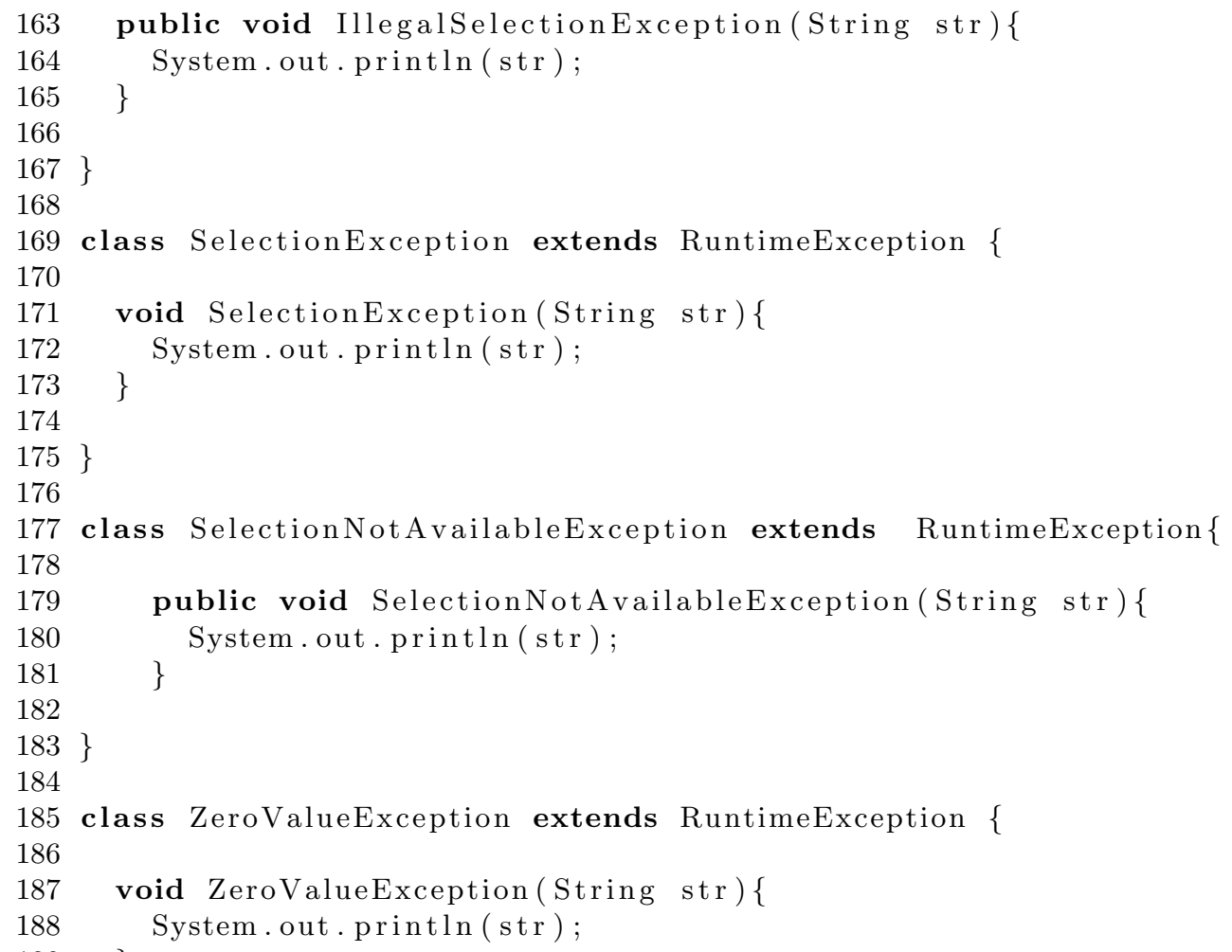

Listagem 6.1: Vending Machine 
Tabela 6.1: Pares de Ativação/Desativação Listagem 6.1 e Regra de Instrumentação

\begin{tabular}{ccc}
\hline Métod & Par & Estado \\
\hline \hline insert & $(53,15)$ & $E_{p}$ \\
\hline \hline returnCoins & $(63,93)$ & $E_{p}$ \\
\hline \hline vend & $(<72,93>, 93)$ & $E_{a}$ \\
& $(<78,86>, 86)$ & $E_{m}$ \\
& $(<78,86>, 93)$ & $E_{m}$ \\
& $(<78,86>, 96)$ & $E_{m}$ \\
& $(<78,86>, 99)$ & $E_{m}$ \\
& $(<78,86>, 102)$ & $E_{m}$ \\
\hline \hline dispenser & $(119,96)$ & $E_{p r}$ \\
& $(126,99)$ & $E_{p r}$ \\
& $(132,102)$ & $E_{p r}$ \\
\hline \hline main & $(<6,11>, 11)$ & $E_{m}$ \\
& $(<6,11>, 15)$ & $E_{m}$ \\
& $(<6,11>, 19)$ & $E_{m}$ \\
& $(<6,11>, 23)$ & $E_{m}$ \\
\hline
\end{tabular}

Os pares de ativação/desativação da Listagem 6.1 são apresentados na Tabela 6.1, 
Tabela 6.2: Regra de Instrumentação para os Pares de Ativação/Desativação da Listagem 6.1

\begin{tabular}{ccc}
\hline Métod & Par & Regra \\
\hline insert & $(53,15)$ & 2 \\
\hline \hline returnCoins & $(63,93)$ & 2 \\
\hline \hline vend & $(<72,93>, 93)$ & 3 \\
& $(<78,86>, 86)$ & 4 \\
& $(<78,86>, 93)$ & 4 \\
& $(<78,86>, 96)$ & 4 \\
& $(<78,86>, 99)$ & 4 \\
& $(<78,86>, 102)$ & 4 \\
\hline \hline dispenser & $(119,96)$ & 2 \\
& $(126,99)$ & 2 \\
& $(<6,11>, 11)$ & 4 \\
\hline \hline main & $(<6,11>, 15)$ & 4 \\
& $(<6,11>, 19)$ & 4 \\
& $(<6,11>, 23)$ & 4 \\
\hline
\end{tabular}

A Tabela 6.2 identifica a regra de instrumentação à qual o par se submete. 
Tabela 6.3: Pares de Ativação/Desativação Listagem 6.1 e Exceção Vinculada ao Par

\begin{tabular}{ccc}
\hline Método & Par & Exceção \\
\hline insert & $(53,15)$ & IllegalCoinException \\
\hline \hline returnCoins & $(63,93)$ & ZeroValueException \\
\hline \hline vend & $(<72,93>, 93)$ & ZeroValueException \\
& $(<78,86>, 86)$ & SelectionException \\
& $(<78,86>, 93)$ & ZeroValueException \\
& $(<78,86>, 96)$ & IllegalSelectionException \\
& $(<78,86>, 99)$ & SelectionNotAvailableException \\
& $(<78,86>, 102)$ & IllegalAmountException \\
\hline \hline dispenser & $(119,96)$ & IllegalSelectionException \\
& $(126,99)$ & SelectionNotAvailableException \\
& $(132,102)$ & IllegalAmountException \\
\hline \hline main & $(<6,11>, 11)$ & SelectionException \\
& $(<6,11>, 15)$ & IllegalCoinException \\
& $(<6,11>, 19)$ & IllegalAmountException \\
& $(<6,11>, 23)$ & ZeroValueException \\
\hline
\end{tabular}

A Tabela 6.3 identifica qual exceção deve ser ativada.

Com base nas Tabelas 6.2 e 6.3 faremos a inserção de comentários nos locais nos quais o código de instrumentação deve ser posto respeitando as regras estabelecidas neste Capítulo, ver Listagem 6.2 .

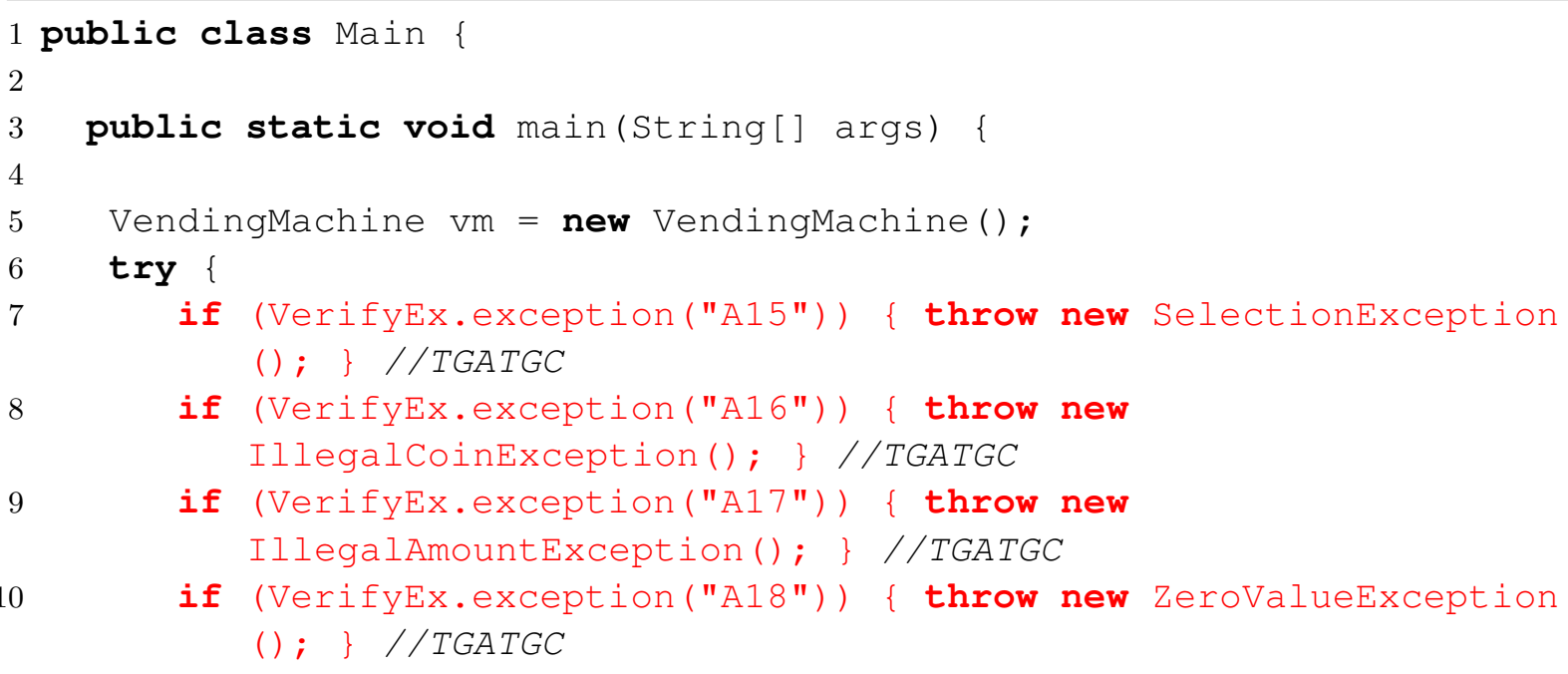

11

vm.insert ( 10$)$;

vm. vend ( 6$)$;

\} catch (SelectionException $s$ ) \{

Monitor.monitor("D5");//TGATGC

System.out.println( "Transaction aborted" );

Main.main (null);

\} catch (IllegalCoinException i) \{

Monitor.monitor("D6"); //TGATGC

System.out.println( "Illegal coin");

Main.main (null);

\} catch (IllegalAmountException i ) \{

Monitor.monitor("D7");//TGATGC 


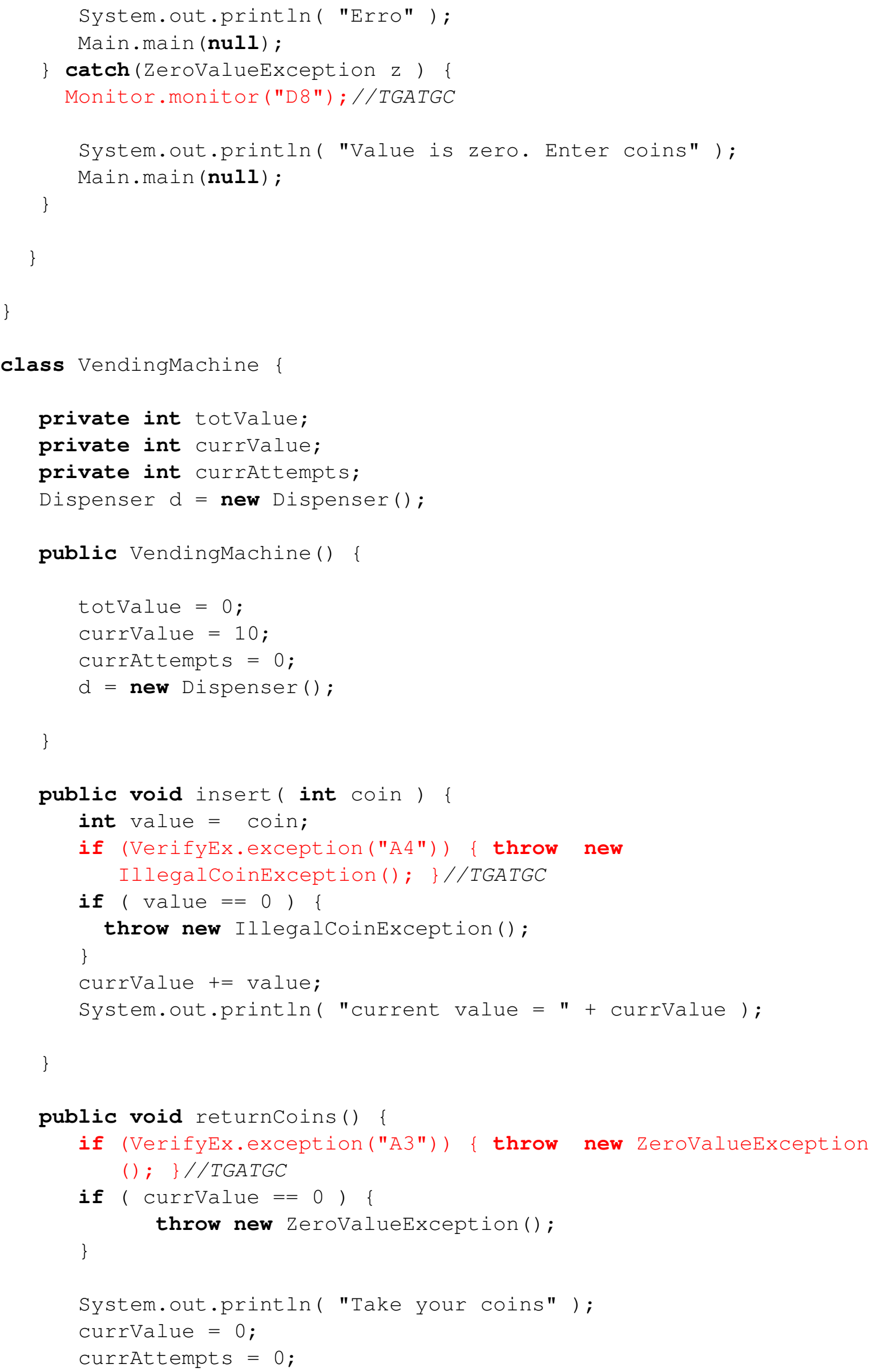


\}

public void vend( int selection) throws ZerovalueException

if (VerifyEx.exception("A14")) \{ throw new ZeroValueException() ; ) //TGATGC 
121

$122\}$

123

$124\}$

125

126 class Dispenser \{

127

128 public void dispense( int currval, int sel ) \{

129 if (VerifyEx.exception("A2")) \{ throw new IllegalselectionException ( ) ; \}//TGATGC

130 if $($ sel $<0||$ sel $>100)\{$

131 System.out.println( "selection "+sel+" is invalid" );

132 throw new IllegalselectionException();

133

$134\}$ else \{

135 if (VerifyEx.exception("A1")) \{ throw new SelectionNotAvailableException(); \}//TGATGC

136 if $(\operatorname{sel}=50)\{$

137

138

139

140

141

142 System.out.println( "selection "+sel+" is unavailable" );

throw new SelectionNotAvailableException();

else \{

int $\operatorname{val}=5$;

if (VerifyEx.exception("AO")) \{ throw new IllegalAmountException(); //TGATGC

144 if ( currVal < val ) \{

145

146

throw new IllegalAmountException();

147

148

149

150

151

152

153

154

155

$156\}$

157

158 class IllegalAmountException extends RuntimeException

159

160 public void IllegalAmountException(String str) \{

161 System.out.println(str);

$162\}$

163

$164\}$

165

166 class IllegalCoinException extends RuntimeException \{

167

168 public void IllegalCoinException(String str) \{

169 System.out.println(str); 
173

174

175

176

public void IllegalSelectionException(String str) \{

System.out.println(str);

177

178

179

$180\}$

181

182 class SelectionException extends RuntimeException \{

183

184

void SelectionException (String str) \{

System.out.println (str);

\}

187

$188\}$

189

190 class SelectionNotAvailableException extends RuntimeException \{

191

192 public void SelectionNotAvailableException(String str) \{

$193 \quad$ System.out.println (str);

$194 \quad\}$

195

$196\}$

197

198 class ZeroValueException extends RuntimeException \{

199

200 void ZeroValueException(String str) \{

201 System.out.println(str);

$202\}$

203

$204\}$

Listagem 6.2: Vending Machine - Pontos de Instrumentação

Na Listagem 6.2, as linhas em vermelho representam os pontos nos quais o código responsável pelo lançamento das exceções foi automaticamente inserido. As linhas vermelhas nas quais são feitas as chamadas para a classe Monitor representam a instrumentação responsável por registrar qual exceção lançada acessou à estrutura de tratamento monitorada. No final de cada uma das inhas de instrumetação, inseridas no código, temos um comentário contendo a string TGATGC, este comentário é utilizado para identificar a linha de instrumentação em um processo de limpeza do código fonte no qual o código inserido é removido. A Tabela 6.4 identifica a relação entre os pares e os pontos de instrumentação. 
Tabela 6.4: Pares de Ativação/Desativação Listagem 6.2 e Instrumentação do Código

\begin{tabular}{ccc}
\hline Método & Par & Rotulos \\
\hline insert & $(53,15)$ & $(A 4, D 6)$ \\
\hline \hline returnCoins & $(63,93)$ & $(A 3, D 10)$ \\
\hline \hline vend & $(<72,93>, 93)$ & $(A 14, D 10)$ \\
& $(<78,86>, 86)$ & $(A 19, D 9)$ \\
& $(<78,86>, 93)$ & $(A 20, D 10)$ \\
& $(<78,86>, 96)$ & $(A 21, D 11)$ \\
& $(<78,86>, 99)$ & $(A 22, D 12)$ \\
& $(<78,86>, 102)$ & $(A 23, D 13)$ \\
\hline \hline dispenser & $(119,96)$ & $(A 2, D 11)$ \\
& $(126,99)$ & $(A 1, D 12)$ \\
& $(132,102)$ & $(A 0, D 13)$ \\
\hline \hline main & $(<6,11>, 11)$ & $(A 15, D 5)$ \\
& $(<6,11>, 15)$ & $(A 16, D 6)$ \\
& $(<6,11>, 19)$ & $(A 17, D 7)$ \\
& $(<6,11>, 23)$ & $(A 18, D 8)$ \\
\hline & &
\end{tabular}

Dessa forma, com base nas Regras de Instrumentação, cada elemento do SUT vinculado a um lançamento e a um tratamento de exceção foi identificado e pode agora ser verificado no tocante ao seu comportamento. O esperado é que cada exceção lançada, ponto de ativação, seja tratada pelo correspondente ponto de tratamento, ponto de desativação.

\subsection{Resultados Obtidos}

Para determinar o ganho no uso da técnica em termos de exercício de comportamento excepcional e, com isso, oferecer um aumento no conhecimento dos possíveis comportamentos que o SUT pode manifestar, principalmente o excepcional, apresentamos a execução do código da Listagem 6.2 em três condições distintas, que são:

- Execução sem instrumentação diretamente na Máquina Virtual Java.

- Execução do código instrumentado diretamente na Máquina Virtual Java.

- Execução do código instrumentado por meio do uso da ferramenta de teste JUnit.

- Execução do código instrumentado por meio do Model Checker JPF.

O objetivo dessas execuções é demonstrar que o comportamento excepcional de um dado SUT não é, por padrão, exercitado por ferramentas comuns de teste e verificação. Para comparar as diferentes execuções usaremos a ferramenta Eclemma [Ecl] que fornece o percentual de cobertura de código para um dado critério $^{2}$. No caso desse estudo, o critério escolhido foi o de cobertura de linhas. A escolha desse critério, linhas, deve-se ao fato de o Eclemma contabilizar linhas de comentário. Logo, comentando o código instrumentado da Listagem 6.2 e realizando uma medida de cobertura de linhas não ocorrerá influência real no número de linhas quando da execução do código com as linhas de instrumentação não comentadas. Desta forma será possível a comparação das métricas.

\footnotetext{
${ }^{2} \mathrm{O}$ teste de cobertura não será aplicado ao model checker JPF dado que a ferramenta Eclemma verificaria a cobertura do código do JPF e não do SUT.
} 
Tabela 6.5: Cobertura da Listagem 6.2 Sem Instrumentação

\begin{tabular}{ccccc}
\hline Classe & Método & Linhas Cobertas & Linhas Não Cobertas & Percentual \\
\hline Main & main & 5 & 7 & $41,7 \%$ \\
\hline \hline VendingMachine & VendingMachine & 7 & 0 & $100 \%$ \\
& insert & 5 & 1 & $83 \%$ \\
& returnCoins & 5 & 1 & $83 \%$ \\
& vend & 8 & 8 & $50 \%$ \\
\hline Dispenser & dispenser & 6 & 5 & $54,5 \%$ \\
\hline
\end{tabular}

Tabela 6.6: Cobertura da Listagem 6.2 Com Instrumentação

\begin{tabular}{ccccc}
\hline Classe & Método & Linhas Cobertas & Linhas Não Cobertas & Percentual \\
\hline Main & main & 24 & 0 & $100 \%$ \\
\hline \hline VendingMachine & VendingMachine & 7 & 0 & $100 \%$ \\
& insert & 6 & 1 & $85,7 \%$ \\
& returnCoins & 6 & 1 & $85,7 \%$ \\
& vend & 31 & 1 & $96,9 \%$ \\
\hline Dispenser & dispenser & 9 & 5 & $64,3 \%$ \\
\hline
\end{tabular}

\subsubsection{Execução da Listagem 6.2 e Determinação dos Valores de Cobertura para JVM}

A execução da Listagem 6.2, comentando as linhas de instrumentação, resulta na cobertura apresentada na Tabela 6.5

A Tabela 6.6 apresenta os valores de cobertura para execução da Listagem 6.2 na JVM com as linhas de instrumentação não comentadas.

Comparando os resultados obtidos nas Tabelas 6.5 e 6.6 podemos notar que houve um aumento significativo no número de linhas cobertas para os métodos main da primeira execução em relação à segunda execução. Isto se deve ao fato de que as linhas referentes às estruturas de tratamento de exceção passaram a ser exercitadas. O mesmo efeito é observado na taxa de cobertura da método vend devido à presença de grande quantidade de linhas vinculadas ao tratamento de exceções. Os métodos insert e returnCoins apresentaram menor variação devido à menor presença de estruturas de tratamento de exceções.

\subsubsection{Execução da Listagem 6.2 e Determinação dos Valores de Cobertura para JUnit}

A instrumentação aqui apresentada pode ser utilizada juntamente com ferramentas de teste unitário, JUnit, para exercitar caminhos excepcionais. Para tanto, a listagem 6.2 pode ser exercitada via código JUnit apresentado na Listagem 6.3.

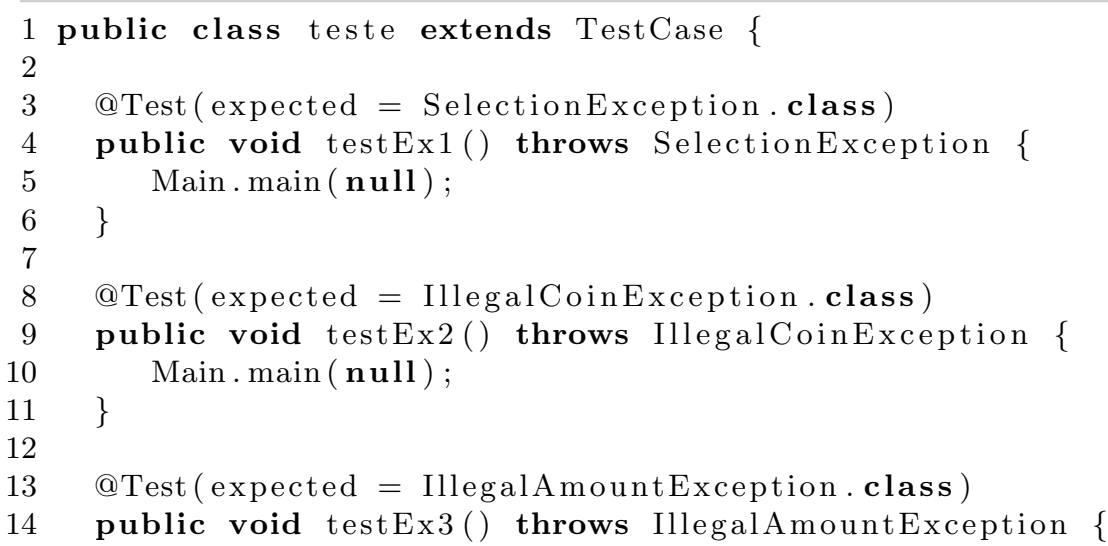




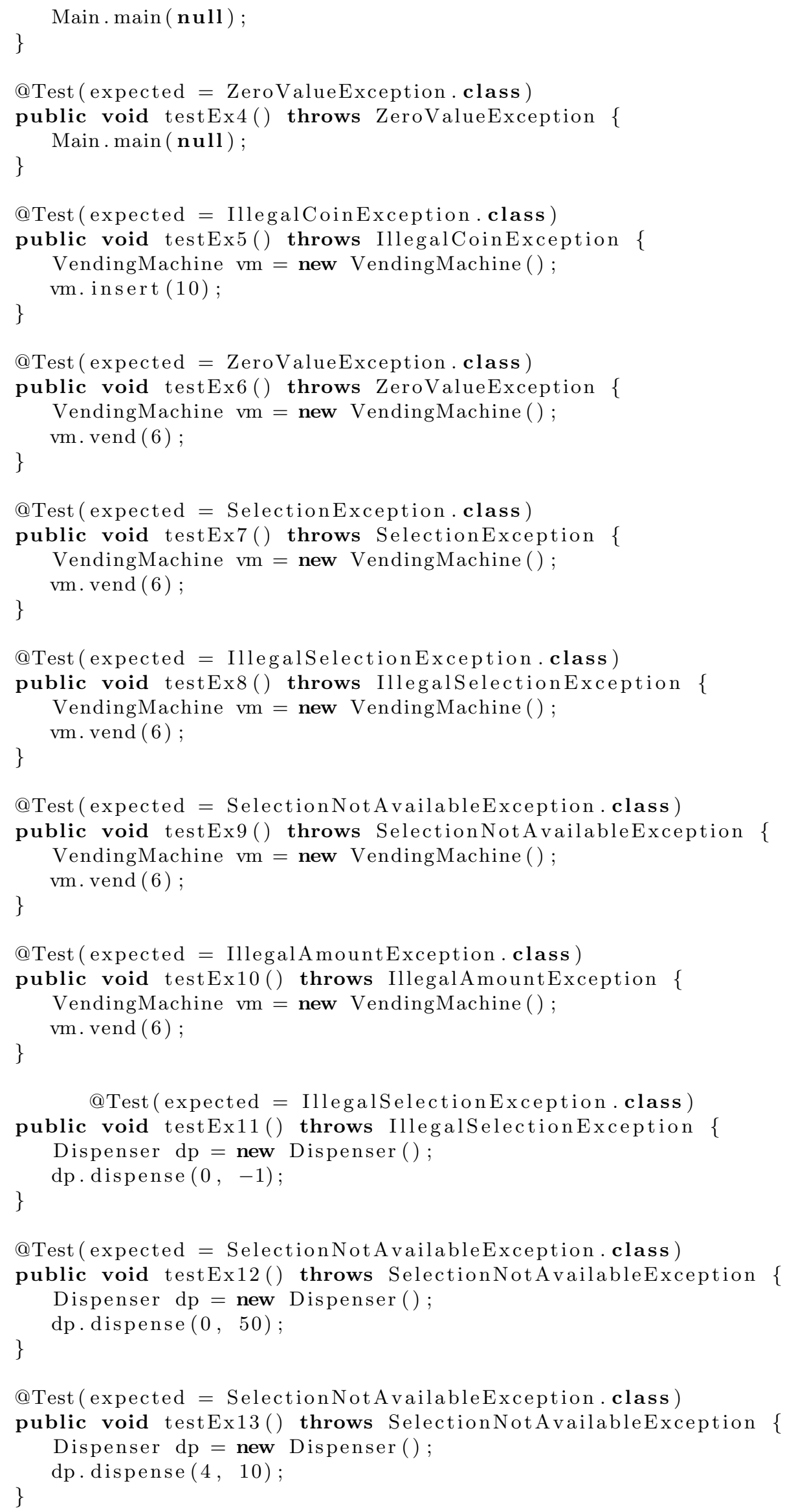


Tabela 6.7: Cobertura da Listagem 6.2 Sem Instrumentação Executada via JUnit

\begin{tabular}{ccccc}
\hline Classe & Método & Linhas Cobertas & Linhas Não Cobertas & Percentual \\
\hline Main & main & 5 & 7 & $41,7 \%$ \\
\hline \hline VendingMachine & VendingMachine & 7 & 0 & $100 \%$ \\
& insert & 5 & 1 & $83 \%$ \\
& returnCoins & 5 & 1 & $83 \%$ \\
& vend & 8 & 8 & $50 \%$ \\
\hline Dispenser & dispenser & 11 & 0 & $100 \%$ \\
\hline
\end{tabular}

Tabela 6.8: Cobertura da Listagem 6.2 Sem Instrumentação Executada via JUnit

\begin{tabular}{ccccc}
\hline Classe & Método & Linhas Cobertas & Linhas Não Cobertas & Percentual \\
\hline Main & main & 24 & 1 & $96 \%$ \\
\hline \hline VendingMachine & VendingMachine & 7 & 0 & $100 \%$ \\
& insert & 6 & 1 & $85,7 \%$ \\
& returnCoins & 6 & 1 & $85,7 \%$ \\
& vend & 31 & 1 & $96,9 \%$ \\
\hline Dispenser & dispenser & 14 & 0 & $100 \%$ \\
\hline
\end{tabular}

\section{Listagem 6.3: Código JUnit}

A execução da Listagem 6.2 via JUnit, comentando-se as linhas de instrumentação, resulta na cobertura apresentada na Tabela 6.7

Por sua vez, a execução da Listagem 6.2 via JUnit resulta na cobertura apresentada na Tabela 6.8

Os resultados obtidos nas Tabelas 6.7 indicam que as linhas de código referentes ao tratamento de exceções não foram exercitadas, o que justifica o baixo valor de cobertura. Por outro lado, a Tabela 6.8 apresenta valores de cobertura maiores por exercitar as estruturas de tratamento de exceções, via instrumentação de código.

As Tabelas 6.5 e 6.7 apresentam valores similares de cobertura bem como as Tabelas 6.6 e 6.8 que também apresentam valores de cobertura similar. Esta semelhança é maior nos métodos que possuem maior número de estruturas de tratamento os quais, ao serem exercitados via instrumentação, apresentaram maior cobertura de linhas dado que as estruturas excepcionais, antes não contabilizadas, passam a ser computadas.

A Listagem 6.4 apresenta a saída do SUT executada pela JUnit.

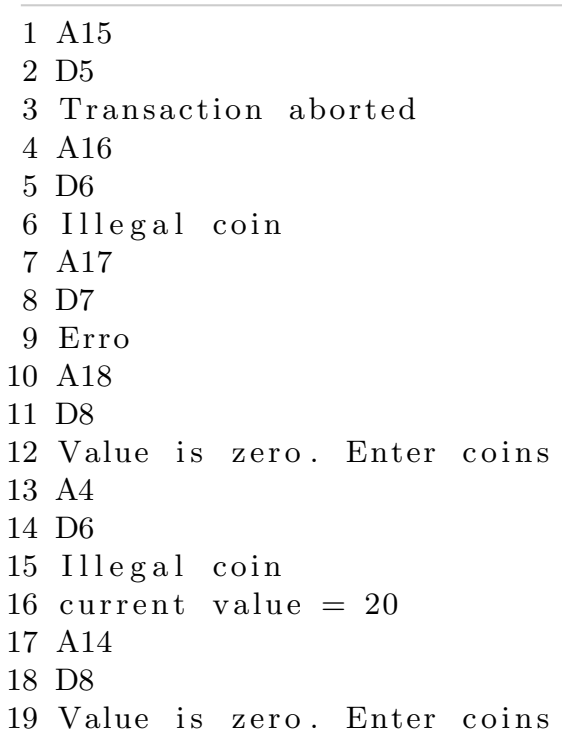




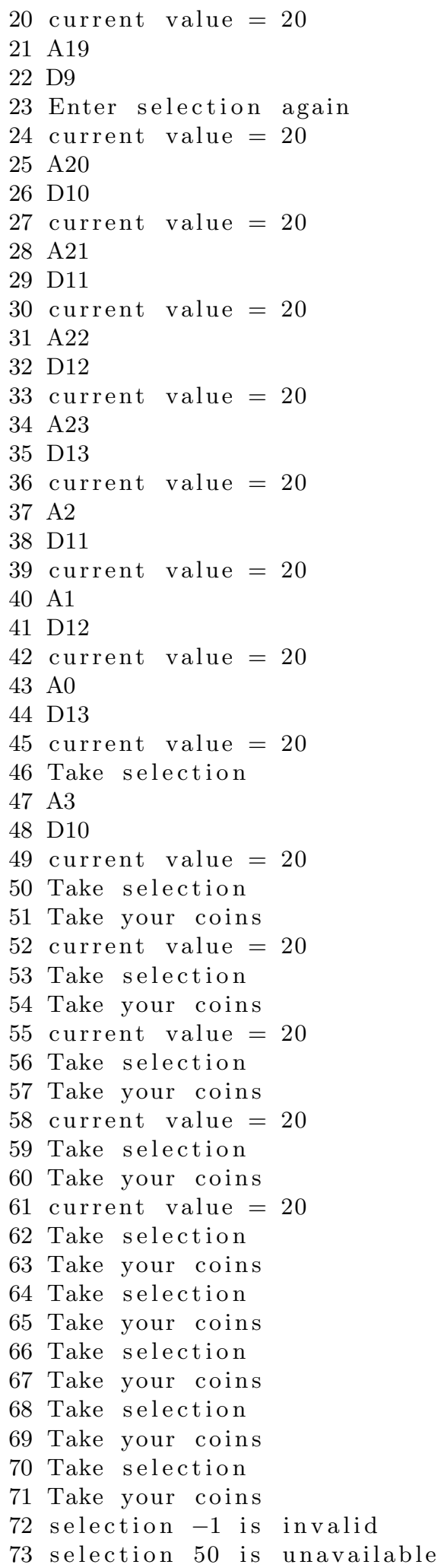

Listagem 6.4: Saída JUnit

A Listagem 6.4 demonstra que todas as exceções foram exercitadas pois todos os rótulos de ativação/desativação foram impressos na tela. Além disso, é possível notar que a sequência de de saída reflete os pares de ativação e desativação esperados dado que, logo após um rótulo de ativação, temos um rótulo de desativação. 


\subsubsection{Execução da Listagem 6.2 na Ferramenta de Verificação JPF}

A execução da Listagem 6.2 via JPF, comentando as linhas de instrumentação, resulta na saída apresentada na listagem 6.5.

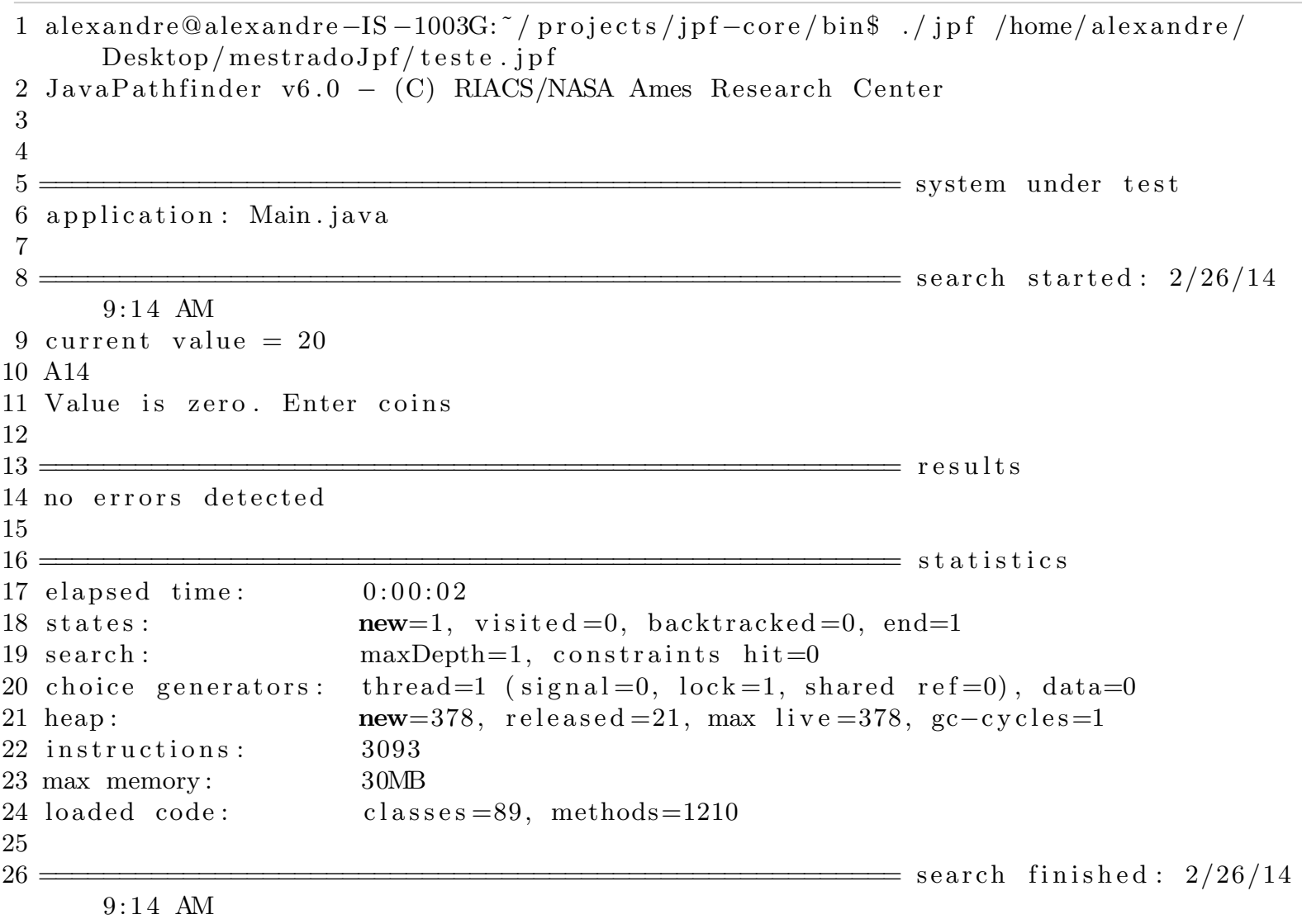

\section{Listagem 6.5: Saída JPF}

A execução da Listagem 6.2, descontando as linhas de instrumentação, resulta na Listagem 6.6.

1 JavaPathfinder v6.0 - (C) RIACS/NASA Ames Research Center

2

3

$4=$ system under test

5 application: Main.java

6

$9: 19 \mathrm{AM}$

8 A15

9 D5

10 Transaction aborted

11 A16

$12 \mathrm{D} 6$

13 Illegal coin

14 A17

15 D7

16 Erro

17 A18

18 D8

19 Value is zero. Enter coins

20 A4

21 D6

22 Illegal coin

23 current value $=20$

24 A14

$25 \mathrm{D} 8$

26 Value is zero. Enter coins 
27 current value $=20$

28 A19

29 D9

30 Enter selection again

31 current value $=20$

32 A20

33 D10

34 current value $=20$

35 A21

36 D11

37 current value $=20$

38 A22

39 D12

40 current value $=20$

41 A23

42 D13

43 current value $=20$

44 A2

45 D11

46 current value $=20$

47 A1

48 D12

49 current value $=20$

50 A0

51 D13

52 current value $=20$

53 Take selection

54 A3

55 D10

56 current value $=20$

57 Take selection

58 Take your coins

59

$60 \Longrightarrow$ results

61 no errors detected

62

$63=$ statistics

64 elapsed time: $\quad 0: 00: 04$

65 states: $\quad$ new $=1$, visited $=0$, backtracked $=0$, end $=1$

66 search :

maxDepth $=1$, constraints hit $=0$

67 choice generators: thread $=1$ ( $\operatorname{signal}=0$, lock=1, shared $\mathrm{ref}=0)$, data $=0$

68 heap :

69 instructions: $\quad 30720$

70 max memory: $\quad 30 \mathrm{MB}$

71 loaded code: $\quad$ classes $=97, \operatorname{methods}=1429$

72

73

$9: 19$ AM

Listagem 6.6: Saída JPF

A Listagem 6.6 demonstra que todos os rótulos referentes às instruções de ativação e desativação de exceções foram exercitados pelo model checker JPF. Desta forma, qualquer verificação que seja feita pelo JPF passa a ser agora aplicada ao comportamento excepcional do SUT.

\subsection{Análise dos Resultados}

A Figura 6.1 relaciona os rótulos vinculados à ativação e às exceções na Listagem 6.2 com os rótulos vinculados à desativação dessas exceções. 


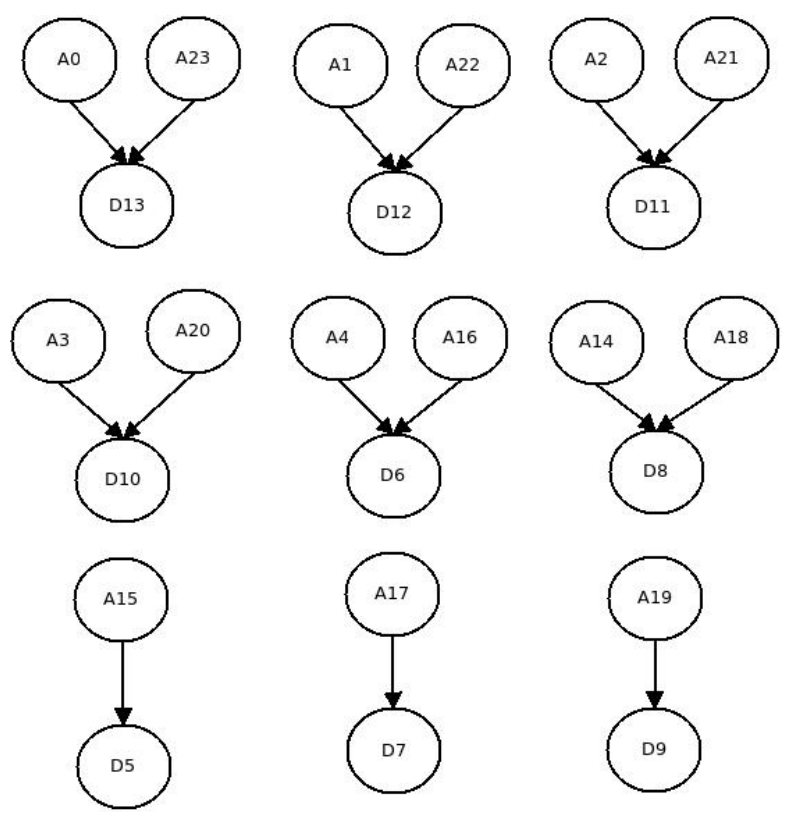

Figura 6.1: Relação de Ativação e Desativação de Exceções

A análise da Figura 6.1 permite identificar que existem pontos de tratamento de exceção que são responsáveis pela desativação de duas exceções lançadas em pontos distintos do código. A Tabela 6.9 identifica estes pontos de tratamento que desativam mais de uma exceção.

Tomando por exemplo os rótulos $A 0, A 23$ e $D 13$ temos:

- o rótulo $A 0$ é referente a um estado programado $\left(E_{p}\right)$ de lançamento de exceção no método dispenser.

- o rótulo $A 23$ é referente a um estado monitorado $\left(E_{m}\right)$ de lançamento de exceção no método vend.

Podemos notar, que o bloco try no método vend monitora a exceção que é lançada pelo método dispenser. Logo, o caminho excepcional exercitado pela instrumentação do rótulo A23 é subcaminho do caminho excepcional exercitado pela instrumentação do rótulo $A 0$. Desta forma, podemos otimizar o processo de verificação de modo a apenas lançar a exceção representada pelo rótulo $A 0$. O mesmo raciocínio se aplica às demais linhas da Tabela 6.9.

Logo, a instrumentação não só permite

- identificar os caminhos excepcionais do SUT;

- exercitar estes caminhos; e

- identificar o comportamento expresso por estes caminhos manifestados.

Tabela 6.9: Pontos de Desativação de Mais de Uma Exceção

\begin{tabular}{cc}
\hline Pontos de Ativação & Desativação \\
\hline \hline$A 0, A 23$ & $D 13$ \\
\hline \hline$A 1, A 22$ & $D 12$ \\
\hline \hline$A 2, A 21$ & $D 11$ \\
\hline \hline$A 3, A 20$ & $D 10$ \\
\hline \hline$A 4, A 16$ & $D 6$ \\
\hline \hline$A 14, A 18$ & $D 8$ \\
\hline
\end{tabular}


Como também permite otimizar o processo de modo a reduzir o número de pontos de instrumentação necessários para o reconhecimento do comportamento excepcional de um dado SUT.

\subsection{Conclusão}

O estudo de caso aqui realizado demonstrou que nossa técnica de instrumentação permite localizar pontos de ativação e desativação de exceções, exercitar estes pontos em diferentes tipos de execução (JVM, JUNIT e JPF) e permite, na maior parte do testes (JVM e JUnit), utilizar ferramentas e testes complementares (Eclemma) os quais passam a ser capazes de gerar informações sobre as partes do SUT vinculadas às estruturas de tratamento de exceção.

No próximo Capítulo, apresentaremos em mais detalhes a ferramenta JPF e os limites que esta ferramenta apresenta ao estudo do comportamento excepcional de um SUT em comparação à nossa técnica de instrumentação. 


\section{Capítulo 7}

\section{Resultados e Conclusão}

\section{$7.1 \quad$ Resultados}

\subsubsection{Resultados Execução JVM e JUnit}

Realizamos testes com programas selecionados do site Evosuite: Automatic Test Suite Generation for Java [sf1]. Os programas selecionados foram o Jipa e o Biff.

O programa Jipa (Java Interpreted Pseudo-Assembly) é constituído por duas classes e trinta e quatro branches. O Jipa é um interpretador Java para linguagem Assembly, recebe como entrada um arquivo contendo pseudo código e, então, realiza sua execução. O Programa Biff é um interpretador pascal escrito em Java. Recebe como entrada um código escrito em pascal e o executa. Seu código fonte possui 6 classes e 825 branches.

O programa Jipa possui 6 estruturas excepcionais, três blocos try e três blocos catch, o que implica que a instrumentação automática inseriu três instruções de lançamento, Estado de Exceção Monitorado, e três instruções de monitoração, Estado de Tratamento.

O programa Biff possui cinco estruturas excepcionais dois blocos try, Estado de Exceção Monitorado, uma instrução throws, Estado de Exceção Anunciada, e dois blocos catch, Estado de Tratamento.

Realizamos inicialmente os testes com execução na JVM e JUnit com em sem instrumentação. Os resultados são apresentados nas Tabelas:

- Tabela 7.1 que apresentam os resultados de cobertura do programa Biff coletados com ferramenta Eclemma.

- Tabela 7.2 que apresenta as exceções lançadas na execução do programa Biff com e sem instrumentação.

- Tabela 7.3 que apresentam os resultados de cobertura do programa Jipa coletados com ferramenta Eclemma.

- Tabela 7.4 que apresenta as exceções lançadas na execução do programa Jipa com e sem instrumentação.

Tabela 7.1: Cobertura Programa Biff

\begin{tabular}{ccccc}
\hline Execução & Código & Instruções Cobertas & Instruções Não Cobertas & $\%$ \\
\hline \hline JVM & não Instrumentado & 3550 & 3693 & 49 \\
\hline JVM & instrumentado & 3569 & 3699 & 49 \\
\hline \hline JUnit & não Instrumentado & 3550 & 3691 & 49 \\
\hline JUnit & Instrumentado & 3569 & 3712 & 49 \\
\hline
\end{tabular}


Tabela 7.2: Estruturas Excepcionais Exercitadas Programa Biff

\begin{tabular}{cccc}
\hline Execução & Sem Instrumentação & Instrumentado & Total \\
\hline \hline JVM & Zero & $(\mathrm{A} 3, \mathrm{D} 4),(\mathrm{A} 1, \mathrm{D} 4)$ & $(\mathrm{A} 3, \mathrm{D} 4),(\mathrm{A} 1, \mathrm{D} 4),(\mathrm{A} 2, \mathrm{D} 0)$ \\
\hline JUnit & Zero & $(\mathrm{A} 3, \mathrm{D} 4),(\mathrm{A} 1, \mathrm{D} 4)$ & $(\mathrm{A} 3, \mathrm{D} 4),(\mathrm{A} 1, \mathrm{D} 4),(\mathrm{A} 2, \mathrm{D} 0)$ \\
\hline \hline
\end{tabular}

Tabela 7.3: Cobertura Programa Jipa

\begin{tabular}{ccccc}
\hline Execução & Código & Instruções Cobertas & Instruções Não Cobertas & $\%$ \\
\hline \hline JVM & não instrumentado & 812 & 551 & 59 \\
\hline JVM & instrumentado & 846 & 544 & 61 \\
\hline JUnit & não instrumentado & 815 & 554 & 59 \\
\hline JUnit & instrumentado & 849 & 547 & 61 \\
\hline
\end{tabular}

Tabela 7.4: Estruturas Excepcionais Exercitadas Programa Jipa

\begin{tabular}{cccc}
\hline Execução & Sem Instrumentação & Com Instruções & Total \\
\hline \hline JVM & (A3, D0), (A5, D2) & (A4, D1), (A3, D0), (A5, D2) & $(\mathrm{A} 4, \mathrm{D} 1),(\mathrm{A} 3, \mathrm{D} 0),(\mathrm{A} 5, \mathrm{D} 2)$ \\
\hline JUnit & (A3, D0), (A5, D2) & $(\mathrm{A} 4, \mathrm{D} 1),(\mathrm{A} 3, \mathrm{D} 0),(\mathrm{A} 5, \mathrm{D} 2)$ & $(\mathrm{A} 4, \mathrm{D} 1),(\mathrm{A} 3, \mathrm{D} 0),(\mathrm{A} 5, \mathrm{D} 2)$ \\
\hline
\end{tabular}

\subsubsection{Análise dos Resultados Execução JVM e JUnit}

As Tabelas 7.1 e 7.3 apontam que não houve ganhos de cobertura derivados do exercício do comportamento excepcional. Isto se deve em parte ao número de estruturas excepcionais e ao conjunto de instruções que se encontra dentro destas estruturas. Contudo, também indica que a instrumentação não afetou a execução do programa dado que tanto o código instrumentado quanto o não instrumentado apresentam coberturas similares.

A Tabela 7.2 apontam para o fato de que o programa Biff não exercita nenhuma exceção quando executado, mas quando executado usando o código instrumentado temos que duas das três possíveis exceções são lançadas. A Tabela e 7.4 indica que o programa Jipa ativa em uma execução normal duas exceções do seu código e com uma execução de código instrumentado temos que todas as exceções são exercitadas. No caso do programa Jipa, a instrumentação não afetou o comportamento do programa, ou seja, lançou exceções que são de fato lançadas e ainda permitiu verificar o comportamento do programa dada uma exceção lançada via instrumentação. 


\subsubsection{Resultados Execução JPF}

A execução dos Programa instrumentado utilizando o model checker JPF resultou nas Listagen 7.1 que representa a saída da execução do Programa Biff e a Listagem 7.2 que representa a saída da execução do Programa Jipa. A execuções dos Programas sem o uso da instrumentação resultou nas Listagens 7.3 e 7.4 .

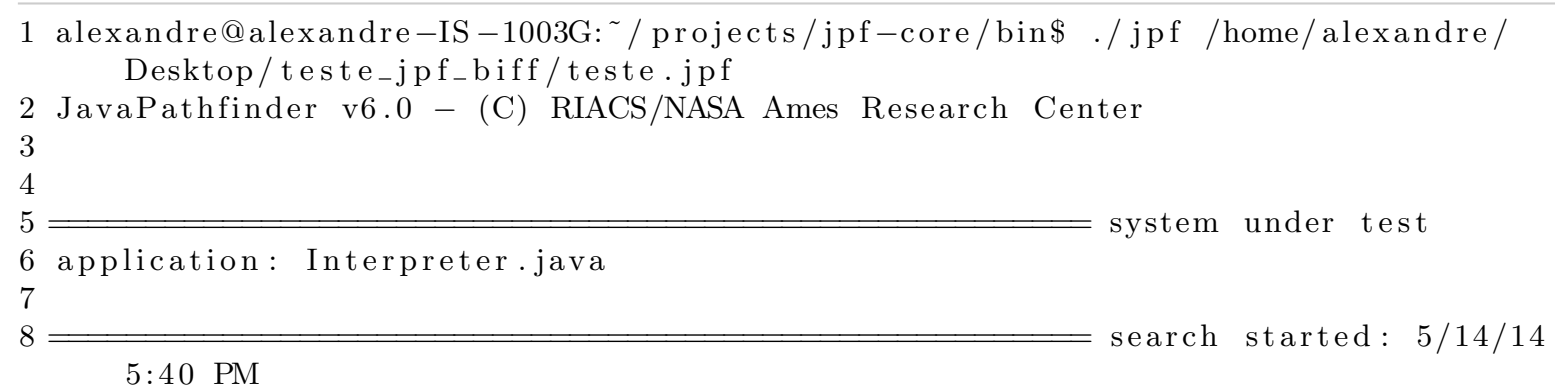


1 alexandre@alexandre-IS-1003G: / projects/jpf-core/bin\$ ./jpf /home/alexandre/ Desktop/teste_jpf_jipa/teste.jpf

2 JavaPathfinder v6.0 - (C) RIACS/NASA Ames Research Center

3

4

$5=$ system under test

6 application: Main.java

7

8

$5: 13 \mathrm{PM}$

9 A4

10 D1

11 java.lang. Exception

12 at Main.loadInstructions (Main.java:296)

13 at Main.main(Main.java:55)

14 A3

15 D0

16 D0

17 D0

18 D0

19 D0

20 D0

21 D0

22 D0

23 JIPA String Examples

24

25 D0

26 D0

27 A5

28 D2

29 D0

30 D0

31 1. Hello

32 D0

33 D0

$34 \mathrm{D} 0$

35 D0

36 D0

$\begin{array}{ll}37 & \mathrm{D} 2\end{array}$

38 2. 0

39 D0

40 D0

41 D0

42 D0

43 D0

44 D0

45 D0

46 D2

47 D2

$\begin{array}{lll}48 & 3 . & 05\end{array}$

49 D0

50 D0

51 D0

52 D2

53 D2

54 4. $0+5$

55 D0

56 D0

57 D0

58 D2

595

60 D0

61 D0

62 D0 


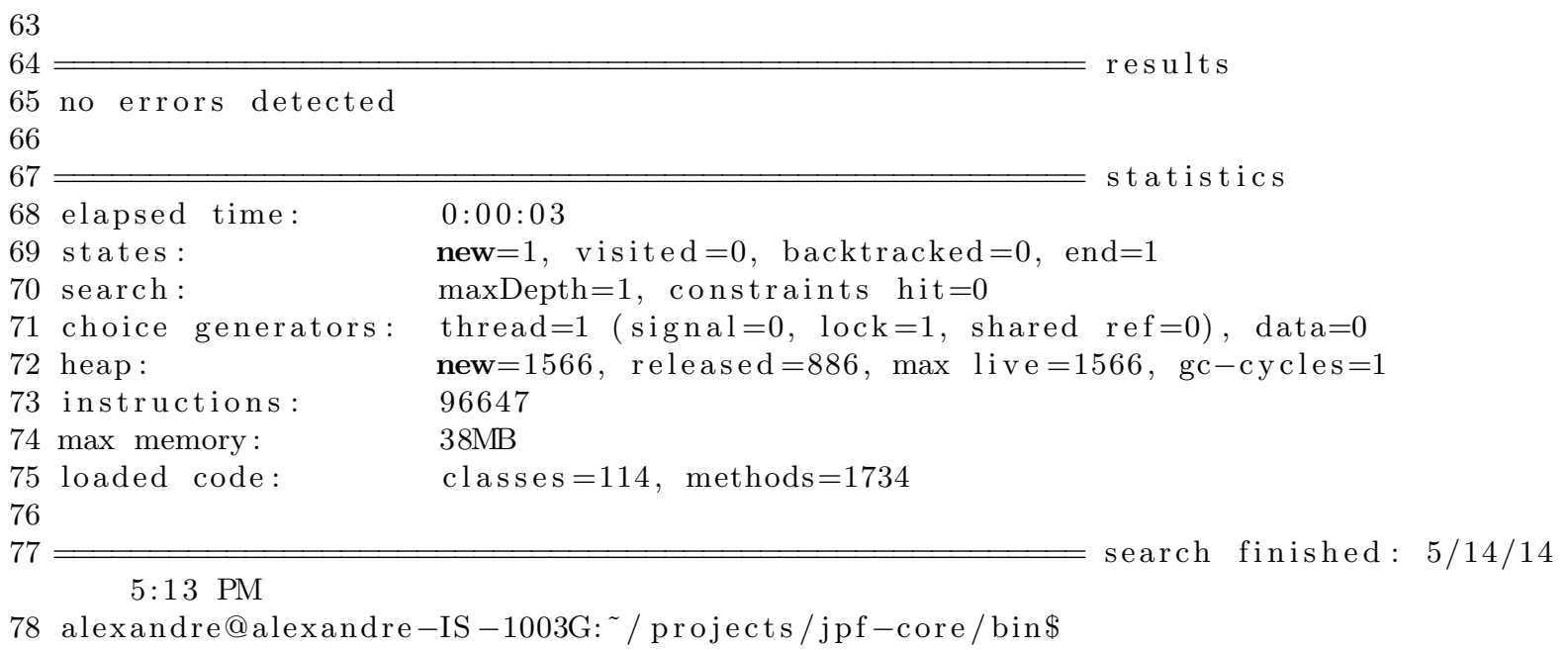

Listagem 7.2: Progrma Jipa Instrumentado Executado no JPF

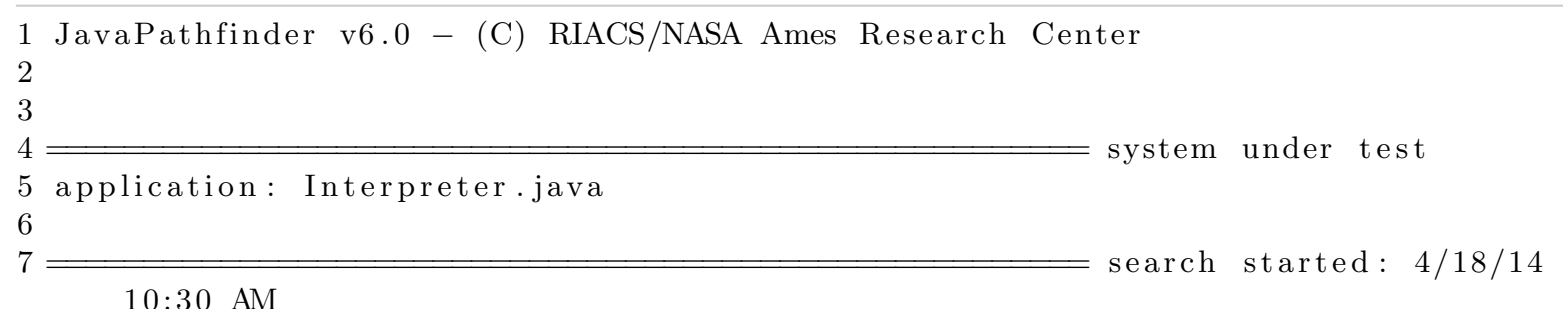

8 No errors !

$9 \overline{\overline{0 !+1}}$

$100 !=1$

11

121 ! = 1

13

142 ! $=2$

15

$163 !=6$

17

184 ! $=24$

19

$205 !=120$

21

$226 !=720$

23

247 ! $=5040$

25

$268 !=40320$

27

$289 !=362880$

29

3010 ! $=3628800$

31

32

$33=$ results

34 no errors detected

35

$36=$ statistics

37 elapsed time: $0: 00: 03$

38 states:

39 search:

40 choice generators:

new $=1$, visited $=0$, backtracked $=0$, end $=1$

$\operatorname{maxDepth}=1$, constraints hit $=0$

41 heap:

42 instructions:

43 max memory:

44 loaded code:

thread $=1 \quad(\operatorname{signal}=0, \quad$ lock $=1$, shared $\mathrm{ref}=0)$, data $=0$ new $=2129$, released $=1597, \max \operatorname{live}=2129$, gc - cycles $=1$ 109450

$30 \mathrm{MB}$

classes $=97$, methods $=1649$ 


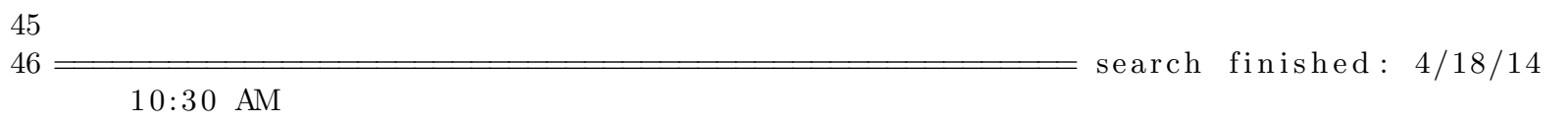

Listagem 7.3: Programa Biff Não Instrumentado Executado no JPF

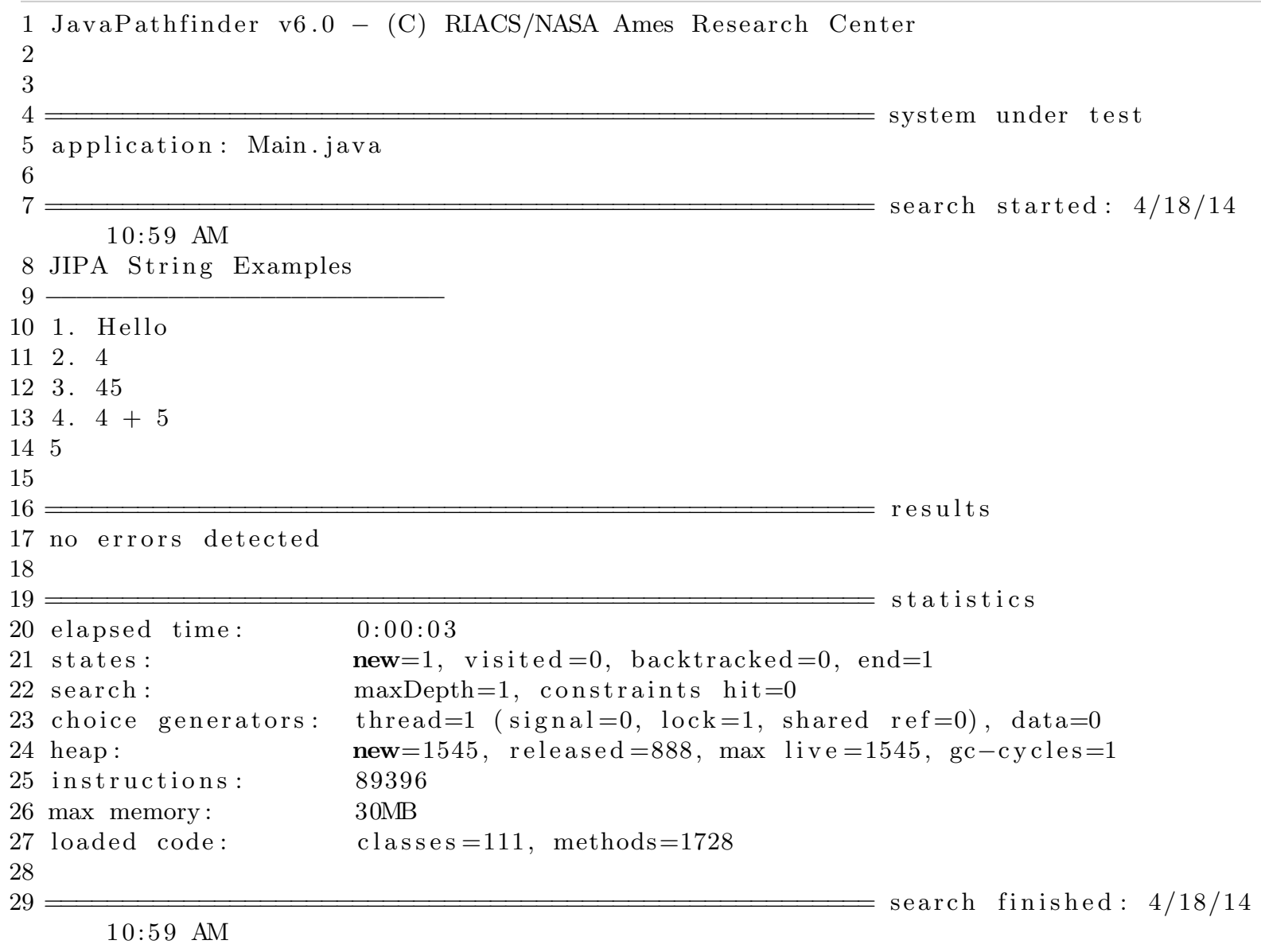

Listagem 7.4: Progrma Jipa Não Instrumentado Executado no JPF 
Baseado nas Listagens desta seção, construimos a Tabela 7.5.

Tabela 7.5: Estruturas Excepcionais Exercitadas Programa Jipa e Biff no JPF

\begin{tabular}{cccc}
\hline Programa & Sem Instrumentação & Com Instruções & Total \\
\hline \hline Jipa & $(\mathrm{A} 3, \mathrm{D} 0),(\mathrm{A} 5, \mathrm{D} 2)$ & $(\mathrm{A} 4, \mathrm{D} 1),(\mathrm{A} 3, \mathrm{D} 0),(\mathrm{A} 5, \mathrm{D} 2)$ & $(\mathrm{A} 4, \mathrm{D} 1),(\mathrm{A} 3, \mathrm{D} 0),(\mathrm{A} 5, \mathrm{D} 2)$ \\
\hline Biff & Zero & $(\mathrm{A} 3, \mathrm{D} 4),(\mathrm{A} 1, \mathrm{D} 4)$ & $(\mathrm{A} 3, \mathrm{D} 4),(\mathrm{A} 1, \mathrm{D} 4),(\mathrm{A} 2, \mathrm{D} 0)$ \\
\hline
\end{tabular}

\subsubsection{Análise dos Resultados Execução JPF}

A Tabela 7.5 indica que o JPF, como a JVM e a JUnit, não exercita as exceções a menos que estas sejam disparadas pelo próprio código, Programa Jipa, mesmo neste caso o comportamento excepcional não é percebido caso não ocorre nenhuma saída que identifique o ocorrido. No caso particular do Programa Jipa, por meio da instrumentação, identificamos que o programador utiliza as estruturas excepcionais do código como estruturas de controle de fluxo, como apresentado na Listagem 7.5. Apesar deste uso, a instrumentação utilizada no JPF não alterou a execução do programa.

O Programa Biff apenas duas das três estruturas de excepcionais foram exercitadas pois o fluxo de controle não acessou o código no qual a instrumentação referente a essa exceção foi inserida. Isto indica que é necessário utilizar um outro dado de entrada ou que o código é inacessível logo a exceção, apesar de identificada, não será exercitada.

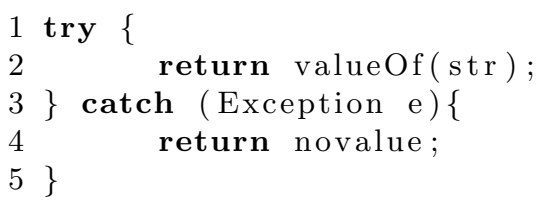

Listagem 7.5: Uso de Exceções Programa Jipa 


\subsection{Conclusão}

Estruturas de tratamento de exceção são extremamente comuns em softwares desenvolvidos em linguagens modernas como Java. Além disso, estas estruturas afetam de forma contundente o comportamento de um software quando exercitadas. Apesar destas duas características, as principais técnicas de verificação, teste de software e verificação formal, e as ferramentas a elas vinculadas (JUnit e Model Checker), tendem a negligenciar o comportamento excepcional em suas análises. Alguns dos fatores que levam a essa negligência são a não especificação do comportamento excepcional em termos de projeto e a consequente implementação das estruturas de tratamento com base no julgamento individual de cada desenvolvedor. Os resultados de tal situação são a desconsideração de partes do código em termos de verificação e,consequentemente, a possibilidade de não serem detectados erros relativos tanto às próprias estruturas de tratamento quanto às estruturas de código vinculadas às de tratamento.

Nesse trabalho, nós propusemos uma técnica de automação do processo de exercício do comportamento excepcional. Nossa técnica é baseada no desenvolvimento de um modelo do comportamento excepcional que é aplicado à linguagem Java, mas que também pode ser aplicado a outras linguagens como $C++$, Python, $C \#$ etc.. Esse modelo permite a modelagem estática do código fonte a fim de identificar as estruturas do código (linha, instruções e exceções) responsáveis pela ativação e desativação de exceções. Com base nesse modelo, o código fonte é instrumentalizado automaticamente por um protótipo de ferramenta desenvolvido nesse trabalho. Essa ferramenta localiza as estruturas de ativação/desativação e insere nessas estruturas código nativo que, durante a execução do código, lança as exceções, registra o comportamento excepcional do SUT após o lançamento da exceção e identifica os pontos de lançamento e de tratamento. Além disso, a instrumentação implementada no SUT pode ser utilizada em diferentes tipos de ferramentas como apresentado no Capítulo 6.

Por fim, o resultado positivo alcançado por esse trabalho é o de demonstrar que é possível aplicar critérios de teste aos caminhos excepcionais, pois eles estão sendo exercitados de forma equivalente ao comportamento normal. De maneira análoga, esse raciocínio aplica-se ao estudo da violação de propriedades de um modelo que agora levaria em conta não somente o comportamento normal, mas também o comportamento excepcional, de um software.

\subsubsection{Resultados Obtidos}

O estudo de caso realizado no Capítulo 6 foi baseado em uma variante do software VendingMachine utilizado nos estudos de Sinha e Harrold [SJ98, SJ00]. Essa escolha deve-se à percepção de que esse SUT é normalmente utilizado para exemplificar manipulações de exceções e por ele conter todas as principais estruturas de ativação e desativação de exceção. Além disso, foram analisados os Programas de teste Biff e Jipa.

Como resultado da análise do estudo de caso mais os Programs de teste podemos chegar a algumas conclusões importantes que são aplicáveis ao estudo do comportamento excepcional, são elas:

- Por meio da nossa técnica, situações que abortam a execução do programa podem ser identificadas e tratadas de modo que o teste seja feito de forma mais eficiente. Desta forma, pode-se minimizar o problema de várias formas de execução do SUT.

- Como as exceções são lançadas via instrumentação, tanto os caminhos normais quanto os excepcionais passam a fazer parte do processo de verificação, ou seja, se pensarmos em termos de cobertura de critérios, as estruturas excepcionais passam a ser contabilizadas nessa cobertura, como demonstrado no Capítulo estcaso.

- A identificação dos pares de ativação/desativação garantem um aumento do entendimento do funcionamento do SUT em tempo de execução, caso do Programa Jipa. Além disso, 
- identificam redundâncias no processo de exercício do comportamento excepcional de modo a reduzir o número de pontos de lançamento, ver Capítulo 6 .

- identificam pontos de congestionamento nos quais várias exceções distintas são tratadas.

- identificam situações nas quais uma exceção é lançada, mas não é tratada.

- O exercício do comportamento excepcional, via instrumentação, permite identificar como o SUT se comporta no caso em que uma exceção ocorra. Podemos notar que, na maioria dos casos, os blocos de tratamento try estão vazios, o que indica que, de fato, nenhum tratamento foi dado. De fato, apesar do SUT testado ser um exemplo teórico, ele representa o que se constata, de modo amplo e efetivo, na prática cotidiana de programação [BP07].

\subsubsection{Trabalhos Futuros}

Um conjunto de atividades futuras que ampliariam, em muito, o escopo deste trabalho são:

- construção de um plugin para IDE Eclipse que incorpore a ferramenta e a instrumentação e permita instrumentação direta de projetos construídos nesta IDE.

- construção de uma ferramenta que permita comparar o comportamento esperado, em termos de tratamento de exceções, com o observado de forma automática.

- realização de um estudo do tipo de exceções assíncronas que ocorrem de forma mais frequente em SUTs escrito em linguagem Java de modo a melhorar a precisão da inserção do código de instrumentação. 


\section{Referências Bibliográficas}

[A.07] Bertolino A. Software testing research: Achievements, challenges, dreams. FOSE '07 2007 Future of Software Engineering, pages 85-103, 2007. 1

[B.99] Berard B. Systems and Software Verification: Model-Checking Techniques and Tools. Splinger, 1999. 1, 10, 11, 12, 14

[BP07] Cabral B. and Marques P. Exception handling: A field study in java and .net. ECOOP 2007, pages 151-175, 2007. 2, 4, 7, 10, 24, 87

[CAS06] Artho C., Biere A., and Honiden S. Exhaustive testing of exception handlers with enforcer. NFM 09, pages 116-120, 2006. 5

[CCS07] Artho C., Sommer C., and Honiden S. Model checking networked programs in the presence of transmission failures. First Joint IEEE/IFIP Symposium on. IEEE, 2007. $2,4,5$

[Cor02] Thomas H Cormen. Algoritmos: teoria e prática. Elsevier, 2002. 40

[CP08] Baier C. and Katoen J. P. Principles of Model Checking. Springer, 2008. 1, 10, 11, 15

[DKW08] Vijay D'silva, Daniel Kroening, and Georg Weissenbacher. A survey of automated techniques for formal software verification. Computer-Aided Design of Integrated Circuits and Systems, IEEE Transactions on, 27(7):1165-1178, 2008. 1

[DOFJ12] Dúlaigh, Keith O., Power J. F., and Clarke P. J. Measurement of exception-handling code: An exploratory study. Exception Handling (WEH), 2012. 2, 7

[dS08] Xavier K. da S. Estudo sobre redução do custo de testes através da utilização de verificação de componentes java com tratamento de exceções. Master Tese, 2008. 1, 10

[Ecl] Eclemma. Eclemma. http://www.eclemma.org/. Accessed: 02/20/2014. 70

[ECM07] Delamaro M. E., Maldonado J. C., and Jino M. Introdução ao Teste de Software. Campus, quarta edition, 2007. 8, 9, 25, 26

[FFAJ01] Garcia A. F., Rubira M. F., Romanovsky A., and Xu J. A comparative study of exception handling mechanisms for building dependable object-oriented software. The Journal of Systems and Software, 59, 2001. 20

[FFE09] Gordon F., Wotawa F., and Ammann P. E. Testing with model checkers: a survey. Software Testing, Verification and Reliability, pages 215-261, 2009. 12

[INF] INFRES. Ada tutorial. http://www.infres.enst.fr/ pautet/Ada95/chap17.htm. Accessed: $11 / 25 / 2013.19$

[J.01] Chilenski J. J. An investigation of three forms of the modified condition decision coverage (mcdc) criterion. DOT/FAA/AR-01/18, 2001. 5

[JP04] Russel S. J. and Norving P. Inteligência Artificial. Campus, segunda edition, 2004. 15 
$\left[\mathrm{K}^{+} 11\right]$ Mohd Khan et al. Different approaches to white box testing technique for finding errors. International Journal of Software Engineering $\mathcal{E}$ Its Applications, 2011. 8

[LHP06] Xin Li, Hoover H., and Rudnicki P. Towards automatic exception safety verification. FM 2006, pages 396-411, 2006. 2, 4, 5

[M.09] Staats M. Towards a framework for generating tests to satisfy complex code coverage in java pathfinder. NFM 09, pages 116-120, 2009. 5

[M.11] Fisher M. An Introduction to Pratical formal Methods Using Temporal Logic. Wiley, 2011. 1, 10, 11, 12

[MJ03] Deitel H. M. and Deitel P. J. Java como programar. Bookman, 2003. 34

[MM08] Pezzè M. and Young M. Teste e Análise de Software: processos, princípios e técnicas. Bookman, primeira edition, 2008. 8, 25

[NA71] Rescher N. and Urquhart A. Temporal Logic. Springer-Verlag, primeira edition, 1971. $11,12,14$

[Oraa] Oracle. Class throwable. http://docs.oracle.com/javase/1.4.2/docs/api/java/lang/ Throwable.html. Accessed: 11/25/2012. 21

[Orab] Oracle. What is an exception? http://docs.oracle.com/javase/tutorial/essential/ exceptions/definition.html. Accessed: 11/25/2012. 2, 21, 23, 34

[Orac] Oracle. Working with java se 7 exception changes. http://www.oracle.com/technetwork/ articles/java/java7exceptions-486908.html. Accessed: 11/25/2012. 23

[P.12] Mathur A. P. Foundations of Software Testing. Person, 1 edition, 2012. 1, 8, 9, 25

[PJ08] Ammann P. and Offutt J. Introducution to Software Testing. Cambridge University Press, 2008. 1, 12, 15, 25

[PN12] Nagar P. and Soni N. Optimizing program-states using exception-handling constructs in java. IJEAT 2, pages 192-199, 2012. 2

[PXC97] Hsia P., Li X., and Kung D. C. Augmenting data flow criteria for class testing. Proceedings of the 1997 Conference of the Centre for Advanced Studies on Collaborative, 1997. 26

[S.08] Hanazumi S. Ambiente integrado para verificaão e teste da coordenação de componentes tolerantes a falhas. Master Tese, January 2008. 10

[sf1] sf100. sf100. http://www.evosuite.org/sf100/. Accessed: 05/11/2014. 79

[SH99] Saurabh Sinha and Mary Jean Harrold. Criteria for testing exception-handling constructs in java programs. In Software Maintenance, 1999.(ICSM'99) Proceedings. IEEE International Conference on, pages 265-274. IEEE, 1999. 25, 26, 27, 28, 35, 40

[SJ98] Sinha S. and Harrold M. J. Analysis of prograns with exception-handling constructs. Proceeding of international conference on Software Maintenance, 1998. 4, 7, 25, 26, 27, $28,40,59,86$

[SJ00] Sinha S. and Harrold M. J. Analysis and testing of programs with exception handling constructs. IEEE Transactions, 26(9):849-871, 2000. xix, 2, 4, 7, 29, 31, 33, 86

[VSF10] Melo A. C. V., Hanazumi S., and Nunes P. R. F. Ocongrax - a tool for dataflow test requirements generation. ETH, 2010. 26, 27, 29, 41

[W.06] Sebesta R. W. Conceitos de Linguagem de Programação. Bookman, 2006. 2, 7, 17, 18, $19,20,21,26,34$ 